SYSTEMATIC REVIEW AND META-ANALYSES OF TRENDELENBURG AND PRONE POSITION ON INTRAOCULAR PRESSURE IN ADULT PATIENTS UNDERGOING SURGERY

\begin{tabular}{c} 
A Dissertation \\
presented to \\
the Faculty of the Graduate School \\
at the University of Missouri-Columbia \\
In Partial Fulfillment \\
of the Requirements for the Degree \\
Doctor of Philosophy \\
\hline SHARON ANN VAN WICKLIN \\
Jo-Ana D. Chase, PhD, APRN-BC, Dissertation Advisor
\end{tabular}

MAY 2019 
The undersigned, appointed by the dean of the Graduate School, have examined the dissertation entitled

\section{SYSTEMATIC REVIEW AND META-ANALYSES OF TRENDELENBURG AND} PRONE POSITION ON INTRAOCULAR PRESSURE IN ADULT PATIENTS UNDERGOING SURGERY

presented by Sharon Ann Van Wicklin, a candidate for the degree of Doctor of Philosophy, and hereby certify that, in their opinion, it is worthy of acceptance.

Jo-Ana D. Chase, PhD, APRN-BC

Vicki S. Conn, PhD, RN, FAAN

Deidre D. Wipke-Tevis, PhD, RN

Christine, Proulx, $\mathrm{PhD}$ 
"Every good and perfect gift is from above, coming down from the Father of the heavenly lights, who does not change like shifting shadows." (James 1:17 New International Version).

This dissertation is dedicated to my husband, James Hudson Van Wicklin, who is one of God's good and perfect gifts to me. My husband has been my constant support and encouragement as I have pursued this doctoral degree and throughout our 45 years of married life. 


\section{ACKNOWLEDGEMENTS}

I would like to thank Jo-Ana D. Chase, PhD, APRN-BC, Vicki S. Conn, PhD, RN, FAAN, Deidre D. Wipke-Tevis, PhD, RN, Sinclair School of Nursing, and Christine Proulx, PhD, Department of Human Development and Family Science, University of Missouri, Columbia, for their support and guidance in writing this dissertation. I would also like to thank Marie Bashaw, DNP, RN, NEA-BC, Department of Nursing, Hartwick College, Oneonta, New York, for her assistance in providing independent review and appraisal of the studies included in the meta-analyses; Danielle Karasko, MSN, CRNP, PhD candidate, Sinclair School of Nursing, University of Missouri, Columbia, and Philadelphia Children's Hospital, Pennsylvania, for her assistance in providing independent coding of the studies included in the meta-analyses; and Rebecca Graves, Health Science Library, University of Missouri, Columbia, for her assistance with developing effective search terms and strategies for the literature searches included in the meta-analyses. 


\section{TABLE OF CONTENTS}

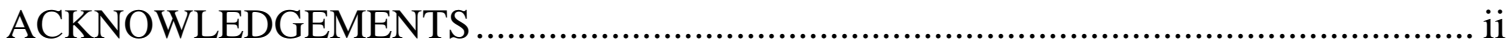

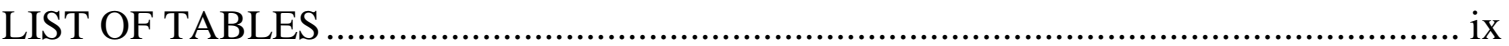

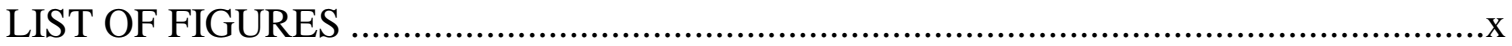

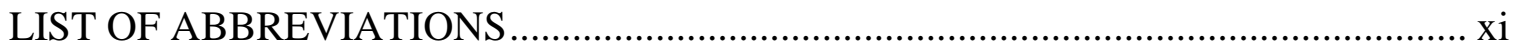

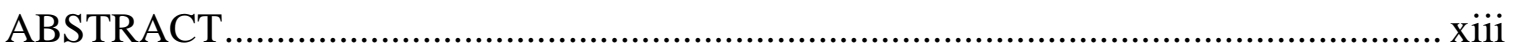

\section{CHAPTER}

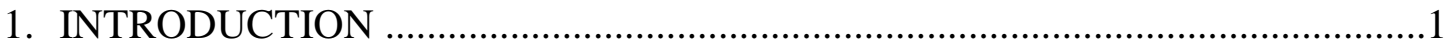

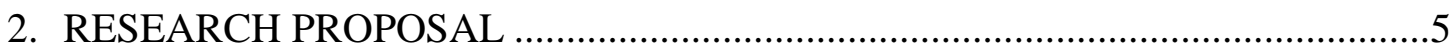

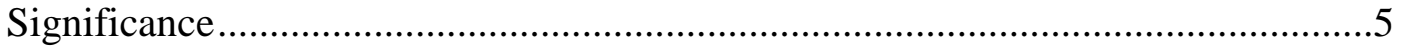

Trendelenburg Position ......................................................................

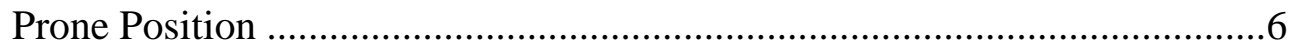

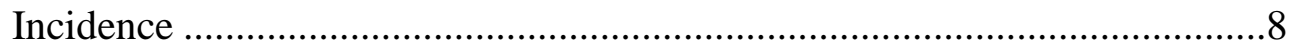

Meta-analysis ............................................................................. 9

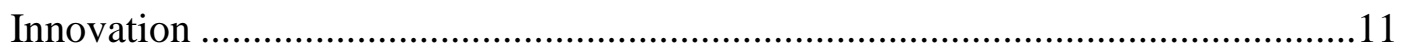

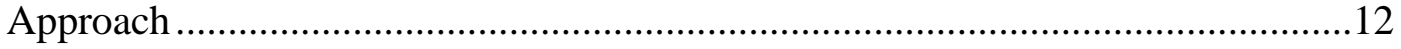

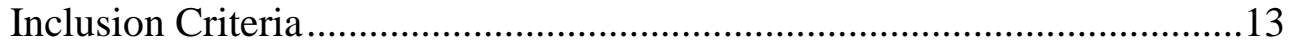

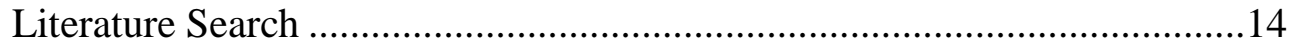

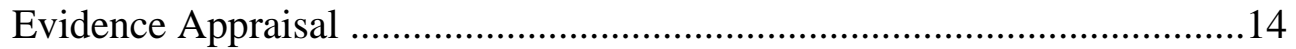

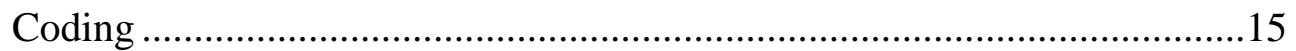

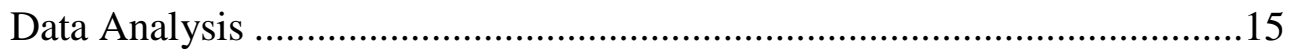

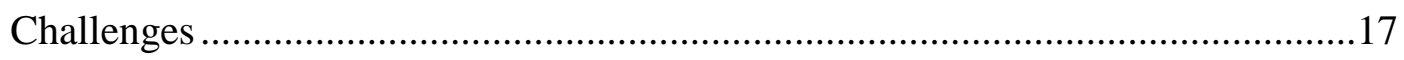

Figure 2.1: Perioperative Patient Focused Model ................................................19 


\section{SYSTEMATIC REVIEW AND META-ANALYSIS OF TRENDELENBURG POSITION ON INTRAOCULAR PRESSURE IN ADULT PATIENTS UNDERGOING SURGERY}

Abstract

Introduction .21

Pathogenesis of Postoperative Vision Loss .........................................................21

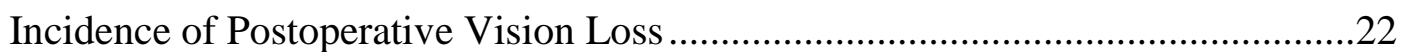

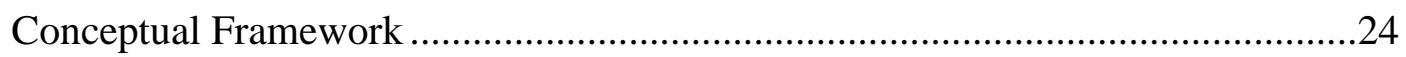

Purpose

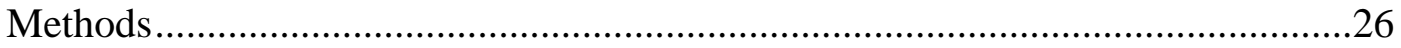

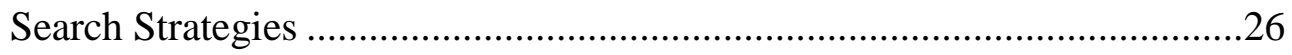

Inclusion and Exclusion Criteria ............................................................26

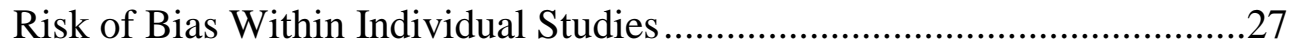

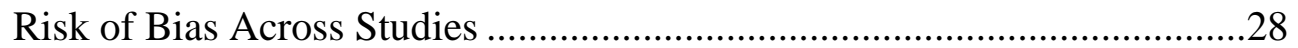

Coding and Data Extraction ...................................................................28

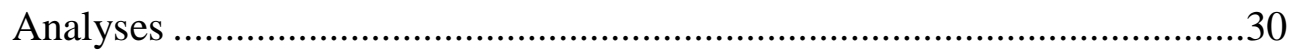

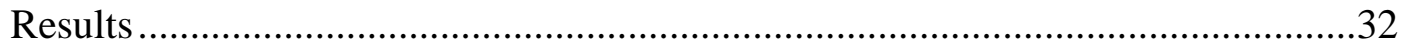

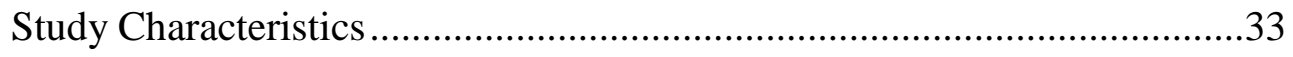

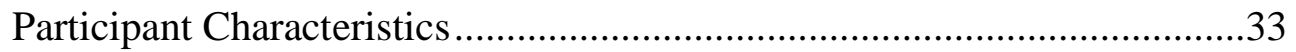

Surgery Characteristics ...............................................................................

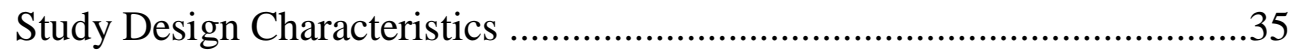

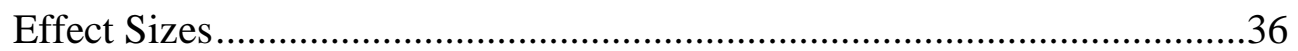

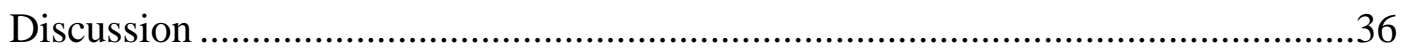

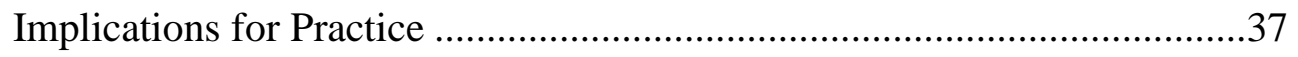

Implications for Future Research ............................................................

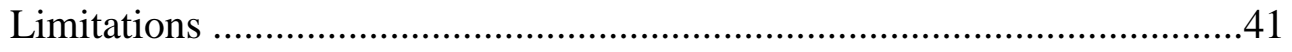




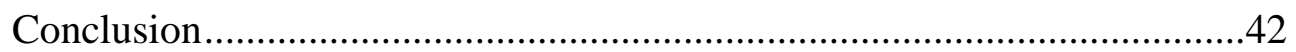

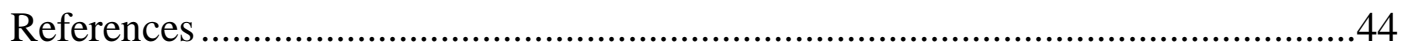

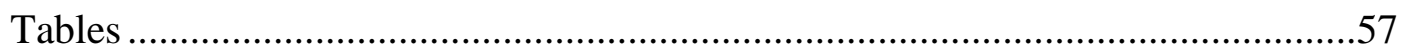

Table 3.1: Summary of Studies Included in the Systematic Review and

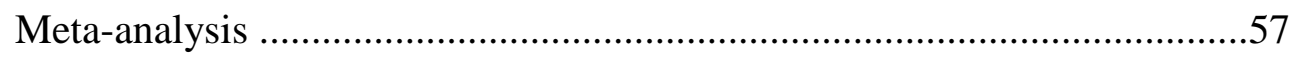

Table 3.2: Study and Participant Characteristics..........................................63

Table 3.3: Effect Sizes and Magnitude of Change in IOP for T1 through

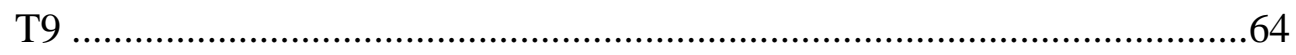

Sidebar: Time Points Analyzed for Changes in IOP .....................................65

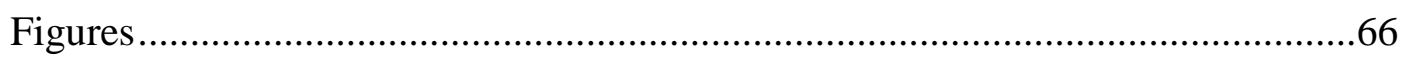

Figure 3.1: Perioperative Patient Focused Model .........................................66

Figure 3.2: Flow Diagram of Meta-analysis Study Selection ......................67

Figure 3.3: Magnitude of Change in IOP for T0 through T9 ......................68

Figure 3.4: Magnitude of Change in IOP and Upper Prediction Intervals of

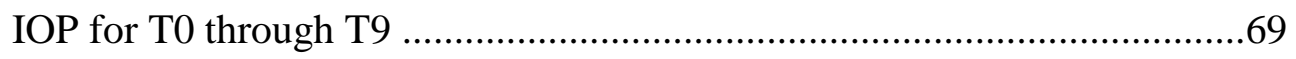

Figure 3.5: Forest Plot of Meta-analysis of T6 ……………………............

Figure 3.6: Funnel Plot of Publication Bias for T6 ......................................

4. SYSTEMATIC REVIEW AND META-ANALYSIS OF PRONE POSITION ON INTRAOCULAR PRESSURE IN ADULT PATIENTS UNDERGOING

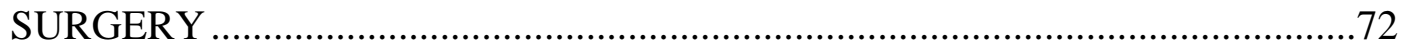

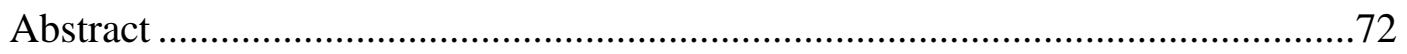

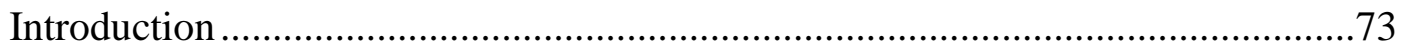

Pathogenesis of Postoperative Vision Loss ...........................................................74

Ischemic Optic Neuropathy ......................................................................

Central Retinal Artery Occlusion ................................................................

Risk Factors for Postoperative Vision Loss …………..................................76 
Incidence of Postoperative Vision Loss ..............................................................76

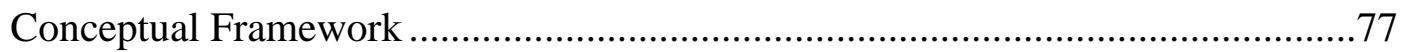

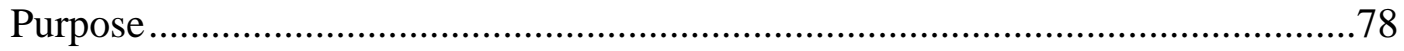

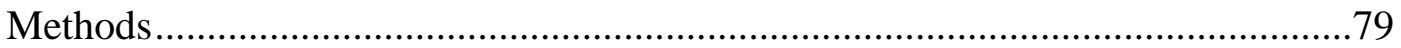

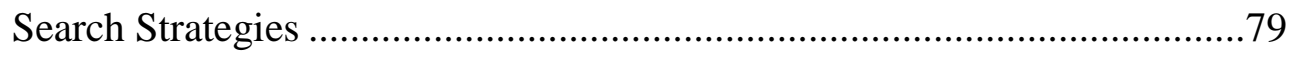

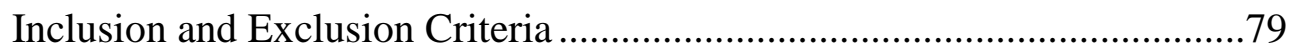

Risk of Bias Within Individual Studies ..........................................................

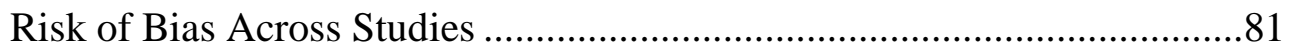

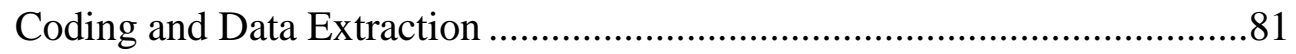

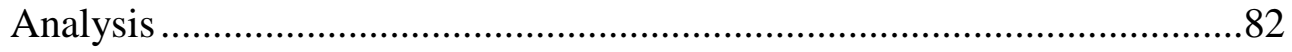

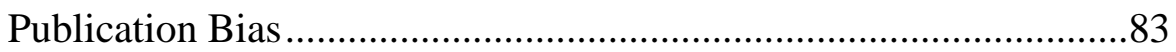

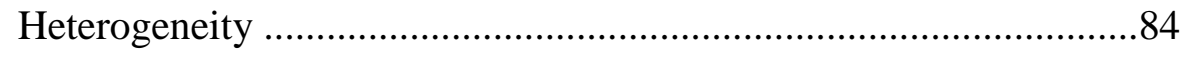

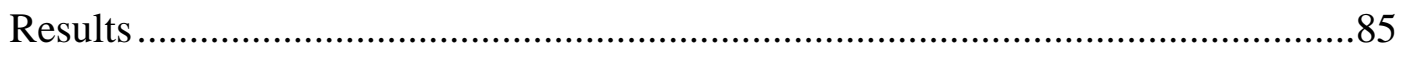

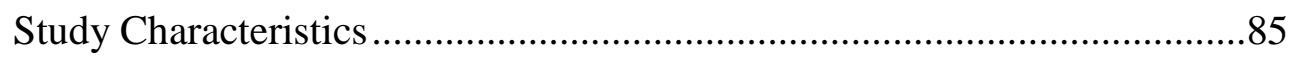

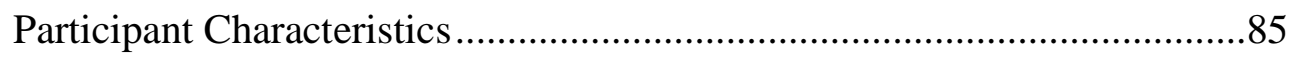

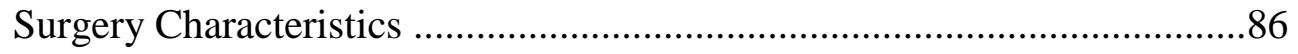

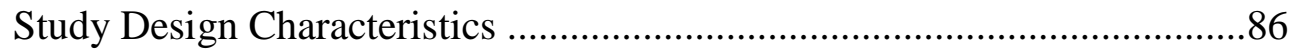

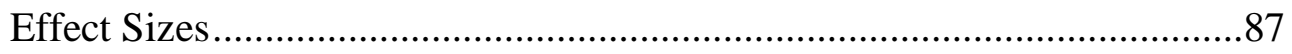

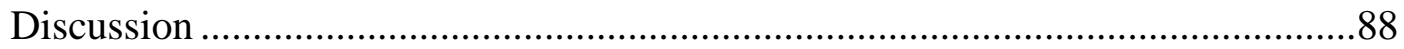

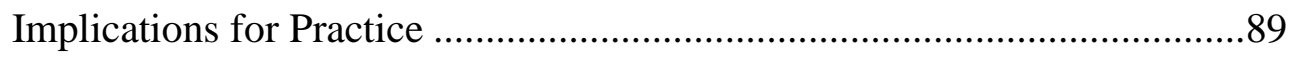

Implications for Future Research ...........................................................92

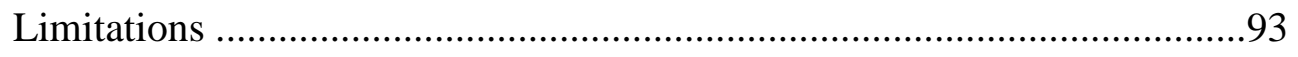

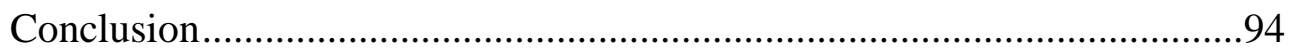

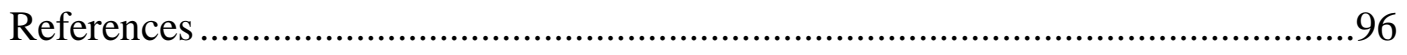

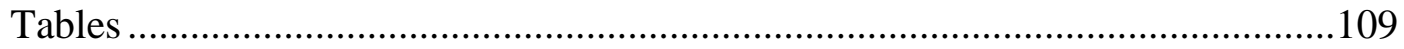


Table 4.1: Summary of Studies Included in the Systematic Review and

Meta-analysis

Table 4.2: Study and Participant Characteristics.

Table 4.3: Effect Sizes and Magnitude of Change in IOP for T1 through

$\mathrm{T} 2$

Figures .114

Figure 4.1: Perioperative Patient Focused Model 114

Figure 4.2: Flow Diagram of Meta-analysis Study Selection .115

Figure 4.3: Magnitude of Change in IOP and Upper Prediction Intervals of

IOP for T0 through T2 116

Figure 4.4: Forest Plot of Meta-analysis of T1 117

Figure 4.5: Forest Plot of Meta-analysis of T2 …...............................118

Figure 4.6: Funnel Plot of Publication Bias for T1 ................................119

5. SUMMARY .120

Introduction 120

Recommendations for Patients Undergoing Surgery in the Trendelenburg

Position 120

Recommendations for Patients Undergoing Surgery in the Prone

Position .123

Recommendations for Preoperative Ophthalmologic Examinations 126

Perioperative Patient Focused Model. 127

Conclusion 128

\section{APPENDIX}

A-1: AORN RESEARCH EVIDENCE APPRAISAL TOOL - STUDY 129

A-2: AORN RESEARCH EVIDENCE APPRAISAL TOOL - STUDY 130 


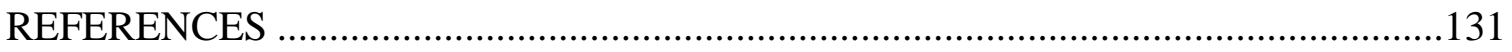

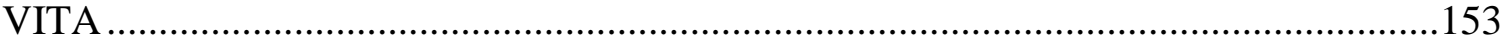




\section{LIST OF TABLES}

TABLE

PAGE

Table 3.1: Summary of Studies Included in the Systematic Review and Meta-analysis...57

Table 3.2: Study and Participant Characteristics .........................................................63

Table 3.3: Effect Sizes and Magnitude of Change in IOP for T1 through T9 ..................64

Sidebar: Time Points Analyzed for Changes in IOP .................................................65

Table 4.1: Summary of Studies Included in the Systematic Review and Meta-analysis.109

Table 4.2: Study and Participant Characteristics ....................................................112

Table 4.3: Effect Sizes and Magnitude of Change in IOP for T1 through T2 ................113 


\section{LIST OF FIGURES}

FIGURE

PAGE

Figure 2.1: Perioperative Patient Focused Model ........................................................19

Figure 3.1: Perioperative Patient Focused Model ....................................................66

Figure 3.2: Flow Diagram of Meta-analysis Study Selection.....................................67

Figure 3.3: Magnitude of Change in IOP for T0 through T9 ......................................68

Figure 3.4: Magnitude of Change in IOP and Upper Prediction Intervals of IOP for T0

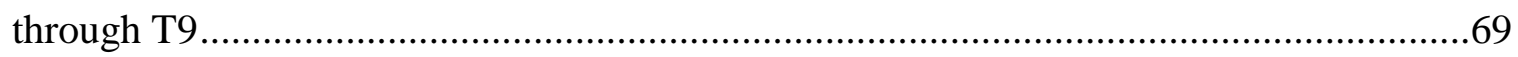

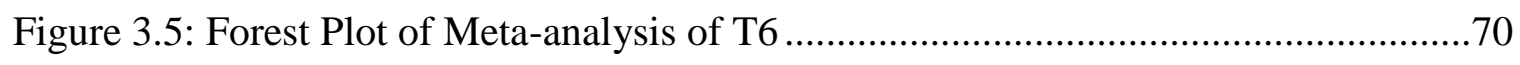

Figure 3.6: Funnel Plot of Publication Bias for T6 ................................................. 71

Figure 4.1: Perioperative Patient Focused Model ......................................................114

Figure 4.2: Flow Diagram of Meta-analysis Study Selection.....................................115

Figure 4.3: Magnitude of Change in IOP and Upper Prediction Intervals of IOP for T0

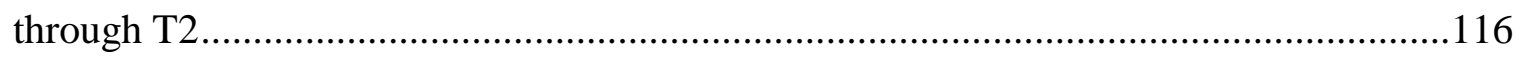

Figure 4.4: Forest Plot of Meta-analysis of T1 ................................................... 117

Figure 4.5: Forest Plot of Meta-analysis of T2 .................................................... 118

Figure 4.6: Funnel Plot of Publication Bias for T1 ................................................119 


\section{LIST OF ABBREVIATIONS}

ABBREVIATION

AORN

ASA.

BMI

CI.

CNOR

CPSN-R

CRNFA(E)

$d$

EBL

F

FAAN.

$I^{2}$

IOP

ISPAN-F

International Society of Plastic and Aesthetic Nurses-Fellow

$k$

$\mathrm{kg} / \mathrm{m}^{2}$

$L L$

$\min$

$\mathrm{mL}$

$\mathrm{mmHg}$

PI

PLNC

Q.
EXPLANATION

Association of periOperative Registered Nurses

American Society of Anesthesiologists body mass index confidence interval .. Certified Nurse Operating Room .Certified Plastic Surgical Nurse-Retired Certified Registered Nurse First Assistant (Emeritus) standard mean difference estimated blood loss fixed effect model Fellow of the American Academy of Nursing I-squared intraocular pressure comparisons kilograms per meter-squared .lower limit minutes milliliters millimeters of mercury principal investigator ..Professional Legal Nurse Consultant Cochrane's Q 
$\mathrm{R}$

$\mathrm{RN}$

$s$

$S D$

SMD

Std

$\mathrm{T}$

$U L$.

... .random effects model registered nurse studies standard deviation standard mean difference standard time points upper limit 


\title{
SYSTEMATIC REVIEW AND META-ANALYSES OF TRENDELENBURG AND PRONE POSITION ON INTRAOCULAR PRESSURE IN ADULT PATIENTS UNDERGOING SURGERY
}

\author{
Sharon Ann Van Wicklin \\ Jo-Ana D. Chase, PhD, APRN-BC, Dissertation Advisor
}

\begin{abstract}
Background. Patients undergoing surgery in the Trendelenburg and prone positions may be at risk for postoperative vision loss associated with increased intraocular pressure. The purpose of this dissertation research is to estimate the magnitude of the increase in intraocular pressure at specific perioperative time points in adult patients undergoing surgery in the Trendelenburg and prone positions.

Methods. Comprehensive search strategies were used to identify eligible studies for two meta-analyses and to address the research questions. For each meta-analysis, standardized mean difference effect sizes were calculated for selected perioperative time points.

Results. Using a random effects model, the meta-analysis examining the effect of Trendelenburg position, showed that intraocular pressure decreased significantly after induction and before arousal. Intraocular pressure increased significantly after abdominal insufflation and during Trendelenburg position. The meta-analysis examining the effect of prone position, showed that intraocular pressure increased significantly between induction of anesthesia and up to 10 minutes of prone position and continued to increase significantly until the end of the prone position.
\end{abstract}

Conclusions. Intraocular pressure increases of the magnitude found in this research demonstrate the need for implementing interventions to reduce the risk for postoperative vision loss in patients undergoing surgery in the Trendelenburg and prone positions. 


\section{INTRODUCTION}

This research project involved conducting two meta-analyses to estimate the overall magnitude and effect of the Trendelenburg and prone positions on intraocular pressure (IOP) in adult patients undergoing surgery. Patients 18 years or older were considered to be adult patients. The increase in IOP that occurs when the Trendelenburg and prone positions are used can potentially lead to postoperative vision loss and other ocular complications.

In the Trendelenburg position, the patient's feet are higher than the patient's head by 15 degrees to 30 degrees (MacDonald \& Washington, 2012). Many surgeons use a steep Trendelenburg position of 30 degrees to 45 degrees, particularly during laparoscopic or robotic surgery, which is frequently used for prostatectomy, hysterectomy, colorectal surgery, and many other procedures. While providing enhanced visualization of the operative field, the Trendelenburg position also decreases venous return from the head, leading to venous pooling and increased IOP (Akhavan, Gainsburg, \& Stock, 2010; Astuto, Minardi, Uva, \& Gullo, 2011; Awad et al., 2009; Borahay et al., 2013; Cullen \& Ferguson, 2012; Ghomi, 2012; Kan, Brown, \& Gainsburg, 2015; Mondzelewski et al., 2015; Taketani et al., 2015). Increased IOP resulting from the use of the Trendelenburg position poses a risk for postoperative glaucoma, detached retina, or partial to complete vision loss (Astuto et al., 2011; Borahay et al., 2013; Emery et al., 2015; Ghomi, Kramer, Askari, Chavan, \& Einarsson, 2012; Gkegkes, Karydis, Tyritzis, \& Iavazzo, 2015; Gould, Cull, Wu, \& Osmundsen, 2012; Grosso et al., 2013; Hoskikawa et al., 2014; Lee \& Newman, 2018; Taketani et al., 2015). 
Partial to complete postoperative vision loss is also a complication of surgery when the patient is positioned face-down on their abdomen in the prone position. This complication occurs with greater frequency after spine, head and neck, cardiac, and some orthopedic procedures (Emery et al., 2015; Lee \& Newman, 2018). There have been reports of postoperative vision loss (Goni et al., 2012; Quraishi, Wolinsky, \& Gokaslan, 2012; Reddy, Foroozan, Edmond, \& Hinckley, 2008; Shifa, Abebe, Bekele, \& Habte, 2016; Stang-Veldhouse, Yeu, Rothenberg, \& Mizen, 2010) as well as subconjunctival hemorrhage (Akhaddar \& Boucetta, 2012), subperiosteal orbital hemorrhage (Russell \& Dutton, 2011), and Horner syndrome (Guillaume \& Gowreesunker, 2013) after prolonged surgery in the prone position. When the anesthetized patient is in the prone position, IOP increases and the extent of this increase is related to the amount of time the patient remains in the prone position (Agah, Ghasemi, Roodneshin, Radpay, \& Moradian, 2011; Eddama, 2013; Kamel \& Barnette, 2014; Kendrick, 2012; Pinkney et al., 2012; Szmuk et al., 2013; Yoshimura, Hayashi, Tanaka, Nomura, \& Kawaguchi, 2015). After only a few minutes in the prone position, IOP can increase significantly (Nuzzi \& Tridico, 2015).

Researchers have independently investigated the quantitative increases of IOP that occur intraoperatively in adult surgical patients in the Trendelenburg (Astuto et al., 2011; Awad et al., 2009; Borahay et al., 2013; Grosso et al., 2013; Hoshikawa et al., 2014; Molloy, 2011; Mondzelewski et al., 2015; Taketani et al., 2015) and prone (Emery et al., 2015; Lee \& Newman, 2018; Nuri Deniz et al., 2013; Quraishi et al., 2012; Shifa et al., 2016; Stang-Veldhouse et al., 2010; Yoshimura et al., 2015) positions. However, there is a need for systematic review and meta-analyses of these studies to demonstrate the magnitude of the increase in IOP and the overall effect sizes. Understanding the 
degree to which IOP can increase intraoperatively can provide high-quality evidence supporting the need for implementing perioperative interventions to mitigate the increase in IOP and reduce the risk for postoperative vision loss in adult patients undergoing surgery in the Trendelenburg and prone positions. Meta-analysis research methods provide increased power compared to individual studies, improve estimates of effect size, and help resolve uncertainty when the results of individual studies disagree (Berlin, 1995). Meta-analysis research provides a high level of objectivity, precision, and generalizability because all of the evidence pertaining to a particular phenomenon is included in the analysis (Thompson, 1994). Patient outcomes can be optimized by reducing the risk for postoperative vision loss and other ocular complications resulting from increased IOP in adult surgical patients. Currently, there has been no quantitative meta-analytic synthesis of the existing studies examining the increase in IOP in surgical patients positioned in the Trendelenburg or prone positions.

The purpose of these systematic reviews and meta-analyses is to estimate the magnitude of the increase in IOP at relevant perioperative time points in adult patients undergoing any type of surgery in the Trendelenburg and prone position. The following chapter presents the research proposal for the systematic reviews and meta-analyses with a description of the approach used, an explanation of the significance and innovation of the project, and a discussion of the anticipated challenges. Chapter 3 is the manuscript to be submitted for publication titled, "Systematic Review and Meta-analysis of Trendelenburg Position on Intraocular Pressure in Adult Patients Undergoing Surgery" and Chapter 4 is the manuscript to be submitted for publication titled, "Systematic Review and Meta-analysis of Prone Position on Intraocular Pressure in Adult Patients 
Undergoing Surgery." Chapter 5 provides a summary of the results of the systematic reviews and meta-analyses as well as evidence-based recommendations for mitigating or reducing IOP when patients undergo surgery in the prone and Trendelenburg positions. These interventions may improve patient outcomes by preventing postoperative vision loss and other ocular complications. 


\section{RESEARCH PROPOSAL}

This research project will involve conducting two systematic reviews and metaanalyses to estimate the overall magnitude and effect of the Trendelenburg and prone positions on intraocular pressure (IOP) in adult patients undergoing surgery. Patients 18 years or older are considered to be adult patients.

\section{Significance}

Understanding and mitigating the magnitude of the intraoperative increase in IOP can improve patient outcomes in adult patients undergoing surgery in the Trendelenburg and prone positions by reducing the risk for postoperative vision loss and other ocular complications.

\section{Trendelenburg Position}

In the Trendelenburg position, the patient's feet are higher than the patient's head by 15 degrees to 30 degrees (MacDonald \& Washington, 2012). Many surgeons use a steep Trendelenburg position of 30 degrees to 45 degrees, particularly during laparoscopic and robotic surgery, which is frequently used for prostatectomy, hysterectomy, colorectal surgery, and various other procedures. This position moves the abdominal viscera cephalad to improve surgical access to the pelvic and abdominal organs. While providing enhanced visualization of the operative field, the Trendelenburg position also decreases venous return from the head, leading to venous pooling and increased IOP (Akhavan, Gainsburg, \& Stock, 2010; Astuto, Minardi, Uva, \& Gullo, 2011; Awad et al., 2009; Borahay et al., 2013; Cullen \& Ferguson, 2012; Ghomi, 2012; Kan, Brown, \& Gainsburg, 2015; Mondzelewski et al., 2015; Taketani et al., 2015). 
Increased IOP resulting from the use of the Trendelenburg position poses a risk for postoperative glaucoma, detached retina, or partial to complete vision loss (Astuto et al., 2011; Borahay et al., 2013; Emery et al., 2015; Ghomi, Kramer, Askari, Chavan, \& Einarsson, 2012; Gkegkes, Karydis, Tyritzis, \& Iavazzo, 2015; Gould, Cull, Wu, \& Osmundsen, 2012; Grosso et al., 2013; Hoshikawa et al., 2014; Lee \& Newman, 2018; Taketani et al., 2015). Postoperative vision loss can be caused by an ischemic process that occurs as a result of decreased blood supply from the arteries of the optic nerve or by venous stasis that occurs as a result of decreased venous outflow (Gkegkes et al., 2015; Kan et al., 2015; Molloy, 2011). Some researchers have found the increased IOP associated with the Trendelenburg position poses a risk for postoperative vision loss, particularly in patients with pre-existing ocular disease (Astuto et al., 2011; Borahay et al., 2013; Grosso et al., 2017; Hoshikawa et al., 2014; Mondzelewski et al., 2015; Taketani et al., 2015). Older patients who have elevated baseline IOP are at greater risk for ischemic optic neuropathy (Freshcoln \& Diehl, 2014; Ghomi, 2012; Grosso et al., 2013; Kan et al., 2015; Mondzelewski et al., 2015). Prolonged use of the steep Trendelenburg position may also lead to retinal detachment (Hewer, 1956). The increase in IOP and risk for postoperative vision loss is directly correlated with the amount of time the patient is in the Trendelenburg position (Mizumoto, Gosho, Iwaki, Zako, 2017; Nuzzi \& Tridico, 2016; Pinkney et al., (2012); Stang-Veldhouse, Yeu, Rothenberg, \& Mizen, 2010; Yoo et al., 2014).

\section{Prone Position}

In the prone position, the patient is positioned face-down on their abdomen. This position provides surgical access to the dorsal aspects of the patient's body. Partial to 
complete postoperative vision loss is a complication of surgery in the prone position, and it occurs with greater frequency after spine, head and neck, cardiac, and some orthopedic procedures (Emery et al., 2015; Lee \& Newman, 2018). There have been reports of postoperative vision loss (Goni et al., 2012; Quraishi, Wolinsky, \& Gokaslan, 2012; Reddy, Foroozan, Edmond, \& Hinckley, 2008; Shifa, Abebe, Bekele, \& Habte, 2016; Stang-Veldhouse et al., 2010), as well as subconjunctival hemorrhage (Akhaddar \& Boucetta, 2012), subperiosteal orbital hemorrhage (Russell \& Dutton, 2011), and Horner syndrome (Guillaume \& Gowreesunker, 2013) after prolonged surgery in the prone position.

Elevated IOP levels decrease perfusion pressure of the optic nerve and increase the patient's risk for postoperative vision loss. According to Hayreh (2001), perfusion pressure of the optic nerve is the difference between pressures of the ciliary arteries in the nerve and the venous drainage of the eye. This difference is approximated by the level of IOP. The "higher the intraocular pressure, the lower the perfusion pressure, and consequently, the lower the blood flow in the optic nerve head" (p. 608). The lower the blood flow in the optic nerve head, the greater the risk for postoperative vision loss.

When the anesthetized patient is in the prone position, IOP increases and the extent of this increase is related to the amount of time the patient is in the prone position (Agah, Ghasemi, Roodneshin, Radpay, \& Moradian, 2011; Eddama, 2013; Kamel \& Barnette, 2014; Kendrick, 2012; Pinkney et al., 2012; Szmuk et al., 2013; Yoshimura, Hayashi, Tanaka, Nomura, \& Kawaguchi, 2015). After only a few minutes in the prone position, IOP can increase significantly (Nuzzi \& Tridico, 2015). The most dramatic increases in IOP occur when the patient is in the jack-knife or Kraske position (i.e., a 
prone position where the patient's hips are elevated and the patient's head is down;

Kendrick, 2012; Pinkney et al., 2012; Nuzzi \& Tridico, 2015). The jack-knife position is used for hemorrhoidectomy or other rectal surgery.

Yoshimura et al., (2015) suggested that measuring IOPs after one hour of surgery in the prone position could provide an opportunity for implementing interventions to prevent additional increases in IOP. Eddama (2013) also suggested that regular measurement of IOPs during prolonged surgeries could provide an opportunity for implementing a change in the patient's position when critical thresholds of IOP are reached.

\section{Incidence}

The exact incidence of postoperative vision loss in adult surgical patients is unknown because the data come largely from retrospective studies and case reports (Lee \& Newman, 2018; Patil, Lad, Lad, Ho, \& Boakye, 2008). In a 10-year prevalence study of postoperative vision loss in the United States, Shen, Drum, and Roth (2009) reviewed data from more than 5.6 million patients included in the Nationwide Inpatient Sample from 1995 to 2005. The researchers found the incidence of postoperative vision loss for patients undergoing laminectomy without fusion was 0.86 per 10,000. For patients undergoing spinal fusion, the incidence was 3.09 per 10,000. According to the American Academy of Orthopedic Surgeons (2014), there were 332,159 spinal fusion surgeries in the United States in 2005. Using the figures provided by Shen et al., this would equate to a total of 102.6 cases of postoperative vision loss. In 2011, the number of spinal fusions increased by 40\% to 465,070 (American Academy of Orthopedic Surgeons (2014), equating to a total of 143.7 cases of postoperative vision loss. 
Although postoperative vision loss may be considered a rare occurrence, as the number of surgeries performed in the Trendelenburg and prone positions increases, the number of cases of postoperative vision loss can be anticipated to increase proportionally. Fingar, Stocks, Weiss, and Steiner (2014) found that in 2012, the most frequently performed surgical procedures in the United States included laminectomy (149.1 per 100,000 population) and spinal fusion (143.6 per 100,000 population). These procedures are typically performed in the prone position. Frequently performed procedures in 2012 also included abdominal or vaginal hysterectomy (99.4 per 100,000 population), unilateral or bilateral oophorectomy (71.3 per 100,000 population), appendectomy ( 97.4 per 100,000 population), and colorectal resection (97.4 per 100,000 population; Fingar et al., 2014). These procedures are often performed in the Trendelenburg position using minimally invasive techniques (e.g., laparoscopic, robotic). The World Health Organization (Weiser et al., 2016) estimated a total global surgical volume of 312.9 operations performed in 2012, a $38.2 \%$ increase from the estimated 226.4 million surgical procedures performed in 2004. In 2016, there were 27.2 million surgical procedures performed in the United States (American Hospital Association, 2019). In light of these large and increasing numbers of surgical procedures, the prevention of postoperative vision loss takes on even greater importance.

\section{Meta-analysis}

Although some researchers have studied the quantitative intraoperative increases of IOP in surgical patients in the Trendelenburg (Astuto et al., 2011; Awad et al., 2009; Borahay et al., 2013; Grosso et al., 2013; Hoshikawa et al., 2014; Molloy, 2011; Mondzelewski et al., 2015; Taketani et al., 2015), and prone position (Emery et al., 2015; 
Lee \& Newman, 2018; Nuri Deniz et al., 2013; Quraishi et al., 2012; Shifa et al., 2016; Stang-Veldhouse et al., 2010; Yoshimura et al., 2015), there is a need for systematic review and meta-analysis of these studies to demonstrate the magnitude and overall effect size of the increase in IOP in adult surgical patients. Meta-analysis research can provide high-quality evidence to support the need for implementing intraoperative interventions designed to mitigate or reduce the increase of IOP and thus decrease the patient's risk for postoperative vision loss or other ocular complications.

In the Trendelenburg position, these interventions may include reducing the degree of Trendelenburg position (Ghomi et al., 2012; Mathew et al., 2018; Ozcan et al., 2017; Raz et al., 2015), monitoring IOP (Hoshikawa et al., 2013; Lee, Dallas, Daniel, \& Cotter, 2016; Vitish-Sharma et al., 2018), and implementing periodic intraoperative position changes (Blecha et al., 2017; Borahay et al., 2013; Freshcoln \& Diehl, 2014; Gkegkes et al., 2015; Gould et al., 2012; Mizrahi, Hugkulstone, Vyakarnam, \& Parker, 2011; Molloy \& Watson, 2012). In the prone position, these interventions include using a head-elevated position (Carey, Shaw, Weber, \& DeVine, 2014; Emery et al., 2015; Fukui, Ahmad, McHugh, Tempelhoff, \& Cheng, 2004; Fukui Tempelhoff, \& Cheng, 2005), monitoring IOP (Eddama, 2013; Yoshimura et al., 2015), or providing periodic position changes (Molloy \& Watson, 2012).

Currently, there has been no quantitative meta-analytic synthesis of the existing studies in these expanding areas of research. There is a need for systematic review and meta-analyses of these studies to demonstrate the magnitude and overall effect size of the intraoperative increase in IOP in adult patients. This research can provide high-quality evidence supporting the need for implementing interventions to mitigate the increase of 
IOP and reduce the risk for postoperative vision loss and other ocular complications in adult patients undergoing surgery in the Trendelenburg and prone positions. Metaanalysis research methods provide increased power compared to individual studies, improve estimates of effect size, and help resolve uncertainty when the results of individual studies disagree (Berlin, 1995). Meta-analysis research provides a high level of objectivity, precision, and generalizability because all of the evidence pertaining to a particular phenomenon is included in the analysis (Thompson, 1994).

\section{Innovation}

This research proposal is innovative in two ways. The first innovative concept is using meta-analysis research to determine the magnitude and effect of two specific surgical positions on a physiological response that increases the potential for ocular injury in adult patients undergoing surgery in these positions. Implementing metaanalysis research to improve the care and outcomes of surgical patients related to specific surgical positions has not been done previously. This meta-analysis research can help to reduce the incidence of postoperative vision loss and other ocular complications by providing high-quality evidence to support guidelines and recommendations for safe patient positioning of adults undergoing all types of surgery in the Trendelenburg and prone positions.

Using the Perioperative Patient Focused Model (Rothrock \& Smith, 2000) as a conceptual framework for each of the proposed meta-analyses is the second innovative approach. The application of this Model to the proposed research is innovative because although the Model is applicable to nursing interventions implemented by perioperative registered nurses (RNs), it has not been previously applied to perioperative nursing 
research. The Model is relevant to nursing interventions executed to prevent patient injury when positioning adult surgical patients in the Trendelenburg and prone positions.

As shown in Figure 2.1, the Model is patient-focused (Rothrock \& Smith, 2000). A primary role of the perioperative $\mathrm{RN}$ is to provide effective perioperative patient care and serve as the patient's advocate. Secondary to being patient focused, the Perioperative Patient Focused Model is outcome focused (Rothrock \& Smith, 2000). The care provided by perioperative RNs is directed toward achieving high quality patient outcomes, such as preventing postoperative vision loss associated with increased IOP. Providing optimal perioperative patient care, serving as the patient's advocate, and achieving high quality outcomes requires specific perioperative knowledge and skillful implementation of best practices for patient positioning.

Consistent with the Perioperative Patient Focused Model (Rothrock \& Smith, 2000), the evidence-based practices implemented by perioperative RNs during patient positioning promote patient safety, and optimal physiological and behavioral responses. Providing evidence about the magnitude of the intraoperative increase in IOP resulting from the Trendelenburg and prone positions will support the implementation of nursing interventions specifically directed at preventing postoperative vision loss and other ocular complications in adult surgical patients.

\section{Approach}

The principal investigator (PI), addressed the research questions related to the effect of Trendelenburg and prone position on IOP in adult patients undergoing surgery with a separate meta-analysis for each position (i.e., one meta-analysis examined the 
magnitude of the effect of Trendelenburg position on IOP, and one meta-analysis

examined the magnitude of the effect of prone position on IOP).

\section{Inclusion Criteria}

For each meta-analysis, the PI searched the literature for studies that addressed the research question and met inclusion criteria. Included studies were those

- written in English;

- reported between January 1, 1990 and September 30, 2018 (for the meta-analysis examining the effect of Trendelenburg position on IOP only);

- that encompassed dissertation research, conference abstracts, and presentations;

- that used either a one-group, pretest posttest comparison or a multiple-group, pretest posttest design;

- where the minimum age of study participants was 18-years or older;

- where the participants IOP was measured using any type of tonometer;

- where the participants received any type of general or spinal anesthesia; and

- with sufficient data to calculate an effect size.

The year 1990 was selected as the initial searching date for the meta-analysis examining the effect of Trendelenburg position on IOP because the first laparoscopic cholecystectomy was performed in 1987 (Vecchio, MacFayden, \& Palazzo, 2000). The use of the steep Trendelenburg position has increased dramatically with the introduction and use of laparoscopic and robotic surgery. There was no initial date restriction for the meta-analysis examining the effect of prone position on IOP. When reports did not include sufficient data to calculate an effect size, the PI contacted the researchers on at least two separate occasions two to three weeks apart to obtain missing data. 


\section{Literature Search}

For each meta-analysis, the PI conducted a comprehensive and exhaustive literature search to avoid bias due to a narrow or limited search. The PI implemented search strategies that included

- online searching of PubMed, CINAHL, Scopus, and Cochrane Database of Systematic Reviews databases for published and unpublished literature;

- ancestry searches of references from relevant reports;

- author searches of individuals identified in the literature as experts in the field;

- hand searches of relevant journals; and a

- dissertation search of the ProQuest database.

The PI collaborated with an expert health sciences reference librarian from the University of Missouri libraries to identify the most appropriate search terms, search dates, and databases and to refine search strategies.

The PI reviewed report abstracts for eligibility and obtained potentially eligible reports using library resources or by contacting the author. As the literature was searched and eligible reports were obtained, the PI used the EndNote bibliographic software (Clarivate Analytics, 2018) to compile a separate reference library for each metaanalysis.

\section{Evidence Appraisal}

Relevant research was independently evaluated and critically appraised according to the strength and quality of the evidence using the Association of periOperative Registered Nurses (AORN) Research Evidence Appraisal Tool - Study (See Appendices A-1 and A-2) by the PI and a second experienced evidence appraiser. The PI and 
evidence appraiser participated in conference calls until 100 percent consensus was achieved on the level of study strength and quality for each of the studies included in each meta-analysis.

\section{Coding}

The PI developed a separate codebook for each meta-analysis and performed detailed coding of the studies for criteria relevant to address each research question and statistically analyze the effects and methodologies of each of the reports. To ensure accuracy of outcome data, a second trained researcher performed independent coding.

For each meta-analysis, the PI used the EndNote bibliographic software (Clarivate Analytics, 2018) to track eligibility and coding status for each meta-analysis. Eligible studies from the EndNote database were exported to an Excel file. The PI searched the Excel file for overlapping reports, and evaluated the identified reports to ensure they were not entered in the analysis more than once.

The PI used the codebook for each meta-analysis to translate key information from the relevant reports into the quantitative values necessary to implement metaanalysis to address the research questions (e.g., study characteristics, participant attributes, study design, effect size data). The PI and second coder independently entered coded data onto Excel spreadsheets. The PI and second coder participated in conference calls until 100 percent consensus was achieved on effect size data for each of the studies included in each meta-analysis. The PI screened the data to identify improbable values, compared questionable values to primary reports, and cleaned the data to ensure accuracy of data entry.

\section{Data Analysis}


Data for each meta-analysis were analyzed using Comprehensive Meta-Analysis, a statistical software developed specifically for meta-analysis research (Borenstein, Hedges, Higgins, \& Rothstein, 2018). The PI obtained education and training to use this software during a course on meta-analysis research methods provided by the University of Missouri Sinclair School of Nursing. The PI further completed an educational and training course provided by the software developers.

For each meta-analysis, the PI used outcome data from eligible studies to calculate an overall mean effect size across reports. A random effects model was selected a priori to synthesize effect sizes. The overall mean effect size is the mean of the treatment group minus the mean of the control group divided by the pooled standard deviation. The effect size values of the individual studies were weighted to account for sample size and adjusted for bias. This process created a unitless, standardized measure of effect size across studies. To facilitate interpretation of effect size findings, for each meta-analysis, the effect size information was converted to the metric used to measure IOP (i.e., millimeters of mercury [mmHg]). If applicable, the PI conducted moderator analyses for different time points. The extent of publication bias for each meta-analysis was assessed by constructing a funnel plot. Notably, a funnel plot may suggest publication bias, but does not eliminate the bias (Sutton, 2009). An Egger's test using linear regression was also conducted to measure symmetry of the funnel plot (Borenstein et al., 2018; Egger, Smith, Schneider, \& Minder, 1997; Sterne, Egger, \& Moher, 2011). When the Egger's test was significant, Orwin's Fail-safe $N$ test was conducted to estimate the number of missing studies required to overturn the conclusions of the metaanalysis (Orwin, 1983; Sutton, 2009). Orwin's Fail-safe $N$ assesses the impact of 
publication bias to determine whether the overall observed effect is robust (Orwin, 1983; Sutton, 2009).

For each meta-analysis, the PI tested for homogeneity of variance among effect sizes using Cochrane's Q, which estimates statistical significance; Tau-squared $\left(T^{2}\right)$, which estimates the absolute value of the true variance between studies, but not the proportion of the variance; and $I$-squared $\left(I^{2}\right)$, which estimates the proportion of true variance, but not the absolute value of the variance, (Borenstein, Hedges, Higgins, \& Rothstein, 2009). Heterogeneity among the studies for each meta-analysis was anticipated due to the diversity of sample characteristics among studies.

\section{Challenges}

When conducting the meta-analysis research, the PI anticipated and prepared for challenges related to sampling, study quality, missing data, and coding. Achieving a successful and valid meta-analysis is dependent upon obtaining as many relevant studies as possible, and because of the nature of the research topics, the PI suspected this would be difficult. Locating and obtaining unpublished literature on the meta-analyses topics was also expected to be challenging; however, this is necessary to minimize publication bias. The PI managed these challenges by collaborating with an expert reference librarian to assist with search strategies and by completing exhaustive literature searches that included thorough ancestry, author, journal, and dissertation searches.

Meta-analysis is a synthesis of the findings of multiple study reports. For this reason, the validity of a meta-analysis of studies can be affected by including poor quality studies (i.e., studies lacking methodological rigor and internal validity). Along with a second reviewer, the PI assessed the level of strength and quality of each of the studies 
included in each meta-analysis using specific criteria (e.g., sample size, generalizability) defined by the AORN Research Evidence Appraisal Tool - Study (Appendices A-1 and A-2).

Coding errors can lead to errors in or inability to analyze data. The PI managed this challenge by developing a codebook that allowed for studies to be coded with minimal coder reasoning or interpretation and by using a second coder to independently code effect size data to assure all studies were coded correctly and accurately. Eligible studies that failed to include sufficient data to calculate an effect size led to challenges in coding and limitations of data analysis. The PI made every attempt possible to obtain missing data by contacting study researchers or statisticians. When the PI was unable to obtain the missing data, the study was excluded from the analysis. 


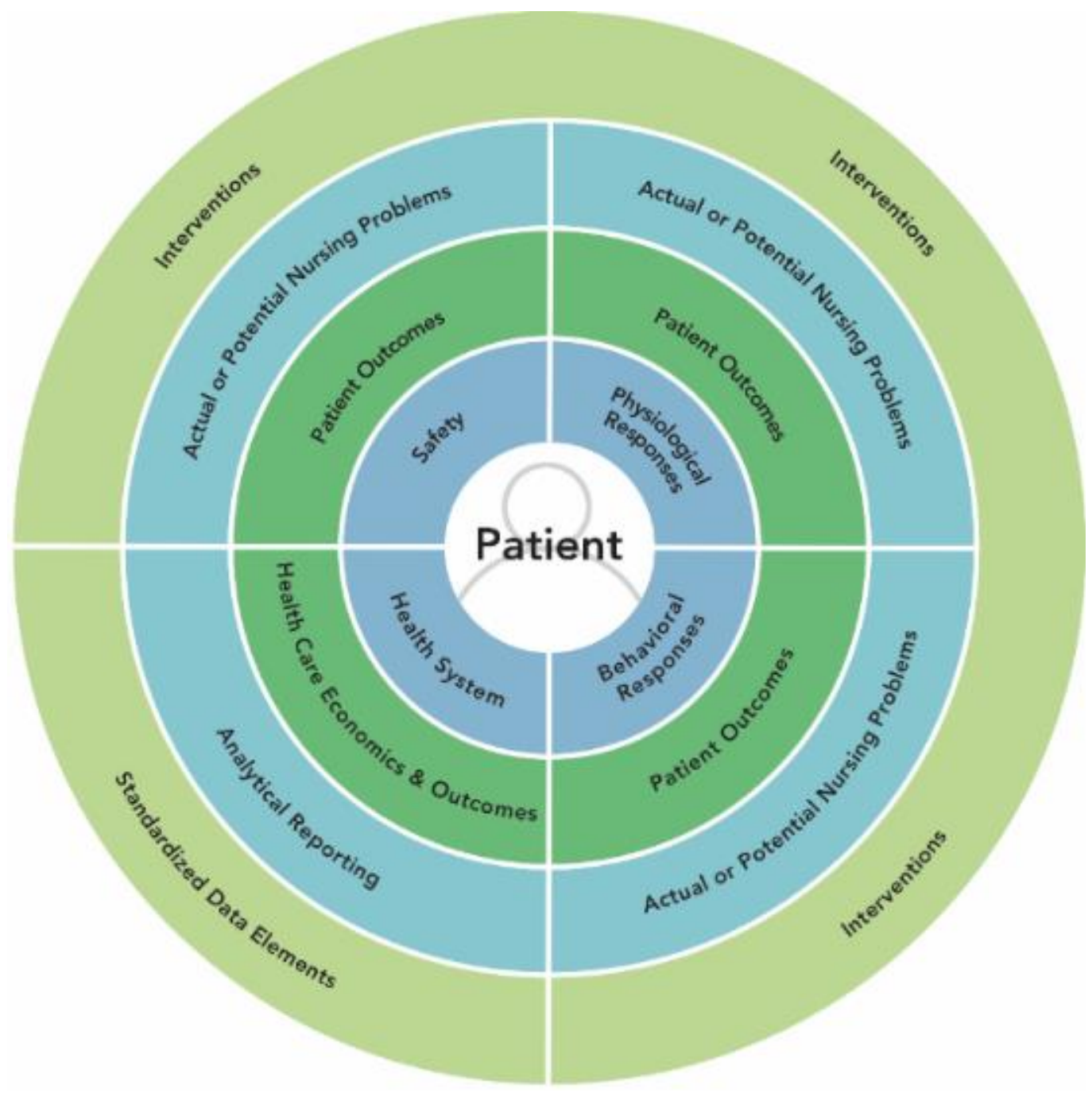

Figure 2.1. Perioperative Patient Focused Model (2017). Reprinted with permission from Guidelines for Perioperative Practice. Copyright (C 2018, AORN, Inc, 2170 S. Parker Road, Suite 400, Denver, CO 80231. All rights reserved. 
3. SYSTEMATIC REVIEW AND META-ANALYSIS OF TRENDELENBURG POSITION ON INTRAOCULAR PRESSURE IN ADULT PATIENTS UNDERGOING SURGERY

Van Wicklin, S. A. (2019). Systematic review and meta-analysis of Trendelenburg position on intraocular pressure in adult patients undergoing surgery. Manuscript in preparation.

\begin{abstract}
Background. Patients undergoing surgery in the Trendelenburg position may be at risk for postoperative vision loss associated with increased intraocular pressure. The purpose of this systematic review and meta-analysis is to estimate the magnitude of the increase in intraocular pressure in adult patients.
\end{abstract}

Methods. Comprehensive search strategies were used to identify 18 eligible studies $(N=$ 762). Standardized mean difference effect sizes were calculated for nine intraoperative time points $(\mathrm{T})$.

Results. Using a random effects model, meta-analysis showed that intraocular pressure increased significantly after abdominal insufflation (T2: $d=1.89, p=<0.001)$ and during Trendelenburg position (T3: $d=1.34, p<0.001$; T4: $d=0.91, p<0.001$; T6: $d=0.30, p$ $<0.001 ; \mathrm{T} 8: d=0.38, p<0.001)$.

Conclusions. Intraocular pressure increases of this magnitude demonstrate the need for implementing intraoperative interventions to reduce the risk for postoperative vision loss in patients undergoing surgery in the Trendelenburg position.

Keywords: intraocular pressure, Trendelenburg position, head-down tilt, pneumoperitoneum, Perioperative Patient Focused Model 
In the Trendelenburg position, the patient's feet are higher than the patient's head by 15 degrees to 30 degrees (MacDonald \& Washington, 2012). Many surgeons use a steep Trendelenburg position of 30 degrees to 45 degrees, particularly during laparoscopic and robotic surgery. The benefit of the Trendelenburg position is that it moves the abdominal viscera cephalad to improve visibility and surgical access to the abdominal and pelvic organs. However, there are potential harms associated with the Trendelenburg position. The Trendelenburg position increases intraocular pressure (IOP; Akhavan, Gainsburg, \& Stock, 2010; Astuto, Minardi, Uva, \& Gullo, 2011; Awad et al., 2009; Borahay et al., 2013; Cullen \& Ferguson, 2012; Ghomi, 2012; Kan, Brown, \& Gainsburg, 2015; Mondzelewski et al., 2015; Taketani et al., 2015). According to the American Academy of Ophthalmology (2018), normal IOP is 10 millimeters of mercury (mmHg) to $21 \mathrm{mmHg}$. Intraocular pressures higher than $21 \mathrm{mmHg}$ pose a risk for glaucoma, detached retina, and postoperative vision loss (Astuto et al., 2011; Borahay et al., 2013; Emery et al., 2015; Ghomi, Kramer, Askari, Chavan, \& Einarsson, 2012;

Gkegkes, Karydis, Tyritzis, \& Iavazzo, 2015; Gould, Cull, Wu, \& Osmundsen, 2012; Grosso et al., 2013; Hoskikawa et al., 2014; Lee \& Newman, 2018; Taketani et al., 2015). Pathogenesis of Postoperative Vision Loss

The specific pathogenesis of postoperative vision loss associated with increased IOP is unclear; however, it is known that elevated IOP can lead to optic nerve injury and decreased ocular perfusion pressure resulting in ischemic optic neuropathy (Kan et al., 2015; Newman, 2008). Ischemic optic neuropathy is the most common cause of postoperative vision loss (Kan et al., 2015; Newman, 2008). The ischemic process can occur as a direct result of decreased blood supply from the arteries of the optic nerve or 
by venous stasis that occurs as a result of decreased venous outflow (Gkegkes et al., 2015; Kan et al., 2015; Molloy, 2011). Periorbital swelling and venous congestion resulting from the Trendelenburg position can lead to a compartment syndrome in the orbital space that compromises blood flow to the eye, retina, and optic nerves (Molloy, 2011; Yoo et al., 2014). The amount of subsequent postoperative vision loss can range from temporary blurring to partial to complete blindness; however, once a loss of vision occurs, it is an irreversible complication (Emery et al., 2015; Lee \& Newman, 2018).

Some researchers have found that increased IOP associated with the Trendelenburg position poses a greater risk for postoperative vision loss in patients who have existing ocular disease compared with patients who do not have ocular disease (Astuto et al., 2011; Borahay et al., 2013; Grosso et al., 2017; Hoshikawa et al., 2014; Mondzelewski et al., 2015; Taketani et al., 2015). Older patients with elevated baseline IOPs are also at greater risk for ischemic optic neuropathy than younger patients with normal baseline IOPs (Freshcoln \& Dieh1, 2014; Ghomi, 2012; Grosso et al., 2013; Kan et al., 2015; Mondzelewski et al., 2015). Likewise, patients with cardiovascular deficits may be at greater risk for postoperative vision loss than patients without cardiovascular deficits (Borahay et al., 2013). The increase in IOP and subsequent risk for postoperative vision loss is related to the amount of time the patient is in the Trendelenburg position (Mizumoto, Gosho, Iwaki, Zako, 2017; Nuzzi \& Tridico, 2016; Pinkney et al., (2012); Stang-Veldhouse, Yeu, Rothenberg, \& Mizen, 2010; Yoo et al., 2014).

\section{Incidence of Postoperative Vision Loss}

The incidence of postoperative vision loss following nonocular surgery has been estimated to be as low as $0.0002 \%$ and as high as $0.2 \%$ (Berg, Harrison, \& Lee, 2010; 
Newman, 2008); however, the incidence of postoperative vision loss in patients undergoing surgery in the Trendelenburg position remains unknown. The potential for serious ocular consequences associated with the use of the Trendelenburg position, including retinal detachment and postoperative vision loss, was first reported by Hewer (1956). To identify cases of ischemic optic neuropathy associated with prostatectomy procedures performed in the Trendelenburg position, Lee (2011) reviewed the American Society of Anesthesiologists Postoperative Vision Loss Registry, a database of 175 cases of postoperative vision loss occurring between 1987 and 2010, and found six cases. Case reports of postoperative vision loss following surgical procedures where the patient was in the Trendelenburg position have also been published.

Williams et al., (1999) reported a case of bilateral anterior ischemic optic neuropathy and branch retinal artery occlusion in a 50-year-old man undergoing laparoscopic radical prostatectomy in the Trendelenburg position. On the second postoperative day, the patient complained of bilateral vision loss. Weber, Colyer, Lesser, and Subramanian (2007) reported two cases of bilateral posterior ischemic optic neuropathy following radical prostatectomy in the Trendelenburg position. The first case involved a 62-year-old man undergoing a robotic-assisted laparoscopic procedure. On the first postoperative day, the patient complained of "purple vision" and loss of inferior visual fields in both eyes (p. 285). The second case involved a 64-year-old man undergoing a laparoscopic procedure (without robotic technology). After surgery, the patient complained of seeing a rainbow in his superior visual fields after which everything went black. Two months after surgery, the patient had no improvement in his vision. 
Mizrahi, Hugkulstone, Vyakarnam, and Parker (2011) and Kumar and Vyakarnam (2013) reported a case of bilateral posterior optic neuropathy after laparoscopic colorectal surgery in a 58-year-old man with mild hypertension and obesity. The patient was positioned in a 45-degree Trendelenburg position for more than five hours. Approximately 14 hours postoperatively the patient complained of blurred vision. Six months after surgery, vision in his left eye was 6/7.5, with no improvement in his right eye. Molloy (2011) also described a case of posterior ischemic optic neuropathy resulting in bilateral blindness in a 63-year-old man following a laparoscopic prostatectomy in the steep Trendelenburg position.

\section{Conceptual Framework}

The Perioperative Patient Focused Model (Figure 3.1; Rothrock \& Smith, 2000) provides a conceptual framework for this systematic review and meta-analyses. During operative procedures when the patient is anesthetized, the perioperative registered nurse (RN) fills an important role as the patient's advocate and also oversees the patient's perioperative care. Secondary to being patient focused, the Perioperative Patient Focused Model is outcome focused (Rothrock \& Smith, 2000). The care provided by perioperative RNs is directed toward achieving high quality patient outcomes, such as preventing postoperative vision loss associated with increased IOP. Providing optimal perioperative patient care, serving as the patient's advocate, and achieving high quality outcomes requires specific perioperative knowledge and skillful implementation of best practices for patient positioning. Consistent with the Perioperative Patient Focused Model, the evidence-based practices implemented by perioperative RNs during patient positioning promote patient safety, and optimal physiological and behavioral responses in 
perioperative patients. Providing evidence about the magnitude of the increase in IOP resulting from the intraoperative use of the Trendelenburg position will support the implementation of nursing interventions to help prevent postoperative vision loss and other ocular complications in adult patients undergoing surgery in the Trendelenburg position.

\section{Purpose}

Although some researchers have studied the quantitative increase of IOP in surgical patients in the Trendelenburg position (Astuto et al., 2011; Awad et al., 2009; Borahay et al., 2013; Grosso et al., 2013; Hoshikawa et al., 2014; Molloy, 2011; Mondzelewski et al., 2015; Taketani et al., 2015), there is a need for systematic review and meta-analysis of these studies to demonstrate the overall effect size and provide highquality evidence supporting the implementation of intraoperative interventions designed to mitigate the increase of IOP and reduce the risk for postoperative vision loss. Metaanalysis research methods provide increased power compared to individual studies, improve estimates of effect size, and help resolve uncertainty when the results of individual studies disagree (Berlin, 1995). Because all of the evidence pertaining to a particular phenomenon is included in the analysis, meta-analysis research provides a high level of objectivity, precision, and generalizability (Thompson, 1994). Currently, there has been no quantitative meta-analytic synthesis of the existing studies examining the increase in IOP in adult patients undergoing surgery in the Trendelenburg position. The purpose of this systematic review and meta-analysis is to estimate the magnitude of the increase in IOP at selected perioperative time points in adult patients (i.e., individuals 18 years and older) undergoing any type of surgery in the Trendelenburg position. 
Consequently, the research question to be addressed by this systematic review and metaanalysis is, "What is the magnitude of the increase in IOP at specific perioperative time points in adults undergoing surgery in the Trendelenburg position?"

\section{Methods}

To ensure rigorous and transparent presentation of the methods and results of this systematic review and meta-analysis, the Preferred Reporting Items for Systematic reviews and Meta-Analyses (PRISMA) guidelines have been followed (Moher, Liberati, Tetzlaff, Altman, \& PRISMA Group, 2009).

\section{Search Strategies}

An expert health sciences reference librarian was consulted to identify the most appropriate search terms and databases and to assist with refining search strategies for an exhaustive and varied literature search. Keywords or medical subject headings (MeSH) included intraocular pressure or ocular tension, and Trendelenburg position or headdown tilt. Search strategies included

- online searching of the PubMed, CINAHL, and Scopus databases, and the Cochrane Database of Systematic Reviews for published and unpublished literature;

- ancestry searching of references from relevant reports to locate additional applicable references;

- author searching of individuals identified in the literature as experts in the field; and a - dissertation search of the ProQuest database.

The author reviewed report abstracts for eligibility and obtained full-text copies of potentially eligible reports.

\section{Inclusion and Exclusion Criteria}


Criteria for inclusion in the meta-analysis were reports written in English; studies reported between January 1, 1990 and September 30, 2018; published or unpublished reports of primary studies that encompassed dissertations, conference abstracts, and presentations; studies that used either a one-group, pretest posttest design or a multiplegroup, pretest posttest design; reports where the minimum age of the study participants was 18-years or older; studies that included a specific measured outcome of IOP using any type of tonometer; studies where the participants received any type of general anesthesia; and reports of studies that included sufficient data to calculate an effect size. The year 1990 was selected as the initial searching date because the first laparoscopic cholecystectomy was performed in 1987 (Vecchio, MacFayden, \& Palazzo, 2000). The use of the steep Trendelenburg position has increased dramatically with the introduction and use of laparoscopic and robotic surgery. When reports did not include sufficient data to calculate an effect size, the author contacted the researchers on at least two separate occasions two to three weeks apart to obtain missing data.

Reports were excluded if the IOP was measured in adults not undergoing surgery. Reports were also excluded if data from only one time point of IOP measurement were provided. Participant groups were additionally excluded if they were receiving an intervention specifically intended to mitigate IOP; however, participant groups representing control arms receiving placebos or no interventions were included in the systematic review and meta-analysis.

\section{Risk of Bias Within Individual Studies}

To assess the risk of bias within individual studies, the Association of periOperative Registered Nurses (AORN) Research Evidence Appraisal Tool - Study, 
available on the AORN website (https://www.aorn.org/guidelines/about-aornguidelines/evidence-rating) was independently used by the author and an experienced, evidence reviewer to evaluate and critically appraise each study for its level of strength and quality. When using the AORN appraisal tool, strong study designs (e.g., randomized controlled trials) are assigned the highest level of strength (i.e., experimental). Nonexperimental designs (e.g., observational studies) are assigned the lowest level of strength and quasi-experimental designs are assigned a moderate level of strength. Measures such as sample size, generalizability, bias, reliability, and validity are assessed to determine whether the study quality is high, good, or low. The author and evidence reviewer participated in conference calls to discuss their independent appraisals until 100 percent consensus was achieved on study design and quality levels for each of the included studies.

\section{Risk of Bias Across Studies}

Risk of bias that may affect cumulative evidence was managed using several strategies (Valentine, 2009). To avoid bias due to a narrow or limited search (White, 2009), a comprehensive and diverse literature search was conducted. Only research studies were included in the systematic review and meta-analysis to ensure the included studies were of sufficient strength and quality. As well, studies that included objective measurements of IOP at less than two or more perioperative time points were excluded. An analysis of publication bias was also conducted to determine whether unpublished research was unintentionally excluded.

\section{Coding and Data Extraction}


An iterative process that included studying codebooks used by experienced metaanalysts for data extraction and coding of their research studies was used to develop the codebook. The relevant literature was also reviewed. After consultation with experienced meta-analysts and content analysis of studies specific to the effects of Trendelenburg position on IOP, the codebook was revised. The codebook was pilot-tested by the author using 10 randomly selected studies before being used to code and extract data from all eligible reports to identify missed coding categories and verify fit between coding categories and study characteristics (Wilson, 2009).

To extract data necessary to address the research question and statistically analyze the effects and methodologies of each of the reports, the author coded eligible studies using the developed codebook. Effect size data for each of the reports included in the systematic review and meta-analysis was independently coded by a trained researcher. The author and independent researcher discussed coding discrepancies until 100 percent consensus was achieved on effect size data for each of the eligible studies.

Data collected from each eligible study included study characteristics (i.e., authors, year of publication, publication status, geographic location, reported funding) and data related to study design (i.e., type of study, study quality, type of tonometer, inclusion of ophthalmologic exams by participants). When available, data related to participant and surgery characteristics (i.e., age; gender; American Society of Anesthesiologists [ASA; 2018] Physical Status Classification; body mass index [BMI]; comorbidities; type of surgery; degree of Trendelenburg; intra-abdominal pressure; type of anesthesia; duration of anesthesia, pneumoperitoneum, Trendelenburg position, and surgery; estimated blood loss [EBL]) were collected. Data necessary to calculate effect 
sizes were extracted for the multiple time points recorded by the researchers during the perioperative phases of the procedures included in their studies.

\section{Analyses}

Meta-analyses were conducted using Comprehensive Meta-Analysis Software, Version 3, a statistical software developed specifically for meta-analysis research (Borenstein, Hedges, Higgins, \& Rothstein, 2018). Time points for meta-analysis were selected from the time points recorded by the researchers to allow for similarity with the order of events as they occur during surgery and to achieve the greatest number of comparisons for analysis at each time point. Analyses were conducted for the nine time points (T) described in the Sidebar. Standardized mean difference effect sizes were calculated for each participant group and each measured time point (Cohen, 1992).

To account for sample size and adjust for bias, effect size values were weighted by the inverse of the variance. To account for between- and within-study variation, and because heterogeneity was observed among study designs, sample attributes, and outcome measures, a random effects model was selected a priori to synthesize effect sizes. Using a random effects model assumes that the true effect size varies from one study to the next (Borenstein, Hedges, Higgins, \& Rothstein, 2009a, p. 77). A random effects model was used for seven analyses (T1, T2, T3, T5, T6, T7, T8). A fixed effect model was used to synthesize effect sizes for two analyses (T4, T9) because the number of included studies at these time points was limited. Using a fixed effect model assumes that the true effect size is the same for all studies (Borenstein et al., 2009a, p.77). Borenstein et al., (2009a, p. 84) suggest using a fixed effect analysis when the number of included studies is limited, even when heterogeneity among the studies is observed, 
because when using a random effects analysis, the estimate of between-studies variance will have poor precision. Relative to interpretation of effect size, Cohen (1992) suggested that 0.2 be considered a small effect size, 0.5 be considered a medium effect size, and 0.8 or greater be considered a large effect size. Following the procedures described by Lipsey and Wilson (2001), the calculated effect sizes were converted to the metric used to measure IOP (i.e., $\mathrm{mmHg}$ ) to facilitate interpretation of effect size findings.

The extent of publication bias for the meta-analysis was assessed by constructing a funnel plot. Notably, a funnel plot may suggest publication bias, but does not eliminate the bias (Sutton, 2009). In order to create a funnel plot, there must be a minimum of three studies (Borenstein et al., 2018). An Egger's test using linear regression was also conducted to measure asymmetry of the funnel plot (Borenstein et al., 2018; Egger, Smith, Schneider, \& Minder, 1997; Sterne Egger, \& Moher, 2011). Using an Egger's test is not advised when there are less than 10 studies included in the meta-analysis because the power of the test may be too low to distinguish true asymmetry from chance (Sterne et al., 2011). Therefore, when the analysis included 10 or more participant groups (T1, T2, T6), a funnel plot was constructed and an Egger's test was conducted.

The goal of a meta-analysis is three-fold: 1) to obtain a global effect size for the intervention or phenomenon being studied, 2) to determine whether the studies are homogeneous, and 3) if the studies are heterogeneous, to identify possible variables or characteristics moderating the meta-analysis results (Huedo-Medina, Sánchez-Meca, Marín-Martínez, \& Botella, 2006). After deciding on the model and calculating effect sizes, the studies included in the meta-analysis were assessed for heterogeneity. According to the Cochrane Collaboration, heterogeneity is any kind of variability among 
the studies included in a meta-analysis (Deeks, Higgins, \& Altman, 2011). Heterogeneity testing explores the null hypothesis (i.e., that the same effect is being evaluated by all studies; Higgins, Thompson, Decks, \& Altman, 2003). Heterogeneity among the included studies in a meta-analysis is very common and should be anticipated, not regarded as the exception (Berlin, 1995).

Homogeneity of variance among effect sizes was tested using Cochrane's Q, which estimates statistical significance; Tau-squared $\left(T^{2}\right)$, which estimates the absolute value of the true variance between studies, but not the proportion of the variance; and $I$ squared $\left(I^{2}\right)$, which estimates the proportion of true variance, but not the absolute value of the variance, (Borenstein, Hedges, Higgins, \& Rothstein, 2009b). Higgins and Thompson (2002) recommend using an $I^{2}$ test for quantifying the impact of heterogeneity in a metaanalysis as this test quantifies the influence (as opposed to the amount) of heterogeneity and expresses the percentage of variability due to heterogeneity rather than chance ( $\mathrm{p}$. 1553). An $I^{2}$ value of $0 \%$ indicates there is no heterogeneity, values of $25 \%$ reflect low observed variation, values of $50 \%$ reflect moderate levels, and values of $75 \%$, reflect high levels of observed variation (Higgins et al., 2003). Prediction intervals for each time point were also calculated to show the dispersion of true effect sizes around the mean (Borenstein, Hedges, Higgins, \& Rothstein, 2009c).

\section{Results}

The flow of study selection is depicted in Figure 3.2. In total, 2693 records were identified for possible inclusion, and of these, 18 studies were included in the systematic review and meta-analysis. Four non-experimental studies had multiple participant groups (Agrawal, Dureja, Verma, \& Kang, 2013; Kaur, Sharma, Kalra, Purohit, \& Chauhan, 
2018; Nishikawa, Watanabe, \& Kurahashi, 2017; Yoo et al., 2015), resulting in a total of 24 participant groups and 762 participants for analysis. Table 3.1 contains a summary of the studies included in this review and meta-analysis.

\section{Study Characteristics}

All 18 studies included in the systematic review and meta-analysis were obtained from peer-reviewed journals. The researchers of six studies $(33.3 \%)$ reported receiving some type of funding or donated supplies (Adisa, Onakpoya, Adenekan, \& Awe, 2016; Blecha et al., 2017; Hirooka et al., 2018; Molloy \& Cong, 2014; Molloy, Cong, \& Watson, 2016; Yoo et al., 2015). Although the literature was searched from 1990 through 2018, studies included in the systematic review and meta-analysis were published between 2011 and 2018. Some earlier studies were located during the literature search (Awad et al., 2009; Lentschener, Benhamou, Niessen, Mercier, \& Fernandez, 1996; Mowafi, Al-Ghamdi, \& Rushood, 2003); however, these were excluded because of insufficient effect size data. The greatest number of studies $(s)$ were published in 2015 ( $s$ $=4)$ and $2018(s=4)$, but the greatest number of participants occurred in $2013(n=147)$. The majority $(s=14)$ were conducted in Asia $(s=7)$ or North America $(s=7)$, with the majority of participants also from Asia $(n=361)$ or North America $(n=292)$.

\section{Participant Characteristics}

Participant and surgery characteristics are shown in Table 3.2. The mean age of the participants was 55.2 years $( \pm 11.9)$ and ranged from 30.5 years to 66.9 years. The majority of the participants were men $(n=415 ; 67.0 \%)$. Participant race was only reported by two researchers (Adisa et al, 2016; Borahay et al, 2013). Socioeconomic status was not reported by any researchers. Participants were slightly overweight with a 
mean BMI of $27.5 \mathrm{~kg} / \mathrm{m}^{2}( \pm 2.3$; Centers for Disease Control and Prevention, 2016). The ASA physical classification status was reported by the researchers of 10 reports. Some researchers reported that all participants were ASA class I or II ( $s=2$; Agrawal et al., 2013; Taketani et al., 2015), other researchers reported the number or percentage of participants who were ASA class I, II, or III ( $s=8$; Adisa et al., 2016; Blecha et al., 2017; Grosso, et al., 2013; Kaur et al., 2018; Kitamura et al., 2018; Molloy, 2011; Molloy \& Watson, 2012; Yoo et al., 2015). The majority of participants $(n=432 ; 95.4 \%)$ were ASA class I (healthy) or II (with mild systemic disease; American Society of Anesthesiologists, 2018). Notably, some researchers had exclusion criteria for participant age, BMI, and ASA classification (see Table 3.1). Researchers reported patient comorbidities for 191 participants $(s=6)$ that included asthma ( $n=2$ of $76 ; 2.6 \%)$, diabetes $(n=8$ of $107 ; 7.5 \%)$, and hypertension $(n=44$ of $117 ; 37.6 \%$; Borahay et al., 2013; Kitamura et al., 2018; Molloy, 2011; Molloy \& Watson, 2012; Raz et al., 2015; Yoo et al., 2015).

\section{Surgery Characteristics}

The majority of the participants underwent robotic-assisted laparoscopic radical prostatectomy $(n=335 ; 44.0 \%)$ or laparoscopic gynecologic surgery $(n=151 ; 19.8 \%)$. All participants $(N=762)$ received general anesthesia by either inhalation $(n=298$; $39.1 \%)$, intravenous propofol $(n=242 ; 31.8 \%)$, or unspecified methods $(n=222$; 29.1\%). Intra-abdominal pressure for maintaining carbon dioxide pneumoperitoneum ranged between $12 \mathrm{mmHg}$ and $15 \mathrm{mmHg}$ with a mean of $13.6 \mathrm{mmHg}( \pm 1.3)$. The mean degree of Trendelenburg was $28.4( \pm 6.5)$ with a range of 17.5 to 45 . The mean duration 
of surgery was 197.9 minutes $( \pm 64.4)$ with a range of 111 minutes to 318 minutes. The mean EBL was 252.4 milliliters $(\mathrm{mL} ; \pm 113.3)$ with a range of $69.4 \mathrm{~mL}$ to $467 \mathrm{~mL}$.

\section{Study Design Characteristics}

The 18 reports included in the systematic review and meta-analysis comprised four experimental ( $n=100$; Kitamura et al., 2018; Mathew et al., 2018; Molloy et al., 2016; Raz et al., 2015), two quasi-experimental ( $n=168$; Molloy \& Cong, 2014; Molloy \& Watson, 2012), and 12 non-experimental ( $n=494$; Adisa et al., 2016; Agrawal et al., 2013; Blecha et al., 2017; Borahay et al., 2013; Grosso et al., 2013; Hirooka et al., 2018; Kaur et al., 2018; Molloy, 2011; Mondzelewski et al., 2015; Nishikawa et al., 2017; Taketani et al., 2015; Yoo et al., 2015). Nine were high quality ( $n=461$; Blecha et al., 2017; Kaur et al., 2018; Kitamura et al., 2018; Mathew et al., 2018; Molloy, 2011; Molloy \& Cong, 2014; Molloy et al., 2016; Molloy \& Watson, 2012; Yoo et al., 2015) and nine were good quality $(\mathrm{n}=301$; Adisa et al., 2016; Agrawal et al., 2013; Borahay et al., 2013; Grosso et al., 2013; Hirooka et al., 2018; Mondzelewski et al., 2015; Nishikawa et al., 2017; Raz et al., 2015; Taketani et al., 2015). The researchers used five different types of tonometers to measure IOP, the Tono-Pen XL was used most frequently $(s=9 ; n$ =420). The researchers reported having 195 participants undergo preoperative ophthalmologic examinations ( $s=7$; Adisa et al., 2016; Grosso et al., 2013; Hirooka et al., 2018; Kaur et al., 2018; Mathew et al., 2018; Mondzelewski et al., 2015; Taketani et al., 2015), and 100 participants undergo postoperative ophthalmologic examinations $(s=$ 4; Hirooka et al., 2018; Mathew et al., 2018; Mondzelewski et al., 2015; Taketani et al., 2015). Notably, all participants who received postoperative ophthalmologic examinations also received preoperative examinations $(n=100)$. 


\section{Effect Sizes}

Results of the synthesized effect sizes, prediction intervals, and meta-analyses for each time point of IOP measurement are shown in Table 3.3. A graphical representation of the magnitude of changes in IOP for T0 through T9 is shown in Figure 3.3. In total, between abdominal insufflation in supine position (T2) and 5 minutes (T3), 60 minutes (T4), 150 minutes (T6), and 240 minutes (T8) of Trendelenburg position, IOP increases significantly by $13.6 \mathrm{mmHg}$ (i.e., $3.5 \mathrm{mmHg}+4.4 \mathrm{mmHg}+2.6 \mathrm{mmHg}+1.5 \mathrm{mmHg}+$ $1.6 \mathrm{mmHg}=13.6 \mathrm{mmHg}$ ). Based on the upper limits of the prediction intervals (Figure 3.4), in $95 \%$ of all populations, IOP could increase by as much as $28.1 \mathrm{mmHg}$ (i.e., 7.6 $\mathrm{mmHg}+8.5 \mathrm{mmHg}+6.6 \mathrm{mmHg}+2.3 \mathrm{mmHg}+3.1 \mathrm{mmHg}=28.1 \mathrm{mmHg})$. The greatest increase in IOP occurs after the patient is placed into the Trendelenburg position (T3: $+4.4 \mathrm{mmHg}$ ). The IOP continues to increase significantly while the patient is in Trendelenburg position, but to a lesser degree (T4: $+2.6 \mathrm{mmHg}$; $6:+1.5 \mathrm{mmHg}$; $\mathrm{T} 8$ :

$+1.6 \mathrm{mmHg}$ ). Intraocular pressure decreases significantly after induction of anesthesia in supine position (T1: $-5.2 \mathrm{mmHg}$ ) and after a return to supine position for arousal from anesthesia (T5: -7.5 mmHg; T7: $-8.2 \mathrm{mmHg}$; T9: $-6.0 \mathrm{mmHg}$ ). The forest plot of effect sizes for each participant group included in the meta-analysis for T6 is shown in Figure 3.5. The funnel plot for publication bias for T6 is shown in Figure 3.6.

\section{Discussion}

The results of this systematic review and analysis have shown that IOP increases significantly for adult patients undergoing surgery in the Trendelenburg position. As shown in Figure 3.3, if an individual had a baseline IOP of $16.5 \mathrm{mmHg}$ before induction of anesthesia (as indicated by the pooled mean calculated for T0), after 180 minutes to 
240 minutes in the Trendelenburg position, the patient's IOP could increase to 24.9 $\mathrm{mmHg}(16.5 \mathrm{mmHg}-5.2 \mathrm{mmHg}+3.5 \mathrm{mmHg}+4.4 \mathrm{mmHg}+2.6 \mathrm{mmHg}+1.5 \mathrm{mmHg}+$ $1.6 \mathrm{mmHg}=24.9 \mathrm{mmHg}$ ). Based on the upper limits of the prediction intervals (Figure 3.4), after 180 minutes to 240 minutes in the Trendelenburg position, IOP could increase to $35 \mathrm{mmHg}(16.5 \mathrm{mmHg}-9.6 \mathrm{mmHg}+7.6 \mathrm{mmHg}+8.5 \mathrm{mmHg}+6.6 \mathrm{mmHg}+2.3$ $\mathrm{mmHg}+3.1 \mathrm{mmHg}=35 \mathrm{mmHg}$ ). An IOP of $24.9 \mathrm{mmHg}$ to $35 \mathrm{mmHg}$ is above the highest parameter of normal IOP (i.e., $21 \mathrm{mmHg}$ ). As shown in Table 3.2, the mean duration of Trendelenburg position for the studies included in this systematic review and meta-analysis is 104.8 minutes $( \pm 58.2)$ with a range of 68 minutes to 207 minutes. The greatest increases in IOP occur during abdominal insufflation and within the first 60 minutes after Trendelenburg position; however, based on the collective range of 68 minutes to 207 minutes for duration of Trendelenburg position, a Trendelenburg time of 180 minutes to 240 minutes is not implausible. Another important consideration regarding the findings of this systematic review and meta-analysis is that the mean degree of Trendelenburg position was 28.4. Steep Trendelenburg is generally considered to be a head-down tilt of 30 degrees to 45 degrees (Demasi, Porpiglia, Tempia, \& D’Amelio, 2017; Ghomi et al., 2012; Gould et al., 2012); thus, it is likely that Trendelenburg positions greater than 28.4 degrees would have produced even greater increases in IOP.

\section{Implications for Practice}

Increased IOP puts the patient at risk for glaucoma, detached retina, or partial to complete vision loss (Astuto et al., 2011; Borahay et al., 2013; Emery et al., 2015; Ghomi et al., 2012; Gkegkes et al., 2015; Gould et al., 2012; Grosso et al., 2013; Hoskikawa et al., 2014; Lee \& Newman, 2018; Taketani et al., 2015). Intraocular pressure increases of 
the magnitude found in this systematic review and meta-analysis clearly demonstrate the need for implementing intraoperative interventions to mitigate the increase in IOP and reduce the potential for serious ocular complications in patients undergoing surgery in the Trendelenburg position. These intraoperative interventions may include

- monitoring IOP at established intervals or continuously (Hoshikawa et al., 2013; Lee, Dallas, Daniel, \& Cotter, 2016; Vitish-Sharma et al., 2018),

- reducing the degree of Trendelenburg position (Ghomi et al., 2012; Mathew et al., 2018; Ozcan et al., 2017; Raz et al., 2015),

- implementing a modified Trendelenburg position (Raz et al., 2015),

- providing periodic position changes or rest periods (Blecha et al., 2017; Borahay et al., 2013; Freshcoln \& Diehl, 2014; Gkegkes et al., 2015; Gould et al., 2012; Mizrahi et al., 2011; Molloy \& Watson, 2012), and

- administering specific medications or anesthetics (Agrawal et al., 2013; Hwang et al., 2013; Joo, Koh, Lee, \& Lee, 2016; Joo, Kim, \& Lee, 2017; Kan et al., 2015; Kaur et al., 2018; Kim et al., 2015; Mathew et al., 2018; Mowafi et al., 2003).

Because IOP increases during abdominal insufflation and Trendelenburg position, intraoperative monitoring of IOP either continuously or at established intervals or time points (e.g., after abdominal insufflation, after initiation of Trendelenburg position, after 60 minutes of Trendelenburg position, etc.) seems prudent. Elevated IOPs can be an indication of ocular venous congestion and decreased perfusion of the optic nerve (Yoo et al., 2014). Monitoring IOP can provide a baseline IOP and an objective measure that can help the surgical team maintain awareness of the patient's IOP, implement interventions 
to reduce IOP as needed, and thus reduce the potential for ocular complications and postoperative vision loss (Hoshikawa et al., 2013; Lee et al., 2016).

Steeper degrees of Trendelenburg increase the risk for postoperative complications because they place greater physiologic stress on the patient's body (Ghomi et al., 2012; Gould et al., 2012; Kadono et al., 2013). Ghomi et al., (2012) found that robotic-assisted gynecologic surgery could be performed successfully with a modest head-down tilt of 16.4 degrees. In a study to determine the head-down tilt necessary to provide surgical access and visibility, Gould et al., (2012) found the mean head-down tilt most often selected by the surgeons was 28.1 degrees, which was much less than the 40 degree head-down tilt the surgeons were using.

Raz et al., (2015) found that modifying the Trendelenburg position so that the patient's head and shoulders remained level significantly decreased IOP and accelerated its return to baseline levels. Implementing periodic intraoperative position changes or rest periods in supine position (or positions where the ocular level is above the heart) can help to reduce IOP. In a quasi-experimental study, Molloy and Watson (2012) implemented a five-to-seven-minute level supine intervention after 60 minutes of 32-degree to 40-degree Trendelenburg position and found there was a significant decrease in IOP after 120 minutes of Trendelenburg position (Intervention: $18.7 \mathrm{mmHg} \pm 5.22$; Control: 35.7 $\mathrm{mmHg} \pm 10.56 ; p<0.001)$. The dramatic and significant decrease in IOP that occurs before arousal from anesthesia found in this systematic review and meta-analysis (T5: $7.5 \mathrm{mmHg}, p<0.001$; T7: $-8.2 \mathrm{mmHg}, p<0.001$; T9: $-6.0 \mathrm{mmHg}, p<0.001)$ also supports the implementation of periodic intraoperative position changes or rest periods as a mechanism to help reduce IOP. 
Administering specific medications or anesthetics may also be effective in reducing IOP or mitigating the intraoperative increase in IOP (Agrawal et al., 2013; Hwang et al., 2013; Joo et al., 2016; Joo et al., 2017; Lee et al., 2016; Kaur et al., 2018; Kim et al., 2015; Mathew et al., 2018; Mowafi et al., 2003). Agrawal et al., (2013) found that induction and maintenance of anesthesia with intravenous propofol was the most effective option for mitigating the increase in IOP in adult patients undergoing surgery in the Trendelenburg position. Likewise, Kaur et al., (2018) found that propofol-based total intravenous anesthesia was more effective than inhalational anesthesia with sevoflurane in mitigating the increase in IOP in patients undergoing laparoscopic surgery in the Trendelenburg position. Kitamura et al., (2018) found that continuous administration of dexmedetomidine in combination with propofol-based total intravenous anesthesia decreased IOP in patients undergoing robotic-assisted laparoscopic radical prostatectomy. Molloy and Cong (2014) found that intraoperative treatment with dorzolamide-timolol eyedrops significantly reduced elevated IOP in patients undergoing lengthy laparoscopic procedures in the Trendelenburg position, while Molloy et al., (2016) found that prophylactic therapy with dorzolamide-timolol eyedrops significantly reduced IOP in patients undergoing robotic-assisted laparoscopic prostate and gynecologic procedures. Another important consideration for practice is the need to evaluate whether patients undergoing surgery in the Trendelenburg position should receive a preoperative ophthalmologic examination to reduce the risk for ocular injury (Borahay et al., 2013; Lee et al., 2016). Preoperative ophthalmologic examinations may be helpful in identifying patients at risk for postoperative vision loss. Increases in IOP may be more harmful in older patients or patients who are predisposed to developing diabetes or 
glaucoma than in younger, healthier patients (Borahay et al., 2013; Grosso et al., 2013; Mondzelewski et al., 2015; Taketani et al., 2015).

The results of this systematic review and meta-analysis support the use of the Perioperative Patient Focused Model as the conceptual foundation for this perioperative research. Providing quantitative evidence about the magnitude of the intraoperative increase in IOP resulting from the Trendelenburg position supports the implementation of nursing interventions that are patient-focused and will improve patient outcomes by mitigating increases in IOP and reducing the risk for permanent postoperative vision loss and other ocular complications in adult surgical patients.

\section{Implications for Future Research}

Further research relative to the magnitude of IOP increases in patients undergoing surgery in the Trendelenburg position is warranted. Further research to provide validation and demonstrate reliability of the Perioperative Patient Focused Model is also warranted. To allow for consistent data collection, comparison, meta-analysis, and reporting, researchers of future studies should use standardized time points for measurement (i.e., before arousal, after arousal, after abdominal insufflation, after change to Trendelenburg position and every 30 minutes to 60 minutes thereafter, after return to supine position, before arousal, and postoperatively). Further, researchers should present data in a consistent format for each time point (i.e., sample size, mean, standard deviation). Additionally, to determine whether certain variables affect the strength of the relationship between Trendelenburg position and IOP, researchers should include patients of all ages (e.g., children, older adults), without restriction of BMI or comorbidities.

\section{Limitations}


This systematic review and meta-analyses has several limitations. The literature search yielded 107 potentially eligible studies. Studies were excluded for a variety of reasons (see Figure 3.2); however, 25 studies were excluded from the analyses because of a lack of data necessary to calculate an effect size. The researchers were contacted a minimum of two times to obtain missing data, but most did not respond. Some of the researchers excluded participants based on age, BMI, and comorbidities; therefore, the mean values for these variables may not fully reflect the true characteristics of all adult surgical patients. Because researchers measured IOP at different intraoperative time points, all studies could not be included at all time points examined in the meta-analysis. Likewise, there were not enough studies included at each time point to allow for moderator analyses. With the exception of T6 and T8, heterogeneity was significant, indicating that variation across studies was substantial, potentially limiting generalizability. The non-significant Egger's regression intercept (bias $=-0.05 ; p=0.47$ ) is indicative of the absence of bias in the studies included in the meta-analysis for the T6 time point $(s=12)$; however, the Egger's test has low power for meta-analyses containing small to moderate numbers of studies (Sutton, 2009).

\section{Conclusion}

Intraocular pressure increases significantly between abdominal insufflation in supine position and 240 minutes of Trendelenburg position. The greatest increases in IOP occur after insufflation of the abdomen (while the patient is in the supine position) and within five minutes after the patient is placed into the Trendelenburg position. The IOP continues to increase significantly while the patient is in Trendelenburg position, but to a lesser degree. Intraocular pressure increases of the magnitude found in this systematic 
review and meta-analysis clearly demonstrate the need for implementing intraoperative interventions to mitigate the increase in IOP and reduce the risk for postoperative vision loss and other ocular complications in patients undergoing surgery in the Trendelenburg position. 


\section{References}

Adisa, A. O., Onakpoya, O. H., Adenekan, A. T., \& Awe, O. O. (2016). Intraocular pressure changes with positioning during laparoscopy. Journal of the Society of Laparoendoscopic Surgeons, 20(4), e2016.00078. doi: 10.4293/JSLS.2016.00078

Agrawal, M., Dureja, V., Verma, A. P., \& Kang, L. S. (2013). A comparative study of four combinations of anesthetic drugs for assessing the intraocular pressure changes during gynaecological laparoscopic procedures. Anesthesia Essays and Researches, 7(3), 319-325. doi: 10.4103/0259-1162.123221

Akhavan, A., Gainsburg, D. M., \& Stock, J. A. (2010). Complications associated with patient positioning in urologic surgery. Urology, 76(6), 1309-1316. doi: 10.1016/j.urology.2010.02.060

American Academy of Ophthalmology. (2018). Intraocular pressure. Retrieved from https://www.aao.org/bcscsnippetdetail.aspx?id=f010bbf6-3f3e-486b-b5cd0ad86ddb9d74

American Society of Anesthesiologists. (2018). ASA Physical Status Classification System. Retrieved from https://www.asahq.org/standards-and-guidelines/asaphysical-status-classification-system

Astuto, M., Minardi, C., Uva, M. G., \& Gullo, A. (2011). Intraocular pressure during laparoscopic surgery in paediatric patients. British Journal of Ophthalmology, 95(2), 294-295. doi: 10.1136/bjo.2010.195396

Awad, H., Santilli, S., Ohr, M., Roth, A., Yan, W., Fernandez, S, . . Patel, V. (2009). The effects of steep Trendelenburg positioning on intraocular pressure during 
robotic radical prostatectomy. Anesthesia \& Analgesia, 109(2), 473-478. doi: 10.1213/ane.0b013e3181a9098f

Berg, K. T., Harrison, A. R., \& Lee, M. S. (2010). Perioperative visual loss in ocular and nonocular surgery. Clinical Ophthalmology, 4, 531-546.

Berlin, J. A. (1995). Invited commentary: Benefits of heterogeneity in meta-analysis of data from epidemiological studies. American Journal of Epidemiology, 142(4), 465-468. doi: 10.1093/oxfordjournals.aje.a117645

Blecha, S., Harth, M., Schlachetzki, F., Zeman, F., Blecha, C., Flora, P., . . Pawlik, M. T. (2017). Changes in intraocular pressure and optic nerve sheath diameter in patients undergoing robotic-assisted laparoscopic prostatectomy in steep $45^{\circ}$ Trendelenburg position. BMC Anesthesiology, 17(1), 40. doi: 10.1186/s12871017-0333-3

Borahay, M. A., Patel, P. R., Walsh, T. M., Tarnal, V., Koutrouvelis, A., Vizzeri, G., . . . Kilic, G. S. (2013). Intraocular pressure and steep Trendelenburg during minimally invasive gynecologic surgery: Is there a risk? Journal of Minimally Invasive Gynecology, 20(6), 819-824. doi: 10.1016/j.mig.2013.05.005

Borenstein, M., Hedges, L. V., Higgins, J., \& Rothstein, H. (2009a). Fixed-effect versus random-effects models. In Introduction to meta-analysis (pp. 77-86). West Sussex, UK: John Wiley \& Sons, Ltd.

Borenstein, M., Hedges, L. V., Higgins, J., \& Rothstein, H. (2009b). Identifying and quantifying heterogeneity. In Introduction to meta-analysis (pp. 107-125). West Sussex, UK: John Wiley \& Sons, Ltd. 
Borenstein, M., Hedges, L. V., Higgins, J., \& Rothstein, H. (2009c). Prediction intervals. In Introduction to meta-analysis (pp. 127-133). West Sussex, UK: John Wiley \& Sons, Ltd.

Borenstein, M., Hedges, L. V., Higgins, J., \& Rothstein, H. (2018). Comprehensive Meta-Analysis. Retrieved from https://www.meta-analysis.com

Centers for Disease Control and Prevention. (2016). Defining adult overweight and obesity. Retrieved from https://www.cdc.gov/obesity/adult/defining.html

Cohen, J. A. (1992). Power primer. Psychological Bulletin, 12(1), 155-159.

Cullen, A., \& Ferguson, A. (2012). Perioperative management of the severely obese patient: A selective pathophysiological review. Canadian Journal of Anesthesia, 59(10), 974-996.

Deeks, J. J., Higgins, J. P. T., \& Altman, D. G. (Eds.). (2011). Chapter 9: Analyzing data and undertaking meta-analysis. In J. J. Deeks, J. P. T Higgins, \& D. G. Altman (Eds.). Cochrane handbook for systematic reviews of interventions Version 5.1.0 (Updated March 2011). Retrieved from www.handbook.cochrane.org

Demasi, C. L., Porpiglia, F., Tempia, A., \& D’Amelio, S. (2017). Ocular blood flow in steep Trendelenburg positioning during robotic-assisted radical prostatectomy. European Journal of Ophthalmology, 28(3), 333-338. doi: 10.5301/ejo.5001061

Egger, M., Smith, G. D., Schneider, M., \& Minder, C. E. (1997). Bias in meta-analysis detected by a simple, graphical test. BMJ Clinical Research, 315(7109), 629-634. doi: $10.1136 / \mathrm{bmj} .315 .7109 .629$

Emery, S. E., Daffner, S. D., France, J. C., Ellison, M., Grose, B. W., Hobbs, G. R., \& Clovis, N. B. (2015). Effect of head position on intraocular pressure during 
lumbar spine fusion: A randomized, prospective study. Journal of Bone \& Joint Surgery (American), 97(22), 1817-1823. doi: 10.2106/JBJS.O.00091

Freshcoln, M. \& Diehl, M. R. (2014). Repositioning during robotic procedures to prevent postoperative visual loss. OR Nurse, 8(4), 36-41.

Ghomi, A. (2012). Robotics in practice: New angles on safer positioning. Contemporary $O B / G Y N, 57(10), 26-37$.

Ghomi, A., Kramer, C., Askari, R., Chavan, N. R., \& Einarsson, J. I. (2012). Trendelenburg position in gynecologic robotic-assisted surgery. Journal of Minimally Invasive Gynecology, 19(4), 485-489. doi: 10.1016.j.jmig.2012.03.019

Gkegkes, I. D., Karydis, A., Tyritzis, S. I., \& Iavazzo, C. (2015). Ocular complications in robotic surgery. International Journal of Medical Robotics, 11(3), 269-274. doi: $10.1002 /$ rcs. 1632

Gould, C., Cull, T., Wu, Y. X., \& Osmundsen, B. (2012). Blinded measure of Trendelenburg angle in pelvic robotic surgery. Journal of Minimally Invasive Gynecology, 19(4), 465-468. doi: 10.1016/j.jmig.2012.03.014

Grosso, A., Ceruti, P., Morino, M., Marchini, G., Amisano, M., \& Fioretto, M. (2017). Comment on the paper by Mondzelewski and colleagues: "Intraocular pressure during robotic assisted laparoscopic procedures utilizing steep Trendelenburg positioning.” Journal of Glaucoma, 26(4), e166-e167. doi:

10.1097/IJG.0000000000000494

Grosso, A., Scozzari, G., Bert, F., Mabilia, M. A., Siliquini, R., \& Morino, M. (2013). Intraocular pressure variation during colorectal laparoscopic surgery: Standard 
pneumoperitoneum leads to reversible elevation in intraocular pressure. Surgical Endoscopy, 27(9), 3370-3376. doi: 10.1007/s00464-013-2919-2

Hewer, C. L. (1956). The physiology and complications of the Trendelenburg position. Canadian Medical Association Journal, 74(4), 285-288.

Higgins, J. P. T., \& Thompson, S. G. (2002). Quantifying heterogeneity in a metaanalysis. Statistics in Medicine, 21(11), 1539-1558. doi: 10.1002/sim.1186

Higgins, J. P. T., Thompson, S. G., Decks, J. J., \& Altman, D. G. (2003). Measuring inconsistency in meta-analysis. $B M J, 327(7414), 557-560$. doi: 10.1136/bmj.327.7414.557

Hirooka, K., Ukegawa K., Nitta, E., Ueda, N., Hayashida, Y., Hirama, H., . . Kakehi, Y. (2018). The effect of steep Trendelenburg positioning on retinal structure and function during robotic-assisted laparoscopic procedures. Journal of Ophthalmology, 2018, 1027397. doi: 10.1155/2018/1027397

Hoshikawa, Y., Tsutsumi, N., Ohkoshi, K., Serizawa, S., Hamada, M., Inagaki, K., . . . Deshpande, G. A. (2014). The effect of steep Trendelenburg positioning on intraocular pressure and visual function during robotic-assisted radical prostatectomy. British Journal of Ophthalmology, 98(3), 305-308. doi: 10.1136/bjophthalmol-2013-303536

Huedo-Medina, T., Sánchez-Meca, J., Marín-Martínez, F., \& Botella, J. (2006). Assessing heterogeneity in meta-analysis: $Q$ statistic or $I 2$ index? Psychological Methods, 11(2), 193-206. doi: 10.1037/1082-989X.11.2.193

Hwang, J. W., Oh, A. Y., Hwang, D. W., Jeon, Y. T., Kim, Y. B., \& Park, S. H. (2013). Does intraocular pressure increase during laparoscopic surgeries? It depends on 
anesthetic drugs and the surgical position. Surgical Laparoscopy, Endoscopy \& Percutaneous Techniques, 23(2), 229-232. doi: 10.1097/SLE.0b013e31828a0bba

Joo, J., Koh, H., Lee, K., \& Lee, J. (2016). Effects of systemic administration of dexmedetomidine on intraocular pressure and ocular perfusion pressure during laparoscopic surgery in a steep Trendelenburg position: Prospective, randomized, double-blinded study. Journal of Korean Medical Science, 31(6), 989-996. doi: 10.3346/jkms.2016.31.6.989

Joo, J., Kim, J., \& Lee, J. (2017). Effect of continuous systemic administration of esmolol on intraocular pressure during surgery in a sustained steep Trendelenburg position. Journal of Glaucoma, 26(12), 1068-1071. doi:

10.1097.IJG.0000000000000746

Kadono, Y., Yaegashi, H., Machioka, K., Ueno, S., Miwa, S., Maeda, Y., . . Namiki, M. (2013). Cardiovascular and respiratory effects of the degree of head-down angle during robot-assisted laparoscopic radical prostatectomy. International Journal of Medical Robotics and Computer Assisted Surgery, 9(1), 17-22. doi:

$10.1002 /$ rcs. 1482

Kan, K. M., Brown, S. E., \& Gainsburg, D. M. (2015). Ocular complications in roboticassisted prostatectomy: A review of pathophysiology and prevention. Minerva Anestesiologica, 81(5), 557-566.

Kaur, G., Sharma, M., Kalra, P., Purohit S., \& Chauhan, K. (2018). Intraocular pressure changes during laparoscopic surgery in Trendelenburg position in patients anesthetized with propofol-based total intravenous anesthesia compared to 
sevoflurane anesthesia: A comparative study. Anesthesia Essays and Researches, 12(1), 67-72. doi: 10.4103/aer.AER_177_17

Kim, N. Y., Yoo, Y. C., Park, H. J., Choi, Y. D., Kim, C. Y., \& Bai, S. J. (2015). The effect of dexmedetomidine on intraocular pressure increase in patients during robot-assisted laparoscopic radical prostatectomy in the steep Trendelenburg position. Journal of Endourology, 29(3), 310-316. doi: 10.1089/end.2014.0381

Kitamura, S., Takechi, K., Nishihara, T., Konishi, A., Takasaki, Y., \& Yorozuya, T. (2018). Effect of dexmedetomidine on intraocular pressure in patients undergoing robot-assisted laparoscopic radical prostatectomy under total intravenous anesthesia: A randomized, double blinded placebo controlled clinical trial. Journal of Clinical Anesthesia, 49, 30-35. doi: 10.1016/j.clinane.2018.06.006

Kumar, G., \& Vyakarnam, P. (2013). Postoperative vision loss after colorectal laparoscopic surgery. Surgical Laparoscopy, Endoscopy \& Percutaneous Techniques, 23(2), e87-e88. doi: 10.1097/SLE.0b013e318277d2ae

Lee, L. A. (2011). Visual loss, venous congestion, and robotic prostatectomies. ASA Monitor, 75(2), 26-27.

Lee, L. A., \& Newman, N. (2018). Postoperative visual loss after anesthesia for nonocular surgery. UpToDate. Retrieved from https://www.uptodate.com/contents/postoperative-visual-loss-after-anesthesia-fornonocular-surgery

Lee, M., Dallas, R., Daniel, C., \& Cotter, F. (2016). Intraoperative management of increased intraocular pressure in a patient with glaucoma undergoing robotic 
prostatectomy in the Trendelenburg position. Anesthesia \& Analgesia Case Reports, 6(2), 19-21. doi: 10.1213/XAA.0000000000000213

Lentschener, C., Benhamou, D., Niessen, F., Mercier, F. J., \& Fernandez, H. (1996). Intra-ocular pressure changes during gynaecological laparoscopy. Anaesthesia, $51,1106-1108$.

Lipsey, M., \& Wilson, D. (2001). Interpreting and using meta-analysis results. In Practical meta-analysis: Applied social research (Vol 49, pp. 146-168). Thousand Oaks, CA: Sage.

MacDonald, J. J. \& Washington, S. J. (2012). Positioning the surgical patient. Anaesthesia and Intensive Care Medicine, 13(11), 528532.

Mathew, D. J., Greene, R. A., Mahsood, Y. J., Hallaji, N., Vargas, A. M. B., Jin, Y. P., . . . Buys, Y. M. (2018). Preoperative brimonidine tartrate $0.2 \%$ does not prevent an intraocular pressure rise during prostatectomy in steep Trendelenburg position. Journal of Glaucoma. Advance online publication. doi:

10.1097/IJG.0000000000001047

Mizrahi, H., Hugkulstone, C. E., Vyakarnam, P., \& Parker, M. C. (2011). Bilateral ischaemic optic neuropathy following laparoscopic proctocolectomy: A case report. Annals of the Royal College of Surgery of England, 93(5), e53-e54. doi: $10.1308 / 147870811 X 582828$

Mizumoto, K., Gosho, M., Iwaki, M., \& Zako, M. (2017). Ocular parameters before and after steep Trendelenburg positioning for robotic-assisted laparoscopic radical prostatectomy. Clinical Ophthalmology, 11, 1643-1650. doi:

10.2147/OPTH.S139874 
Moher, D., Liberati, A., Tetzlaff, J., Altman, D. G., \& PRISMA Group. (2009). Preferred reporting items for systematic reviews and meta-analyses: The PRISMA statement. PLoS Medicine, 6(7), e1000097. doi: 10.1371/journal.pmed.1000097

Molloy, B. L. (2011). Implications for postoperative visual loss: Steep Trendelenburg position and effects on intraocular pressure. AANA Journal, 79(2), 115-121.

Molloy, B. L., \& Cong, X. (2014). Perioperative dorzolamide-timolol intervention for rising intraocular pressure during steep Trendelenburg positioned surgery. AANA Journal, 82(3), 203-211.

Molloy, B. L., Cong, X., \& Watson, C. (2016). Preventive dorzolamide-timolol for rising intraocular pressure during steep Trendelenburg position surgery. AANA Journal, 84(3), 189-196.

Molloy, B. L., \& Watson, C. (2012). A comparative assessment of intraocular pressure in prolonged steep Trendelenburg position versus level supine position intervention. Journal of Anesthesiology \& Clinical Science. doi: 10.7243/2049-9752-1-9

Mondzelewski, T. J., Schmitz, J. W., Christman, M. S., Davis, K. D., Lujan, E., L’Esperance, J. O., \& Auge, B. K. (2015). Intraocular pressure during roboticassisted laparoscopic procedures utilizing steep Trendelenburg positioning. Journal of Glaucoma, 24(6), 399-404. doi: 10.1097/IJG.0000000000000302

Mowafi, H. A., Al-Ghamdi, A., Rushood, A. (2003). Intraocular pressure changes during laparoscopy in patients anesthetized with propofol total intravenous anesthesia versus isoflurane inhaled anesthesia. Anesthesia \& Analgesia, 97(2), 471-474. doi: 10.1213/01.ANE.0000067532.56354.58 
Newman, N. J. (2008). Perioperative visual loss after nonocular surgeries. American Journal of Ophthalmology, 145(4), 604-610. doi: 10.1016/j.ajo.2007.09.016

Nishikawa, M., Watanabe, H., \& Kurahashi, T. (2017). Effects of 25- and 30-degree Trendelenburg positions on intraocular pressure changes during robot-assisted radical prostatectomy. Prostate International, 5(4), 135-138. doi:

10.1016/j.prnil.2017.03.008

Nuzzi, R., \& Tridico, R. (2016). Ocular complications in laparoscopic surgery: Review of existing literature and possible prevention and treatment. Seminars in Ophthalmology, 31(6), 584-592. doi: 10.3109/08820538.2015.1009557

Ozcan, M. F., Akbulut, Z., Gurdal, C., Tan, S., Yildiz, Y., Bayraktar, S., Ozcan, A. N., . . . Balbay, M. D. (2017). Does steep Trendelenburg positioning effect the ocular hemodynamics and intraocular pressure in patients undergoing robotic cystectomy and robotic prostatectomy? International Urology and Nephrology, 49(1), 55-60. doi: $10.1007 / \mathrm{s} 11255-016-1449-\mathrm{y}$

Pinkney, T. D., King, A. J., Walter, C., Wilson, T. R., Maxwell-Armstrong, C., \& Acheson, A. G. (2012). Raised intraocular pressure (IOP) and perioperative visual loss in laparoscopic colorectal surgery: A catastrophe waiting to happen? A systematic review of evidence from other surgical specialties. Techniques in Coloproctology, 16(5), 331-335. doi: 10.1007/s10151-012-0879-5

Raz, O., Boesel, T. W., Arianayagam, M., Lau, H., Vass, J., Huynh, C. C., . . Varol, C. (2015). The effect of the modified Z Trendelenburg position on intraocular pressure during robotic assisted laparoscopic radical prostatectomy: A 
randomized, controlled study. Journal of Urology, 193(), 1213-1219. doi: 10.1016/j.juro.2014.10.094

Rothrock, J. D., \& Smith, D. A. (2000). Selecting the perioperative patient focused model. AORN Journal, 71(3), 1030-1037.

Stang-Veldhouse, K. N., Yeu, E., Rothenberg, D. M., \& Mizen, T. R. (2010). Unusual presentation of perioperative ischemic optic neuropathy following major spine surgery. Journal of Clinical Anesthesia, 22(1), 52-55. doi:

10.1016/j.jclinane.2009.01.018.

Sterne, J. A. C., Egger, M., \& Moher, D. (Eds.). (2011). Chapter 10: Addressing reporting biases. In J. J. Deeks, J. P. T Higgins, \& D. G. Altman (Eds.). Cochrane handbook for systematic reviews of interventions Version 5.1.0 (Update March 2011). Retrieved from www.handbook.cochrane.org

Sutton, A. J. (2009). Publication bias. In H. Cooper, L. V. Hedges, \& J. C. Valentine (Eds.). The handbook of research synthesis and meta-analysis (2nd ed., pp. 435452). New York, NY: Russell Sage Foundation.

Taketani, Y., Mayama, C., Suzuki, N., Wada, A., Oka, T., Inamochi, K., \& Nomoto, Y. (2015). Transient but significant visual field defects after robot-assisted laparoscopic radical prostatectomy in deep Trendelenburg position. PLoS ONE, 10(4), e0123361. doi: 10.1037/journal.pone.0123361

Thompson, S. G. (1994). Why sources of heterogeneity in meta-analysis should be investigated. BMJ, 309(6965), 1351-1355. 
Valentine, J. C. (2009). Judging the quality of primary research. In H. Cooper, L. V. Hedges, \& J. C. Valentine, (Eds.), The handbook of research synthesis and metaanalysis (2nd ed., pp. 129-146). New York, NY: Russell Sage Foundation.

Vecchio, R., MacFayden, B. V., \& Palazzo, F. (2000). History of laparoscopic surgery. Panminerva Medica, 42(1), 87-90.

Vitish-Sharma, P., Acheson, A. G., Stead, R., Sharp, J., Abbas, A., Hovan, M., . . King, A. J. (2018). Can the SENSIMED Triggerfish ${ }^{\circledR}$ lens data be used as an accurate measure of intraocular pressure? Acta Ophthalmologica, 96(2), e242-e246. doi: 10.1111/aos. 13456

Weber, E. D., Colyer, M. H., Lesser, R. L., \& Subramanian, P. S. (2007). Posterior ischemic optic neuropathy after minimally invasive prostatectomy. Journal of Neuro-Ophthalmology, 27(4), 285-287.

White, H. D. (2009). Scientific communication and literature retrieval. In H. Cooper, L. V. Hedges, \& J. C. Valentine (Eds.). The handbook of research synthesis and meta-analysis (2nd ed., pp. 51-71). New York, NY: Russell Sage Foundation.

Williams, G. C., Lee, A. G., Adler, H. L., Coburn, A., Rosas, A. L., Tang, R. A., \& Scardino, P. T. (1999). Bilateral anterior ischemic optic neuropathy and branch retinal artery occlusion after radical prostatectomy. Journal of Urology, 162(4), 1384-1385.

Wilson, D. B. (2009). Systematic coding. In H. Cooper, L. V. Hedges, \& J. C. Valentine, (Eds.), The handbook of research synthesis and meta-analysis (2nd ed., pp. 159176). New York, NY: Russell Sage Foundation. 
Yoo, Y. C., Shin, S., Choi, E. K., Kim, C. Y., Choi, Y. D., Bai, S. J. (2014). Increase in intraocular pressure is less with propofol than with sevoflurane during laparoscopic surgery in the steep Trendelenburg position. Canadian Journal of Anesthesia, 61(4), 322-329. doi: 10.1007/s12630-014-0112-2

Yoo, Y. C., Kim, N. Y., Shin, S., Choi, Y. E., Hong, J. H., Kim, C. Y., . . Bai, S. J. (2015). The intraocular pressure under deep versus moderate neuromuscular blockade during low-pressure robot assisted laparoscopic radical prostatectomy in a randomized trial. PLOS ONE, 10(8), e0135412. doi:

10.1371/journal.pone.0135412 
Table 3.1.

Summary of Studies Included in the Systematic Review and Meta-analysis $(s=18)$.

\begin{tabular}{|c|c|c|c|c|c|}
\hline $\begin{array}{l}\text { First Author } \\
\text { (Year) } \\
\text { Country }\end{array}$ & $\begin{array}{l}\text { Study Design } \\
\text { (Quality) }^{\mathrm{a}}\end{array}$ & $\begin{array}{l}\text { Participant Groups and } \\
\text { Observations/Interventions }\end{array}$ & $\begin{array}{l}\text { IOP Measures } \\
\text { (Tonometer) }\end{array}$ & Outcome Measures & $\begin{array}{l}\text { Effect Sizes } \\
(\text { Cohen's } d)\end{array}$ \\
\hline $\begin{array}{l}\text { Adisa } \\
(2016) \\
\text { Nigeria }\end{array}$ & $\begin{array}{l}\text { Non- } \\
\text { experimental } \\
(\text { Good) }\end{array}$ & $\begin{array}{l}\text { - } 20 \text { patients undergoing } \\
\text { laparoscopic surgery in } \\
\text { Trendelenburg position } \\
\text { 20 patients undergoing } \\
\text { laparoscopic surgery in reverse } \\
\text { Trendelenburg position }{ }^{\mathrm{b}} \\
\text { Note. Patients with BMI } \geq 35 \\
\mathrm{~kg} / \mathrm{m}^{2} \text { excluded. }\end{array}$ & $\begin{array}{l}\text { Measurement of } \\
\text { IOP at seven } \\
\text { different time } \\
\text { points } \\
\text { (Perkins) }\end{array}$ & $\begin{array}{l}\text { Differences in IOP levels } \\
\text { at each time point }\end{array}$ & $\begin{array}{l}\text { T1: }-1.043 \\
\text { T2: } 0.013 \\
\text { T3: } 0.839\end{array}$ \\
\hline $\begin{array}{l}\text { Agrawal } \\
(2013) \\
\text { India }\end{array}$ & $\begin{array}{l}\text { Non- } \\
\text { experimental } \\
\text { (Good) }\end{array}$ & $\begin{array}{l}\text { - } 30 \text { women undergoing } \\
\text { laparoscopic gynecologic } \\
\text { surgery in Trendelenburg } \\
\text { position with anesthesia using } \\
\text { propofol for induction and } \\
\text { propofol for maintenance (A) } \\
30 \text { women undergoing } \\
\text { laparoscopic gynecologic } \\
\text { procedures in Trendelenburg } \\
\text { position with anesthesia using } \\
\text { propofol for induction and } 1 \% \\
\text { isoflurane for maintenance (B) } \\
\text { 30 women undergoing } \\
\text { laparoscopic gynecologic } \\
\text { procedures in Trendelenburg } \\
\text { position with anesthesia using } \\
\text { thiopentone for induction and } \\
\text { propofol for maintenance (C) } \\
\text { 30 women undergoing } \\
\text { laparoscopic gynecologic } \\
\text { procedures in Trendelenburg } \\
\text { position with anesthesia using } \\
\text { thiopentone for induction and }\end{array}$ & $\begin{array}{l}\text { Measurement of } \\
\text { IOP at six } \\
\text { different time } \\
\text { points } \\
\text { (Schiotz) }\end{array}$ & $\begin{array}{l}\text { Differences in IOP levels } \\
\text { at each time point }\end{array}$ & $\begin{array}{l}\text { T1(A:) }-5.047 \\
\text { T1(B): }-2.533 \\
\text { T1(C): }-2.412 \\
\text { T1(D): }-2.027 \\
\text { T2(A): } 1.231 \\
\text { T2(B): } 1.131 \\
\text { T2(C): } 0.859 \\
\text { T2(D): } 1.559 \\
\text { T3(A): } 1.327 \\
\text { T3(B): } 1.523 \\
\text { T3(C): } 1.671 \\
\text { T3(D): } 2.419\end{array}$ \\
\hline
\end{tabular}




\begin{tabular}{|c|c|c|c|c|c|}
\hline $\begin{array}{l}\text { First Author } \\
\text { (Year) } \\
\text { Country }\end{array}$ & $\begin{array}{l}\text { Study Design } \\
{\text { (Quality })^{\mathrm{a}}}^{(\text {Qual }}\end{array}$ & $\begin{array}{l}\text { Participant Groups and } \\
\text { Observations/Interventions }\end{array}$ & $\begin{array}{l}\text { IOP Measures } \\
\text { (Tonometer) }\end{array}$ & Outcome Measures & $\begin{array}{l}\text { Effect Sizes } \\
(\text { Cohen's } d \text { ) }\end{array}$ \\
\hline \multirow{4}{*}{$\begin{array}{l}\text { Blecha } \\
\text { (2017) } \\
\text { Germany }\end{array}$} & \multirow{4}{*}{$\begin{array}{l}\text { Non- } \\
\text { experimental } \\
\text { (High) }\end{array}$} & $\begin{array}{l}1 \% \text { isoflurane for maintenance } \\
\text { (D) }\end{array}$ & \multirow{4}{*}{$\begin{array}{l}\text { Measurement of } \\
\text { IOP at six } \\
\text { different time } \\
\text { points } \\
\text { (Icare PRO) }\end{array}$} & \multirow{4}{*}{$\begin{array}{l}\text { Differences in IOP levels } \\
\text { at each time point }\end{array}$} & \multirow{4}{*}{ T5: -1.650} \\
\hline & & $\begin{array}{l}\text { Note. Patients with weight }>70 \\
\text { kg excluded. }\end{array}$ & & & \\
\hline & & $\begin{array}{l}\text { - } 51 \text { men undergoing robotic- } \\
\text { assisted laparoscopic } \\
\text { prostatectomy in Trendelenburg } \\
\text { position }\end{array}$ & & & \\
\hline & & $\begin{array}{l}\text { Note. } \text { Patients }>80 \text { years, ASA } \\
\text { Class }>\text { III, or BMI }>40 \mathrm{~kg} / \mathrm{m}^{2} \\
\text { excluded. }\end{array}$ & & & \\
\hline $\begin{array}{l}\text { Borahay } \\
\text { (2013) } \\
\text { United States }\end{array}$ & $\begin{array}{l}\text { Non- } \\
\text { experimental } \\
\text { (Good) }\end{array}$ & $\begin{array}{l}\text { - } 10 \text { women undergoing elective } \\
\text { robotic-assisted or } \\
\text { laparoscopic-assisted } \\
\text { hysterectomy procedures in } \\
\text { Trendelenburg position }\end{array}$ & $\begin{array}{l}\text { Measurement of } \\
\text { IOP at five } \\
\text { different time } \\
\text { points } \\
\text { (Tono-Pen XL) }\end{array}$ & $\begin{array}{l}\text { Differences in IOP levels } \\
\text { at each time point }\end{array}$ & T6: 0.132 \\
\hline \multirow[t]{2}{*}{$\begin{array}{l}\text { Grosso } \\
\text { (2013) } \\
\text { Italy }\end{array}$} & \multirow[t]{2}{*}{$\begin{array}{l}\text { Non- } \\
\text { experimental } \\
\text { (Good) }\end{array}$} & $\begin{array}{l}\text { - } 17 \text { patients undergoing } \\
\text { colorectal laparoscopic surgery } \\
\text { in Trendelenburg position } \\
\text { - } 12 \text { patients undergoing } \\
\text { colorectal laparoscopic surgery } \\
\text { in supine position }\end{array}$ & \multirow[t]{2}{*}{$\begin{array}{l}\text { Measurement of } \\
\text { IOP at eight } \\
\text { different time } \\
\text { points } \\
\text { (Icare PRO) }\end{array}$} & \multirow[t]{2}{*}{$\begin{array}{l}\text { Differences in IOP levels } \\
\text { at each time point }\end{array}$} & \multirow[t]{2}{*}{$\begin{array}{l}\text { T2: } 0.975 \\
\text { T3: } 0.204 \\
\text { T4: } 0.010\end{array}$} \\
\hline & & $\begin{array}{l}\text { Note. } \text { Patients }>45 \text { years, ASA } \\
\text { Class > III, or BMI }>35 \mathrm{~kg} / \mathrm{m}^{2} \\
\text { excluded. }\end{array}$ & & & \\
\hline $\begin{array}{l}\text { Hirooka } \\
\text { (2018) } \\
\text { Japan }\end{array}$ & $\begin{array}{l}\text { Non- } \\
\text { experimental } \\
\text { (Good) }\end{array}$ & $\begin{array}{l}\text { - } 40 \text { men undergoing robotic- } \\
\text { assisted laparoscopic radical } \\
\text { prostatectomy in Trendelenburg } \\
\text { position }\end{array}$ & $\begin{array}{l}\text { Measurement of } \\
\text { IOP at six } \\
\text { different time } \\
\text { points } \\
\text { (Tono-Pen XL) }\end{array}$ & $\begin{array}{l}\text { Differences in IOP levels } \\
\text { at each time point }\end{array}$ & $\begin{array}{l}\text { T4: } 0.964 \\
\text { T6: } 0.091 \\
\text { T8: } 0.539\end{array}$ \\
\hline $\begin{array}{l}\text { Kaur } \\
(2018)\end{array}$ & $\begin{array}{l}\text { Non- } \\
\text { experimental }\end{array}$ & $\begin{array}{l}\text { - } 30 \text { patients undergoing lower } \\
\text { abdominal laparoscopic surgery }\end{array}$ & $\begin{array}{l}\text { Measurement of } \\
\text { IOP at seven }\end{array}$ & $\begin{array}{l}\text { Differences in IOP levels } \\
\text { at each time point }\end{array}$ & $\begin{array}{l}\text { T1(P): }-4.087 \\
\text { T1(S): }-4.134\end{array}$ \\
\hline
\end{tabular}




\begin{tabular}{|c|c|c|c|c|c|}
\hline $\begin{array}{l}\text { First Author } \\
\text { (Year) } \\
\text { Country }\end{array}$ & $\begin{array}{l}\text { Study Design } \\
(\text { Quality })^{\mathrm{a}}\end{array}$ & $\begin{array}{l}\text { Participant Groups and } \\
\text { Observations/Interventions }\end{array}$ & $\begin{array}{l}\text { IOP Measures } \\
\text { (Tonometer) }\end{array}$ & Outcome Measures & $\begin{array}{l}\text { Effect Sizes } \\
\text { (Cohen's } d \text { ) }\end{array}$ \\
\hline India & (High) & $\begin{array}{l}\text { in Trendelenburg position with } \\
\text { anesthesia using intravenous } \\
\text { propofol (P) } \\
\text { 30 patients undergoing lower } \\
\text { abdominal laparoscopic surgery } \\
\text { in Trendelenburg position with } \\
\text { anesthesia using inhaled } \\
\text { sevoflurane (S) } \\
\text { Note. Patients with extreme } \\
\text { obesity excluded. }\end{array}$ & $\begin{array}{l}\text { different time } \\
\text { points } \\
\text { (Schiotz) }\end{array}$ & & $\begin{array}{l}\text { T2(P): } 2.275 \\
\text { T2(S): } 4.508\end{array}$ \\
\hline $\begin{array}{l}\text { Kitamura } \\
\text { (2018) } \\
\text { Japan }\end{array}$ & $\begin{array}{l}\text { Experimental } \\
\text { (High) }\end{array}$ & $\begin{array}{l}\text { - } 20 \text { patients undergoing robotic- } \\
\text { assisted laparoscopic radical } \\
\text { prostatectomy in Trendelenburg } \\
\text { position and receiving a } \\
\text { placebo (saline) } \\
20 \text { patients undergoing robotic- } \\
\text { assisted laparoscopic radical } \\
\text { prostatectomy in Trendelenburg } \\
\text { position and receiving } \\
\text { dexmedetomidine } \\
\text { Note. } \text { Patients with BMI }>35 \\
\mathrm{~kg} / \mathrm{m}^{2} \text { excluded. }\end{array}$ & $\begin{array}{l}\text { Measurement of } \\
\text { IOP at eight } \\
\text { different time } \\
\text { points } \\
\text { (Icare PRO) }\end{array}$ & $\begin{array}{l}\text { Differences in IOP levels } \\
\text { at each time point }\end{array}$ & $\begin{array}{l}\text { T1: }-1.466 \\
\text { T6: } 0.165 \\
\text { T8: } 0.611\end{array}$ \\
\hline $\begin{array}{l}\text { Mathew } \\
(2018) \\
\text { Canada }\end{array}$ & $\begin{array}{l}\text { Experimental } \\
\text { (High) }\end{array}$ & $\begin{array}{l}15 \text { men undergoing robotic- } \\
\text { assisted laparoscopic radical } \\
\text { prostatectomy in Trendelenburg } \\
\text { position and receiving a } \\
\text { placebo (artificial tears) } \\
11 \text { men undergoing robotic- } \\
\text { assisted laparoscopic radical } \\
\text { prostatectomy in Trendelenburg } \\
\text { position and receiving } \\
\text { brimonidine tartrate } 0.2 \% \text { b }\end{array}$ & $\begin{array}{l}\text { Measurements of } \\
\text { IOP at six } \\
\text { different time } \\
\text { points } \\
\text { (Tono-Pen AVIA) }\end{array}$ & $\begin{array}{l}\text { Differences in IOP levels } \\
\text { at each time point }\end{array}$ & $\begin{array}{l}\text { T1: }-1.654 \\
\text { T6: } 0.068 \\
\text { T8: } 0.282\end{array}$ \\
\hline $\begin{array}{l}\text { Molloy } \\
\text { (2011) }\end{array}$ & $\begin{array}{l}\text { Non- } \\
\text { experimental }\end{array}$ & $\begin{array}{l}\text { - } 37 \text { patients undergoing } \\
\text { laparoscopic surgery in }\end{array}$ & $\begin{array}{l}\text { Measurements of } \\
\text { IOP at six }\end{array}$ & $\begin{array}{l}\text { Differences in IOP levels } \\
\text { at each time point }\end{array}$ & $\begin{array}{l}\text { T5: }-1.589 \\
\text { T6: } 0.029\end{array}$ \\
\hline
\end{tabular}




\begin{tabular}{|c|c|c|c|c|c|}
\hline $\begin{array}{l}\text { First Author } \\
\text { (Year) } \\
\text { Country }\end{array}$ & $\begin{array}{l}\text { Study Design } \\
(\text { Quality })^{\mathrm{a}}\end{array}$ & $\begin{array}{l}\text { Participant Groups and } \\
\text { Observations/Interventions }\end{array}$ & $\begin{array}{l}\text { IOP Measures } \\
\text { (Tonometer) }\end{array}$ & Outcome Measures & $\begin{array}{l}\text { Effect Sizes } \\
(\text { Cohen's } d \text { ) }\end{array}$ \\
\hline United States & (High) & Trendelenburg position & $\begin{array}{l}\text { different time } \\
\text { points } \\
\text { (Tono-Pen } \mathrm{XL} \text { ) }\end{array}$ & & T7: -1.638 \\
\hline $\begin{array}{l}\text { Molloy } \\
(2012) \\
\text { United States }\end{array}$ & $\begin{array}{l}\text { Quasi- } \\
\text { experimental } \\
\text { (High) }\end{array}$ & $\begin{array}{l}\text { - } 37 \text { patients undergoing } \\
\text { laparoscopic surgery in } \\
\text { Trendelenburg position } \\
\text { - } 29 \text { patients undergoing } \\
\text { laparoscopic surgery in } \\
\text { Trendelenburg position and } \\
\text { receiving a level supine } \\
\text { intervention }\end{array}$ & $\begin{array}{l}\text { Measurement of } \\
\text { IOP at six } \\
\text { different time } \\
\text { points } \\
\text { (Tono-Pen XL) }\end{array}$ & $\begin{array}{l}\text { Differences in IOP levels } \\
\text { at each time point }\end{array}$ & $\begin{array}{l}\text { T5: }-1.497 \\
\text { T6: } 0.330 \\
\text { T7: }-1.855\end{array}$ \\
\hline $\begin{array}{l}\text { Molloy } \\
(2014) \\
\text { United States }\end{array}$ & $\begin{array}{l}\text { Quasi- } \\
\text { experimental } \\
\text { (High) }\end{array}$ & $\begin{array}{l}\text { - } 131 \text { patients undergoing } \\
\text { robotic-assisted laparoscopic } \\
\text { radical prostatectomy or pelvic } \\
\text { gynecologic procedures in } \\
\text { Trendelenburg position } \\
\text { - } 63 \text { patients undergoing robotic- } \\
\text { assisted laparoscopic } \\
\text { prostatectomy or pelvic } \\
\text { gynecologic procedures in } \\
\text { Trendelenburg position } \\
\text { receiving dorzolamide-timolol } \\
\text { when IOP exceeds } 40 \mathrm{mmHg}^{\mathrm{b}}\end{array}$ & $\begin{array}{l}\text { Measurements of } \\
\text { IOP at eight } \\
\text { different time } \\
\text { points } \\
\text { (Tono-Pen XL) }\end{array}$ & $\begin{array}{l}\text { Differences in IOP levels } \\
\text { at each time point }\end{array}$ & $\begin{array}{l}\text { T5: }-0.793 \\
\text { T6: } 0.352 \\
\text { T7: }-1.082 \\
\text { T8: } 0.188 \\
\text { T9: }-1.165\end{array}$ \\
\hline $\begin{array}{l}\text { Molloy } \\
(2016) \\
\text { United States }\end{array}$ & $\begin{array}{l}\text { Experimental } \\
\text { (High) }\end{array}$ & $\begin{array}{l}\text { - } 44 \text { patients undergoing } \\
\text { laparoscopic procedures in } \\
\text { Trendelenburg position and } \\
\text { receiving an ophthalmic } \\
\text { placebo (balanced salt solution) } \\
\text { after induction of anesthesia } \\
\text { - } 63 \text { patients undergoing } \\
\text { laparoscopic procedures in } \\
\text { Trendelenburg position } \\
\text { receiving dorzolamide-timolol } \\
\text { after anesthesia induction and } \\
\text { when IOP exceeded } 40 \mathrm{mmHg}{ }^{b}\end{array}$ & $\begin{array}{l}\text { Measurements of } \\
\text { IOP at eight } \\
\text { different time } \\
\text { points } \\
\text { (Tono-Pen XL) }\end{array}$ & $\begin{array}{l}\text { Differences in IOP levels } \\
\text { at each time point }\end{array}$ & $\begin{array}{l}\text { T5: }-1.519 \\
\text { T6: } 0.497 \\
\text { T7: }-1.922 \\
\text { T8: } 0.536 \\
\text { T9: }-2.758\end{array}$ \\
\hline
\end{tabular}




\begin{tabular}{|c|c|c|c|c|c|}
\hline $\begin{array}{l}\text { First Author } \\
\text { (Year) } \\
\text { Country }\end{array}$ & $\begin{array}{l}\text { Study Design } \\
(\text { Quality })^{\mathrm{a}}\end{array}$ & $\begin{array}{l}\text { Participant Groups and } \\
\text { Observations/Interventions }\end{array}$ & $\begin{array}{l}\text { IOP Measures } \\
\text { (Tonometer) }\end{array}$ & Outcome Measures & $\begin{array}{l}\text { Effect Sizes } \\
\text { (Cohen's } d \text { ) }\end{array}$ \\
\hline $\begin{array}{l}\text { Mondelewski } \\
(2015) \\
\text { United States }\end{array}$ & $\begin{array}{l}\text { Non- } \\
\text { experimental } \\
\text { (Good) }\end{array}$ & $\begin{array}{l}\text { - } 18 \text { patients undergoing robotic- } \\
\text { assisted laparoscopic } \\
\text { procedures in Trendelenburg } \\
\text { position } \\
\text { - } 9 \text { patients undergoing } \\
\text { laparoscopic procedures in } \\
\text { supine position } \\
\text { - } 12 \text { patients undergoing open } \\
\text { procedures in supine position }\end{array}$ & $\begin{array}{l}\text { Measurements of } \\
\text { IOP at } 11 \\
\text { different time } \\
\text { points } \\
\text { (Tono-Pen AVIA) }\end{array}$ & $\begin{array}{l}\text { Differences in IOP levels } \\
\text { at each time point }\end{array}$ & \\
\hline $\begin{array}{l}\text { Nishikawa } \\
(2017) \\
\text { Japan }\end{array}$ & $\begin{array}{l}\text { Non- } \\
\text { experimental } \\
\text { (Good) }\end{array}$ & $\begin{array}{l}15 \text { men undergoing robotic- } \\
\text { assisted laparoscopic radical } \\
\text { prostatectomy in a } 25^{\circ} \\
\text { Trendelenburg position }(25) \\
\text { - } 15 \text { men undergoing robotic- } \\
\text { assisted laparoscopic radical } \\
\text { prostatectomy in a } 30^{\circ} \\
\text { Trendelenburg position }(30)\end{array}$ & $\begin{array}{l}\text { Measurement of } \\
\text { IOP at six } \\
\text { different time } \\
\text { points } \\
\text { (Tono-Pen XL) }\end{array}$ & $\begin{array}{l}\text { Differences in IOP levels } \\
\text { at each time point }\end{array}$ & $\begin{array}{l}\text { T1(25): }-1.934 \\
\text { T1(30): }-1.076 \\
\text { T5(25): }-2.103 \\
\text { T5(30): }-2.584 \\
\text { T6(25): } 0.555 \\
\text { T6(30): } 0.895 \\
\text { T7(25): }-2.887 \\
\text { T7(30): }-3.744\end{array}$ \\
\hline $\begin{array}{l}\text { Raz } \\
(2015) \\
\text { Australia }\end{array}$ & $\begin{array}{l}\text { Experimental } \\
\text { (Good) }\end{array}$ & $\begin{array}{l}\text { - } 21 \text { men undergoing robotic- } \\
\text { assisted laparoscopic radical } \\
\text { prostatectomy in Trendelenburg } \\
\text { position } \\
\text { - } 29 \text { men undergoing robotic- } \\
\text { assisted laparoscopic radical } \\
\text { prostatectomy in a modified-Z } \\
\text { Trendelenburg position }{ }^{\mathrm{b}}\end{array}$ & $\begin{array}{l}\text { Measurement of } \\
\text { IOP at } 18 \\
\text { different time } \\
\text { points } \\
\text { (Tono-Pen AVIA) }\end{array}$ & $\begin{array}{l}\text { Differences in IOP levels } \\
\text { at each time point }\end{array}$ & $\begin{array}{l}\text { T4: } 1.238 \\
\text { T5: }-1.093 \\
\text { T6: } 0.135 \\
\text { T7: }-1.593\end{array}$ \\
\hline $\begin{array}{l}\text { Taketani } \\
(2015) \\
\text { Japan }\end{array}$ & $\begin{array}{l}\text { Non- } \\
\text { experimental } \\
\text { (Good) }\end{array}$ & $\begin{array}{l}\text { - } 25 \text { men undergoing robotic- } \\
\text { assisted laparoscopic radical } \\
\text { prostatectomy in Trendelenburg } \\
\text { position. }\end{array}$ & $\begin{array}{l}\text { Measurement of } \\
\text { IOP at eight } \\
\text { different time } \\
\text { points } \\
\text { (Tono-Pen XL) }\end{array}$ & $\begin{array}{l}\text { Differences in IOP levels } \\
\text { at each time point }\end{array}$ & $\begin{array}{l}\text { T6: } 0.386 \\
\text { T8: } 0.161\end{array}$ \\
\hline $\begin{array}{l}\text { Yoo } \\
(2015) \\
\text { Korea }\end{array}$ & $\begin{array}{l}\text { Non- } \\
\text { experimental } \\
\text { (High) }\end{array}$ & $\begin{array}{l}\text { - } 32 \text { patients undergoing robotic- } \\
\text { assisted laparoscopic radical } \\
\text { prostatectomy in the }\end{array}$ & $\begin{array}{l}\text { Measurement of } \\
\text { IOP at eight } \\
\text { different }\end{array}$ & $\begin{array}{l}\text { Differences in IOP levels } \\
\text { at each time point }\end{array}$ & $\begin{array}{l}\text { T1(M): }-2.952 \\
\text { T1(D): }-3.954 \\
\text { T2(M): } 3.262\end{array}$ \\
\hline
\end{tabular}




\begin{tabular}{|c|c|c|c|c|c|}
\hline $\begin{array}{l}\text { First Author } \\
\text { (Year) } \\
\text { Country }\end{array}$ & 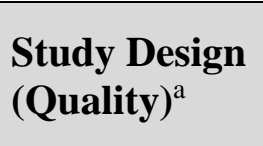 & $\begin{array}{l}\text { Participant Groups and } \\
\text { Observations/Interventions }\end{array}$ & $\begin{array}{l}\text { IOP Measures } \\
\text { (Tonometer) }\end{array}$ & Outcome Measures & $\begin{array}{l}\text { Effect Sizes } \\
(\text { Cohen's } d \text { ) }\end{array}$ \\
\hline & & $\begin{array}{l}\text { Trendelenburg position with } \\
\text { anesthesia using moderate } \\
\text { neuromuscular blockade (M) } \\
34 \text { patients undergoing robotic- } \\
\text { assisted laparoscopic radical } \\
\text { prostatectomy in the } \\
\text { Trendelenburg position with } \\
\text { anesthesia using deep } \\
\text { neuromuscular blockade (D) }\end{array}$ & \multirow[t]{2}{*}{$\begin{array}{l}\text { timepoints } \\
\text { (Tono-Pen XL) }\end{array}$} & & \multirow[t]{2}{*}{ T2(D): 3.389} \\
\hline & & $\begin{array}{l}\text { Note. Patients with } \mathrm{BMI}>30 \\
\mathrm{~kg} / \mathrm{m}^{2} \text { excluded. }\end{array}$ & & & \\
\hline
\end{tabular}

Note. $s=$ studies; IOP $=$ Intraocular pressure; BMI = body mass index; $\mathrm{kg} / \mathrm{m}^{2}=$ kilograms $/$ meter-squared; $\mathrm{kg}=$ kilograms; ASA = American Society of Anesthesiologists Physical Classification Status; $\mathrm{mmHg}=$ millimeters of mercury.

${ }^{\text {a } Q u a l i t y ~ r a t i n g s ~ a r e ~ b a s e d ~ o n ~ c u m u l a t i v e ~ s c o r e s ~ o b t a i n e d ~ f r o m ~ t h e ~ A s s o c i a t i o n ~ o f ~ p e r i O p e r a t i v e ~ R e g i s t e r e d ~ N u r s e s ~(A O R N) ~ R e s e a r c h ~ E v i d e n c e ~}$ Appraisal Tool - Study.

${ }^{\mathrm{b}}$ This group was not eligible for inclusion in the meta-analysis. 
Table 3.2

Study and Participant Characteristics $(s=18 ; N=762)$

\begin{tabular}{|c|c|c|}
\hline Category & $\begin{array}{l}\text { Number of Participants } \\
\text { (Number of Studies) }\end{array}$ & $\begin{array}{l}\text { Mean } \pm S D \\
\text { (Range) or Percent }\end{array}$ \\
\hline Age (years) & $612(16)$ & $\begin{array}{l}55.2 \pm 11.9 \\
(30.5-66.9)\end{array}$ \\
\hline $\begin{array}{l}\text { Gender } \\
\text { Women } \\
\text { Men }\end{array}$ & $\begin{array}{c}624(16) \\
209 \\
415\end{array}$ & $\begin{array}{l}33.0 \\
67.0\end{array}$ \\
\hline BMI $\left(\mathrm{kg} / \mathrm{m}^{2}\right)$ & $287(12)$ & $\begin{array}{l}27.5 \pm 2.3 \\
(23.6-30.7)\end{array}$ \\
\hline $\begin{array}{l}\text { ASA } \\
\text { Class I } \\
\text { Class II } \\
\text { Class III }\end{array}$ & $\begin{array}{c}308(8) \\
107 \\
180 \\
21\end{array}$ & $\begin{array}{l}34.7 \\
58.4 \\
6.9\end{array}$ \\
\hline $\begin{array}{l}\text { ASA } \\
\text { Class I or II }\end{array}$ & $145(2)$ & 100 \\
\hline $\begin{array}{l}\text { Comorbidities } \\
\text { Asthma } \\
\text { Diabetes } \\
\text { Hypertension }\end{array}$ & $\begin{array}{l}300(7) \\
76(2) \\
107(3) \\
117(4)\end{array}$ & $\begin{array}{l}2.6 \\
7.5 \\
37.6\end{array}$ \\
\hline $\begin{array}{l}\text { Surgery type } \\
\text { Laparoscopic } \\
\text { Colorectal } \\
\text { Gynecologic } \\
\text { Prostatectomy } \\
\text { Unspecified } \\
\text { Laparoscopic/Robotic } \\
\text { Unspecified } \\
\text { Robotic } \\
\text { Hysterectomy } \\
\text { Pelvic node } \\
\text { Prostatectomy } \\
\text { Vaginal repair }\end{array}$ & $\begin{array}{c}762(18) \\
292 \\
47 \\
151 \\
14 \\
80 \\
44 \\
44 \\
426 \\
8 \\
1 \\
335 \\
82\end{array}$ & $\begin{array}{c}38.3 \\
6.2 \\
19.8 \\
1.8 \\
10.8 \\
5.8 \\
5.8 \\
55.9 \\
1.0 \\
0.1 \\
44.0 \\
10.8\end{array}$ \\
\hline $\begin{array}{l}\text { Anesthesia } \\
\text { General-Inhalation } \\
\text { General-Propofol } \\
\text { General-Unspecified }\end{array}$ & $\begin{array}{c}762(18) \\
298 \\
242 \\
222\end{array}$ & $\begin{array}{l}39.1 \\
31.8 \\
29.1\end{array}$ \\
\hline Intra-abdominal pressure $(\mathrm{mmHg})$ & $536(12)$ & $\begin{array}{l}13.6 \pm 1.3 \\
(12-15)\end{array}$ \\
\hline Trendelenburg degree & $762(18)$ & $\begin{array}{l}28.4 \pm 6.5 \\
(17.5-45)\end{array}$ \\
\hline $\begin{array}{l}\text { Duration }(\mathrm{min}) \\
\text { Anesthesia }\end{array}$ & $66(1)$ & $\begin{array}{l}158.0 \pm 2.8 \\
(156-160)\end{array}$ \\
\hline Pneumoperitoneum & $126(2)$ & $\begin{array}{l}94.5 \pm 15.1 \\
(80-109.4)\end{array}$ \\
\hline Trendelenburg & $159(3)$ & $\begin{array}{l}104.8 \pm 58.2 \\
(68-207)\end{array}$ \\
\hline Surgery & $484(10)$ & $\begin{array}{l}197.9 \pm 64.4 \\
(111-318)\end{array}$ \\
\hline Estimated blood loss (mL) & $444(11)$ & $\begin{array}{l}252.4 \pm 113.3 \\
(69.4-467)\end{array}$ \\
\hline
\end{tabular}

Note. $s=$ studies; $S D=$ standard deviation; BMI = body mass index; $\mathrm{kg} / \mathrm{m}^{2}=$ kilograms $/ \mathrm{meter}$-squared; ASA = American Society of Anesthesiologists Physical Classification Status; $\mathrm{mmHg}=$ millimeters of mercury; min = minutes; $\mathrm{mL}=$ milliliters. 
Table 3.3

Effect Sizes and Magnitude of Change in IOP for T1 through T9 (Sidebar; $s=18 ; N=762$ ).

\begin{tabular}{|c|c|c|c|c|c|c|c|c|c|c|c|}
\hline \multirow{2}{*}{$\begin{array}{l}\text { Time } \\
\text { Points }\end{array}$} & \multirow{2}{*}{$s$} & \multirow{2}{*}{$\boldsymbol{k}$} & \multirow{2}{*}{$n$} & \multirow{2}{*}{ Model } & \multirow{2}{*}{$d$} & \multicolumn{2}{|c|}{$95 \% \mathrm{CI}$} & \multirow{2}{*}{$\mathbf{Q}$} & \multirow{2}{*}{$I^{2}$} & \multirow{2}{*}{ Mean change in $\mathrm{IOP}^{\mathrm{a}}$} & \multirow{2}{*}{ Prediction Interval $^{b}$} \\
\hline & & & & & & $L L$ & $U L$ & & & & \\
\hline $\mathrm{T} 1$ & 7 & 13 & 331 & $\mathrm{R}$ & $-2.45^{*}$ & -1.70 & -0.30 & $109.82 *$ & 89.07 & $-5.2 \mathrm{mmHg}$ & $-0.9 \mathrm{mmHg}$ to $-9.6 \mathrm{mmHg}$ \\
\hline $\mathrm{T} 3$ & 3 & 6 & 157 & $\mathrm{R}$ & $1.34 *$ & 0.78 & 1.90 & $24.90^{*}$ & 79.92 & +4.4 mmHg from $\mathrm{T} 2$ & $+0.4 \mathrm{mmHg}$ to $+8.5 \mathrm{mmHg}$ \\
\hline $\mathrm{T} 4$ & 3 & 3 & 78 & $\mathrm{~F}$ & $0.91 *$ & 0.57 & 1.25 & $12.96 * *$ & 84.57 & +2.6 mmHg from $\mathrm{T} 3$ & $-1.5 \mathrm{mmHg}$ to $+6.6 \mathrm{mmHg}$ \\
\hline T5 & 7 & 8 & 351 & $\mathrm{R}$ & $-1.54 *$ & -1.93 & -1.16 & $30.71 *$ & 77.20 & $-7.5 \mathrm{mmHg}$ from $\mathrm{T} 4$ & $-3.1 \mathrm{mmHg}$ to $-12.0 \mathrm{mmHg}$ \\
\hline T6 & 11 & 12 & 410 & $\mathrm{R}$ & $0.30 *$ & 0.16 & 0.44 & 7.06 & 0.00 & +1.5 mmHg from $\mathrm{T} 4$ & $+0.9 \mathrm{mmHg}$ to $+2.3 \mathrm{mmHg}$ \\
\hline $\mathrm{T} 7$ & 6 & 7 & 300 & $\mathrm{R}$ & $-1.94 *$ & -2.47 & -1.41 & $33.52 *$ & 82.10 & $-8.2 \mathrm{mmHg}$ from $\mathrm{T} 6$ & $-3.1 \mathrm{mmHg}$ to $-13.3 \mathrm{mmHg}$ \\
\hline $\mathrm{T} 8$ & 6 & 6 & 275 & $\mathrm{R}$ & $0.38 *$ & 0.12 & 0.65 & 1.90 & 0.00 & $+1.6 \mathrm{mmHg}$ from $\mathrm{T} 6$ & $+0.5 \mathrm{mmHg}$ to $+3.1 \mathrm{mmHg}$ \\
\hline
\end{tabular}

Note. $s=$ studies; $k=$ comparisons; $d=$ standardized mean difference; CI = confidence interval; $L L$ lower limit; $U L=$ upper limit; $\mathrm{Q}=\mathrm{Cochrane}$ 's Q; $I^{2}$ $=$ heterogeneity statistic; $\mathrm{IOP}=$ intraocular pressure; $\mathrm{T}=$ time point $; \mathrm{R}=$ Random effects; $\mathrm{mmHg}=$ millimeters of mercury; $\mathrm{F}=$ Fixed effect.

${ }^{a}$ Mean effect sizes were converted to the metric used to measure IOP (i.e., mmHg) following the procedures described by Lipsey and Wilson (2001). Lipsey, M. W., \& Wilson, D. B. (2001). Interpreting and using meta-analysis results. In Practical meta-analysis: Applied social research (Vol 49, pp. 146-168). Thousand Oaks, CA: Sage.

$* p<0.001$. ** $p<0.005$.

b In $95 \%$ of all populations, the true effect size will fall within this range. 


\section{Sidebar}

\section{Time Points Analyzed for Changes in IOP.}

T1 - Before induction of anesthesia to

0 minutes to 5 minutes after induction of anesthesia

T2 - 0 minutes to 5 minutes after induction of anesthesia to 0 minutes to 5 minutes after abdominal insufflation

T3 - 0 minutes to 5 minutes after abdominal insufflation to 0 minutes to 5 minutes after Trendelenburg position

T4 - 0 minutes to 5 minutes after Trendelenburg position to 30 minutes to 60 minutes after Trendelenburg position

T5 - 30 minutes to 60 minutes after Trendelenburg position to before arousal from general anesthesia

T6 - 30 minutes to 60 minutes after Trendelenburg position to 120 minutes to 150 minutes after Trendelenburg position

T7 - 120 minutes to 150 minutes after Trendelenburg position to before arousal from general anesthesia

T8 - 120 minutes to 150 minutes after Trendelenburg position to 180 minutes to 240 minutes after Trendelenburg position

T9 - 180 minutes to 240 minutes after Trendelenburg position to before arousal from general anesthesia

Note. IOP $=$ intraocular pressure; $\mathrm{T}=$ time point. 


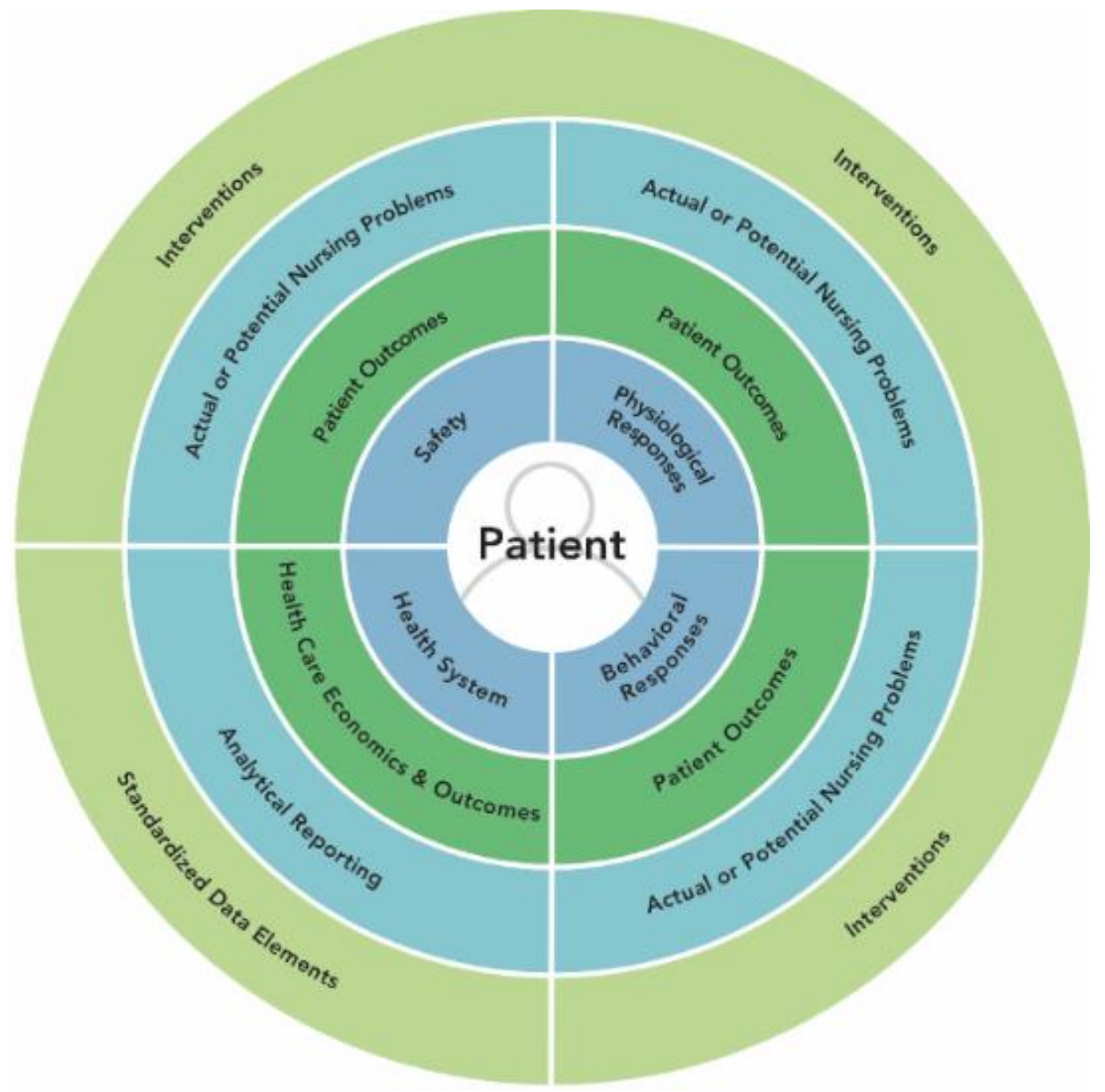

Figure 3.1. Perioperative Patient Focused Model (2017). Reprinted with permission from Guidelines for Perioperative Practice. Copyright (C) 2018, AORN, Inc, 2170 S. Parker Road, Suite 400, Denver, CO 80231. All rights reserved. 


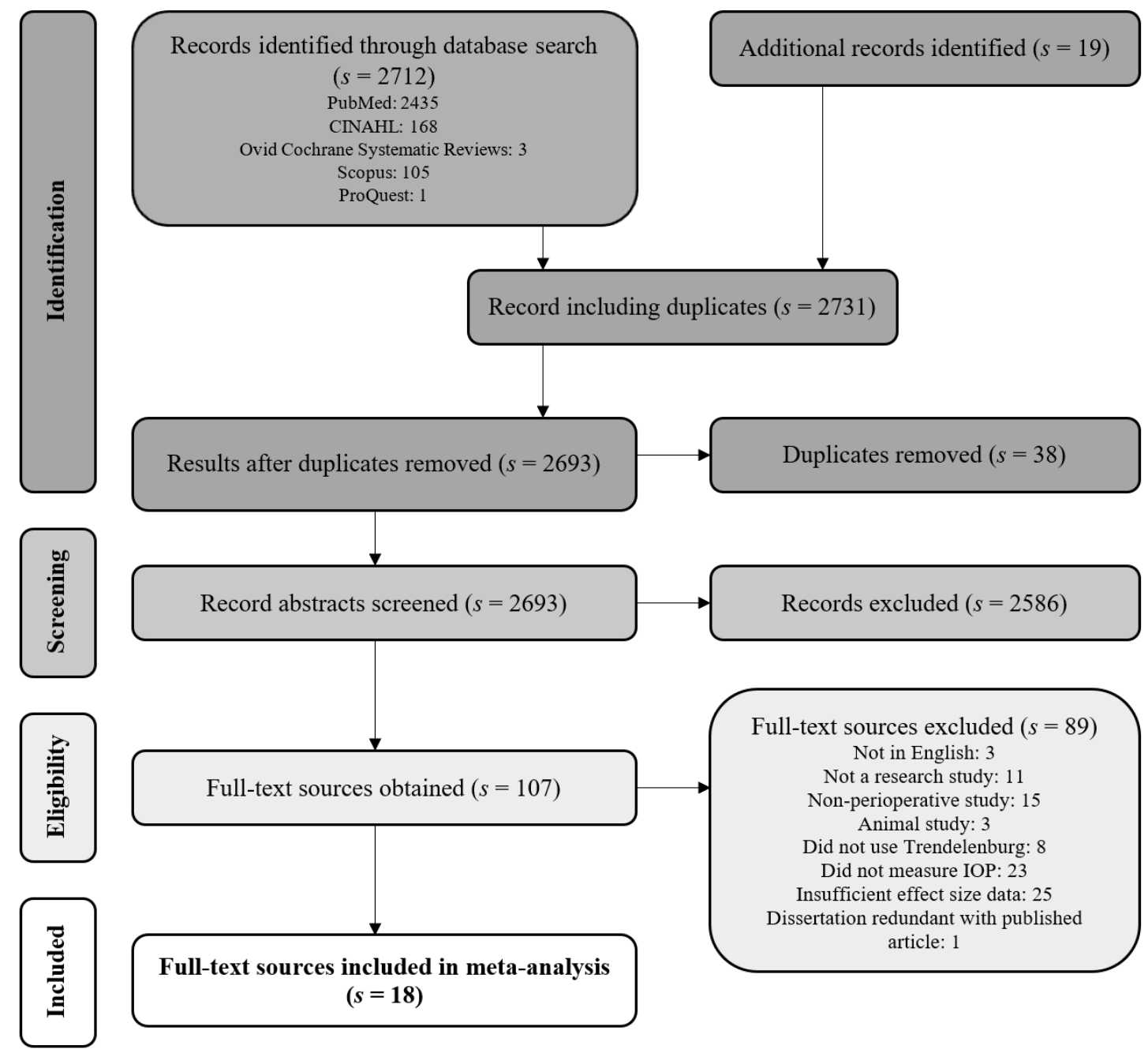

Figure 3.2. Flow diagram of meta-analysis study selection. Note. $s=$ studies. Adapted from Moher D, Liberati A, Tetzlaff J, Atman DG, PRISMA Group (2009). Preferred Reporting Items for Systematic Reviews and Meta-Analyses: The PRISMA Statement. PLoS Medicine, 6(6), e1000097. doi:10.1371/journal.pmed1000097 


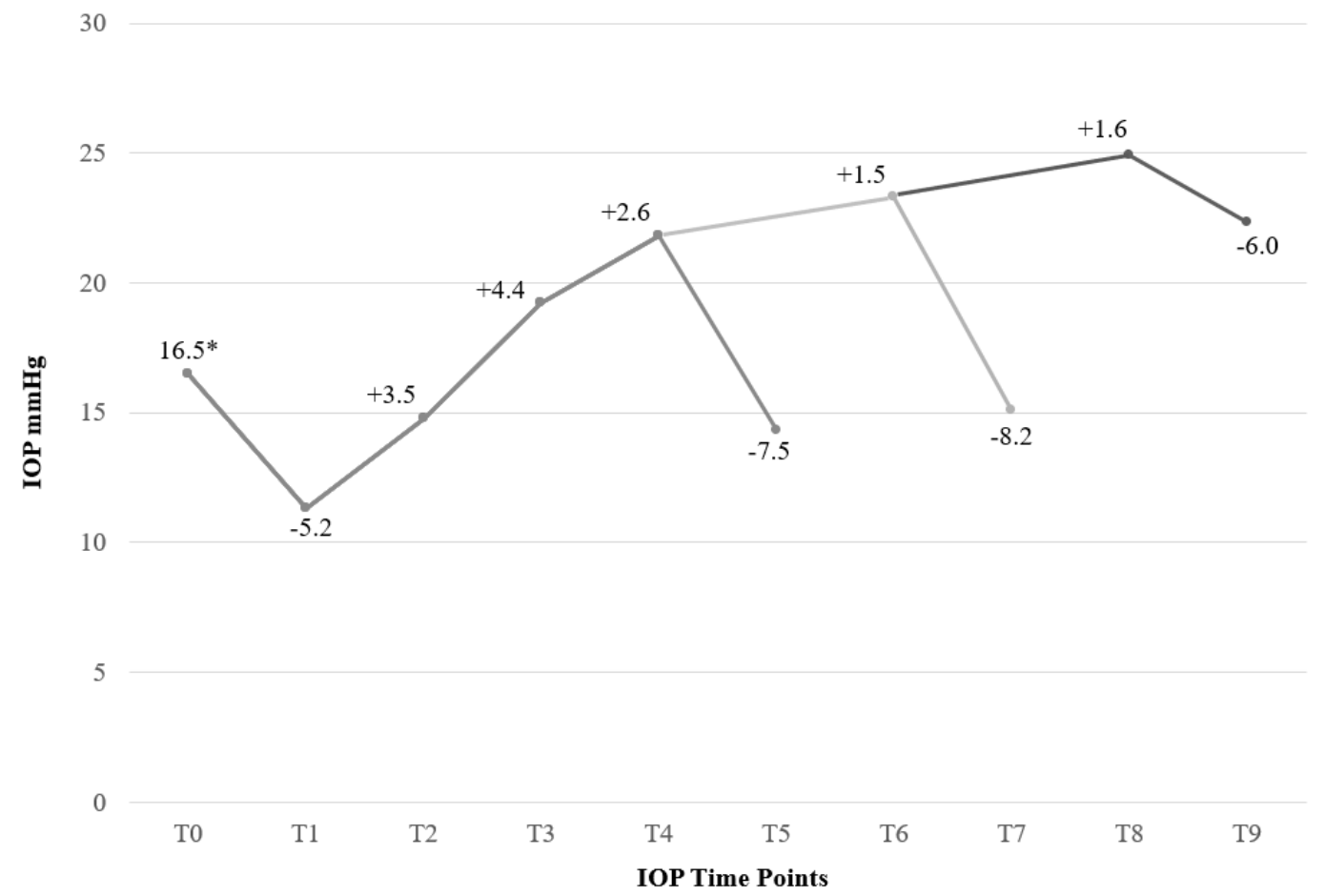

Figure 3.3. Magnitude of change in IOP for T0 through T9 (see Sidebar). Note. IOP = intraocular pressure $; \mathrm{mmHg}=$ millimeters of mercury; $\mathrm{T}=$ time point. IOP decreases significantly after induction of anesthesia $(\mathrm{T} 1:-5.2 \mathrm{mmHg}, p<0.001)$ and before arousal from anesthesia (T5: -7.5 mmHg, $p<0.001 ; \mathrm{T} 7:-8.2 \mathrm{mmHg}, p<0.001$; T9: $-6.0 \mathrm{mmHg}$, $p<0.001$ ) when the patient is in the supine position. IOP increases significantly after abdominal insufflation in the supine position (T2: $+3.5 \mathrm{mmHg}, p<0.001$ ), when the patient is placed in Trendelenburg position (T3: $+4.4 \mathrm{mmHg}, p<0.001)$, and with extended time in the Trendelenburg position (T4: $+2.6 \mathrm{mmHg}, p<0.001$; T6: +1.5 mmHg, $p<0.001$; T8: $+1.6 \mathrm{mmHg}, p<0.001)$. * Pooled mean at T0-Before induction of anesthesia. 


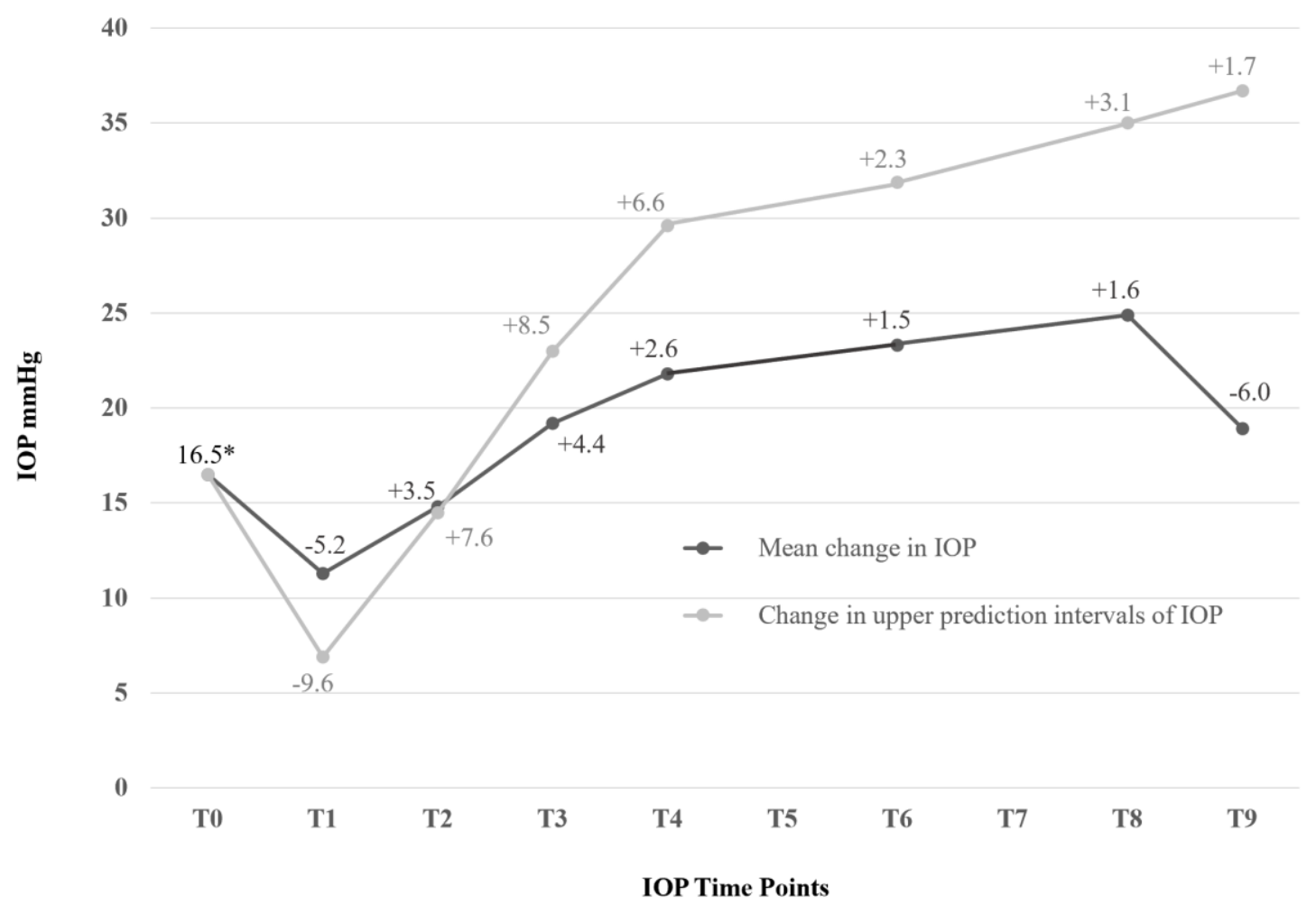

Figure 3.4. Magnitude of change in IOP and upper prediction intervals of IOP for T0 through T9 (see Sidebar). Note. $\mathrm{IOP}=$ intraocular pressure; $\mathrm{mmHg}=$ millimeters of mercury; $\mathrm{T}=$ time point. The upper prediction interval shows that after 180 minutes to 240 minutes in the Trendelenburg position, in $95 \%$ of all populations, IOP could increase to $35 \mathrm{mmHg}(16.5 \mathrm{mmHg}-9.6 \mathrm{mmHg}+7.6 \mathrm{mmHg}+8.5 \mathrm{mmHg}+6.6 \mathrm{mmHg}+2.3$ $\mathrm{mmHg}+3.1 \mathrm{mmHg}=35 \mathrm{mmHg})$. $*$ Pooled mean at $\mathrm{T} 0-$ Before induction of anesthesia. 


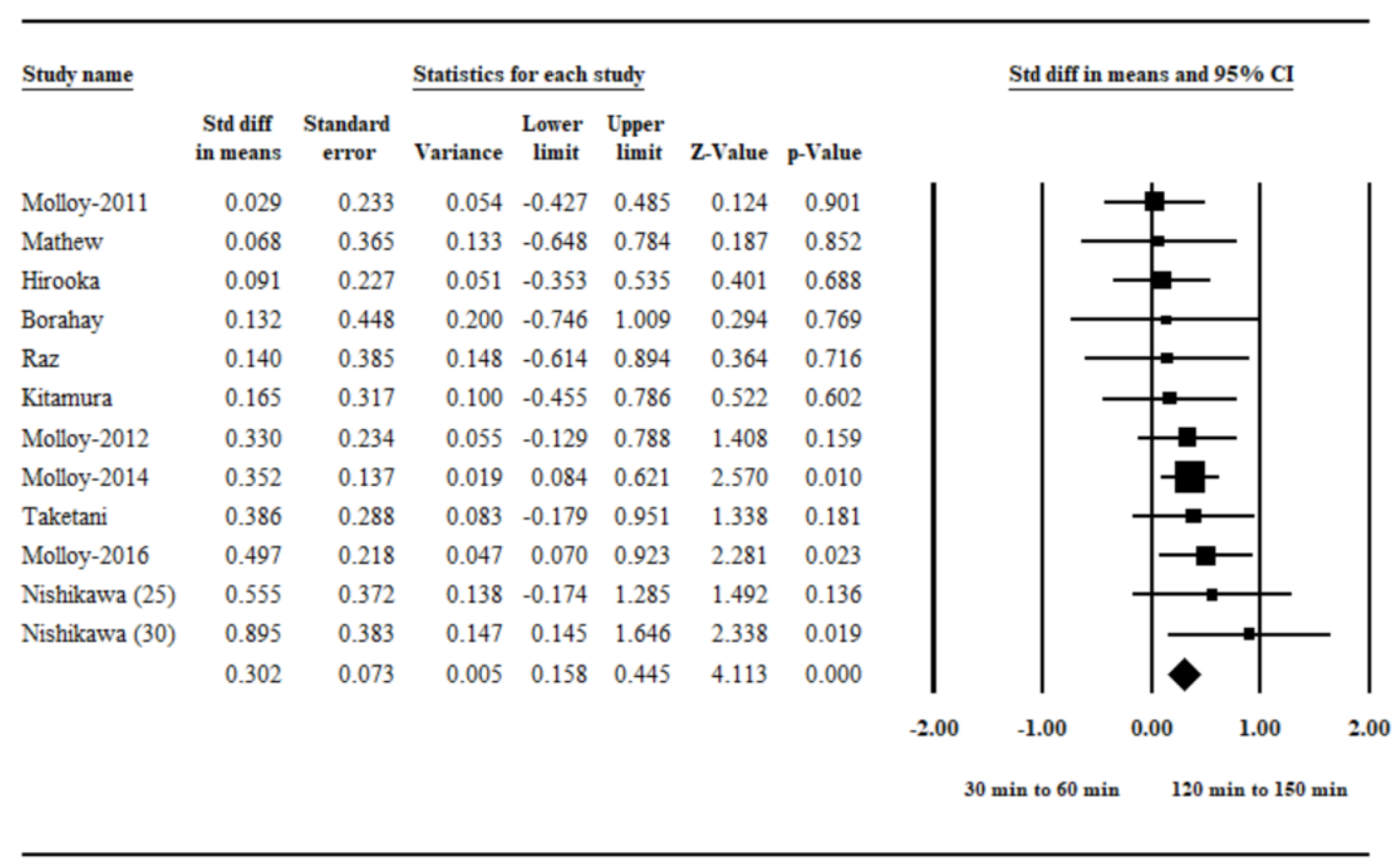

Figure 3.5. Forest plot of meta-analysis of T6. Note. $\mathrm{T}=$ time point; $\mathrm{Std}=$ Standard; $\min$ $=$ minutes. This analysis included 11 studies representing 12 participant groups $(n=410)$. Effect sizes were calculated using a random effects model. The area of each square is proportional to study weight. 


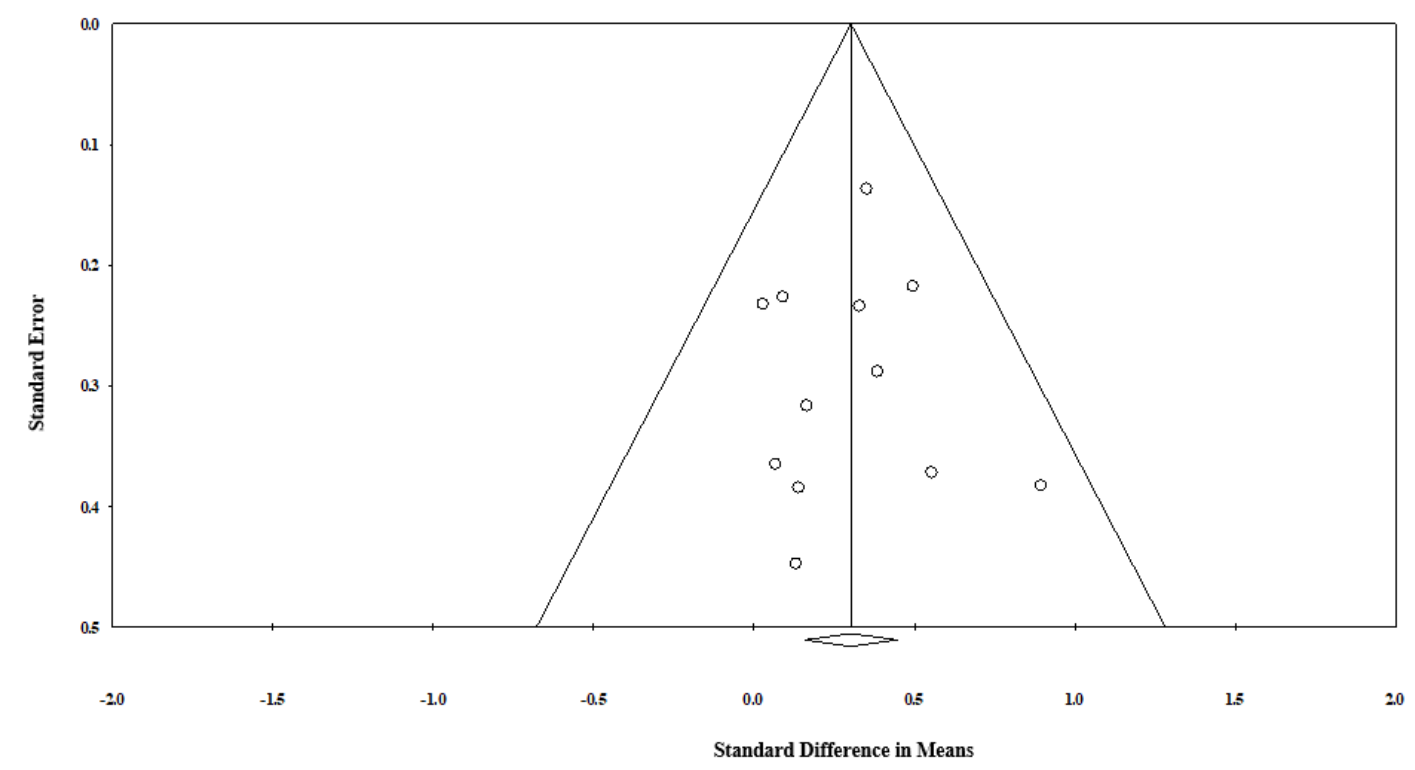

Figure 3.6. Funnel plot of publication bias for T6. Note. $\mathrm{T}=$ time point. Larger studies are shown at the top of the funnel. Positive smaller studies are shown at the right of the mean effect size (i.e., center line). The symmetrical distribution of studies (i.e., data points) around the mean effect size indicates a lack of publication bias. The nonsignificant Egger's regression intercept for this funnel plot (bias $=-0.05 ; p=0.47$ ) is also indicative of the absence of bias in the studies included in the meta-analysis for this time point. 
4. SYSTEMATIC REVIEW AND META-ANALYSIS OF PRONE POSITION ON INTRAOCULAR PRESSURE IN ADULT PATIENTS UNDERGOING SURGERY

Van Wicklin, S. A. (2019). Systematic review and meta-analysis of prone position on intraocular pressure in adult patients undergoing surgery. Manuscript in preparation.

\begin{abstract}
Background. Patients undergoing surgery in the prone position may be at risk for postoperative vision loss associated with increased intraocular pressure. The purpose of this systematic review and meta-analysis is to estimate the magnitude of the increase in intraocular pressure at specific perioperative time points in adult patients.
\end{abstract}

Methods. Comprehensive search strategies were used to identify nine eligible studies $(N$ =229). Standardized mean difference effect sizes were calculated for two intraoperative time points $(\mathrm{T})$.

Results. Meta-analysis showed that intraocular pressure increased significantly between induction of anesthesia and up to 10 minutes of prone position $(\mathrm{T} 1: d=2.5 ; p<0.001)$ and continued to increase significantly until the end of the prone position (T2: $d=3.4 ; p$ $=0.002)$.

Conclusions. Intraocular pressure increases of this magnitude demonstrate the need for implementing interventions to reduce the risk for postoperative vision loss in patients undergoing surgery in the prone position.

Keywords: intraocular pressure, prone position, Perioperative Patient Focused Model, ischemic optic neuropathy, central retinal artery occlusion. 
In the prone position, the patient is positioned face-down on their abdomen. This position provides surgical access to the dorsal aspects of the patient's body. There are ocular complications associated with the prone position. These complications include increased intraocular pressure (IOP; i.e., greater than normal amounts of "pressure exerted by the contents of the eye on its containing wall" [Kamel \& Barnette, 2014, p. 432]), chemosis (i.e., conjunctival edema), ocular or orbital hemorrhage, orbital compartment syndrome, and postoperative vision loss (Amorim Correa \& Acioly, 2018; Kwee, Ho, \& Rozen, 2015; Leibovitch, Casson, Laforest, \& Selva, 2006). Postoperative vision loss, which may be partial or complete and unilateral or bilateral, is a serious complication of surgery in the prone position, and it occurs with greater frequency after spine, head and neck, and some orthopedic procedures (Emery et al., 2015; Lee \& Newman, 2018). Following surgery in the prone position, there have been reports of postoperative vision loss (Abraham, Sakhuja, Sinha, \& Rastogi, 2003; Asok, Aziz, Faisal, Tan, \& Mallika, 2009; Bekar, Türeyen, \& Aksoy, 1996; Dilger et al., 1998; Goni et al., 2012; Grossman \& Ward, 1993; Hollenhorst, Svien \& Benoit, 1954; Hoski, Eismont, \& Green, 1993; Katz, Trobe, Cornblath, \& Kline, 1994; Locastro, Novak, \& Biglan, 1991; Manfredini, Ferrante, Gildone, \& Massari, 2000; Quraishi, Wolinsky, \& Gokaslan, 2012; Reddy, Foroozan, Edmond, \& Hinckley, 2008; Shifa, Abebe, Bekele, \& Habte, 2016; Stang-Veldhouse, Yeu, Rothenberg, \& Mizen, 2010; West, Askin, Clarke, \& Vernon, 1990; Wolfe, Lospinuso, \& Burke, 1992), as well as reports of subconjunctival hemorrhage (Akhaddar \& Boucetta, 2012), subperiosteal orbital hemorrhage (Russell \& Dutton, 2011), orbital compartment syndrome (Amorim Correa \& Acioly, 2018; 
Leibovitch et al., 2006), acute angle-closure glaucoma (Singer \& Salim, 2010; Stewart, Landy, \& Lee, 2016), and Horner syndrome (Guillaume \& Gowreesunker, 2013).

When the patient is in the prone position, IOP increases and the extent of this increase is related to the amount of time the patient is in the prone position (Agah, Ghasemi, Roodneshin, Radpay, \& Moradian, 2011; Eddama, 2013; Kamel \& Barnette, 2014; Kendrick, 2012; Pinkney et al., 2012; Szmuk et al., 2013; Yoshimura, Hayashi, Tanaka, Nomura, \& Kawaguchi, 2015). After only a few minutes in the prone position, IOP can increase significantly (Nuzzi \& Tridico, 2015). According to the American Academy of Ophthalmology (2018), normal IOP is 10 millimeters of mercury (mmHg) to $21 \mathrm{mmHg}$. Intraocular pressures higher than $21 \mathrm{mmHg}$ pose a risk for glaucoma, detached retina, and postoperative vision loss (Emery et al., 2015; Lee \& Newman, 2018; Weinreb \& Khaw, 2004).

\section{Pathogenesis of Postoperative Vision Loss}

Postoperative vision loss in patients undergoing surgery in the prone position is generally related to one of two causes: ischemic optic neuropathy or central retinal artery occlusion (Kamel \& Barnette, 2014; Stambough, Dolan, Werner, \& Godfrey, 2007).

\section{Ischemic Optic Neuropathy}

Ischemic optic neuropathy is the most common cause of postoperative vision loss (Kamel \& Barnette, 2014; Kan, Brown, \& Gainsburg, 2015; Newman, 2008; Stambough et al., 2007). According to the American Academy of Ophthalmology (Boyd, 2018), ischemic optic neuropathy is caused by insufficient blood flow to the optic nerve. Ischemic optic neuropathy may present as anterior (involving ischemia and infarction of the intraocular optic nerve) or posterior (involving ischemia and infarction of the 
intraorbital optic nerve; Kamel \& Barnette, 2014). Although the phenomenon of ischemic optic neuropathy is not well understood, it is known that elevated IOP can lead to optic nerve injury and decreased ocular perfusion pressure (Kamel \& Barnette, 2014; Kan et al., 2015; Newman, 2008). Perfusion pressure is the difference between pressures of the ciliary arteries in the optic nerve and the venous drainage of the eye (Hayreh, 2001). This difference is approximated by the level of IOP. The "higher the intraocular pressure, the lower the perfusion pressure, and consequently, the lower the blood flow in the optic nerve head" (Hayreh, 2001, p. 608). The lower the blood flow in the optic nerve head, the greater the risk for ischemic optic neuropathy and postoperative vision loss. The ischemic process can occur as a direct result of decreased blood supply from the arteries of the optic nerve or by venous stasis that occurs as a result of decreased venous outflow and a compartment syndrome of the optic nerve or optic canal (Gkegkes, Karydis, Tyritzis, \& Iavazzo, 2015; Kamel \& Barnette, 2014; Kan et al., 2015). The subsequent postoperative vision loss can range from temporary blurring to partial to complete blindness; however, once a loss of vision occurs, it is almost always an irreversible complication (Emery et al., 2015; Lee \& Newman, 2018).

\section{Central Retinal Artery Occlusion}

Central retinal artery occlusion is most often caused by pressure on the eye from the prone position, and especially by positioning the patient's head on a prominent headrest. Pressure on the eye increases IOP and decreases blood flow to the retina through the central retinal artery (Kamel \& Barnette, 2014; Li, Swinney, Veeravagu, Bhatti, \& Ratliff, 2015; Stambough et al., 2007). The increased IOP exceeds the profusion pressure of the central retinal artery, leading to ischemia of the retina 
(Stambough et al., 2007). Most patients with central retinal artery occlusion are left with a unilateral, permanent blindness (Li et al., 2015; Stambough et al., 2007).

\section{Risk Factors for Postoperative Vision Loss}

Numerous risk factors for postoperative vision loss have been identified that include older patients with elevated baseline IOPs, patients with existing hypertension, diabetes, obesity, anemia, vascular disease, increased blood viscosity, and patients who smoke, as well as patients who experience intraoperative hypotension, blood transfusion, lower colloid use during fluid administration, or prolonged surgical times, and patients who are positioned on horseshoe-shaped headrests (Freshcoln \& Diehl, 2014; Ghomi, 2012; Kamel \& Barnette, 2014; Stambough et al., 2007). Patients who are predisposed to acute angle-closure glaucoma are also at high risk for ocular injury even during short procedures because the prone position can shift the lens-iris diaphragm forward so it obstructs aqueous humor outflow and increases IOP (Kwee et al., 2015).

\section{Incidence of Postoperative Vision Loss}

The exact incidence of postoperative vision loss is unknown because the data come largely from retrospective studies and case reports (Lee \& Newman, 2018; Patil, Lad, Lad, Ho, \& Boakye, 2008). The incidence of postoperative vision loss following nonocular surgery has been estimated to be as low as $0.0002 \%$ and as high as $0.2 \%$ (Berg, Harrison, \& Lee, 2010; Newman, 2008). In a retrospective cohort study using the National Inpatient Sample, the largest inpatient database in the United States, Patil et al., (2008), examined the records of 4,728,815 patients who underwent spinal procedures between 1993 and 2002. The researchers found that 4134 patients (0.09\%) developed postoperative visual impairment. An additional 271 patients $(0.006 \%)$ had ischemic optic 
neuropathy and an additional 47 patients $(0.001 \%)$ had central retinal artery occlusion. In a 10-year prevalence study of postoperative vision loss in the United States, Shen, Drum, and Roth (2009) reviewed data from more than 5.6 million patients included in the Nationwide Inpatient Sample from 1995 to 2005. The researchers found the incidence of postoperative vision loss for patients undergoing laminectomy without fusion was 0.86 per $10,000(0.009 \%)$. For patients undergoing spinal fusion, the incidence was 3.09 per $10,000(0.03 \%)$ for all fusions, 0.66 per 10,000 $(0.007 \%)$ fusions with anterior approach, and 5.50 per $10,000(0.06 \%)$ fusions with posterior approach.

\section{Conceptual Framework}

The Perioperative Patient Focused Model (Figure 4.1; Rothrock \& Smith, 2000) provides a conceptual framework for this systematic review and meta-analyses. During operative procedures when the patient is anesthetized, the perioperative registered nurse (RN) fills an important role as the patient's advocate and also oversees the patient's perioperative care. Secondary to being patient focused, the Perioperative Patient Focused Model is outcome focused (Rothrock \& Smith, 2000). The care provided by perioperative RNs is directed toward achieving high quality patient outcomes, such as preventing postoperative vision loss associated with increased IOP. Providing optimal perioperative patient care, serving as the patient's advocate, and achieving high quality outcomes requires specific perioperative knowledge and skillful implementation of best practices for patient positioning. Consistent with the Perioperative Patient Focused Model, the evidence-based practices implemented by perioperative RNs during patient positioning promote patient safety, and optimal physiological and behavioral responses in perioperative patients. Providing evidence about the magnitude of the increase in IOP 
resulting from the intraoperative use of the prone position will support the implementation of nursing interventions to help prevent postoperative vision loss and other ocular complications in adult patients undergoing surgery in the prone position.

\section{Purpose}

Although some researchers have studied the quantitative increase of IOP in surgical patients in the prone position (Emery et al., 2015; Lee \& Newman, 2018; Nuri Deniz et al., 2013; Quraishi et al., 2012; Shifa et al, 2016; Stang-Veldhouse et al., 2010; Yoshimura et al., 2015), there is a need for systematic review and meta-analyses of these studies to demonstrate the overall effect size and provide high-quality evidence supporting the need for implementing interventions to mitigate the increase of IOP and reduce the risk for postoperative vision loss. Meta-analysis research methods provide increased power compared to individual studies, improve estimates of effect size, and help resolve uncertainty when the results of individual studies disagree (Berlin, 1995). Because all of the evidence pertaining to a particular phenomenon is included in the analysis, meta-analysis research provides a high level of objectivity, precision, and generalizability (Thompson, 1994).

Currently, there has been no quantitative meta-analytic synthesis of the existing studies examining the increase in IOP in adult patients undergoing surgery in the prone position. The purpose of this systematic review and meta-analysis is to estimate the magnitude of the increase in IOP at selected perioperative time points in adult patients (i.e., individuals 18 years and older) undergoing any type of surgery in the prone position. Consequently, the research question to be addressed by this systematic review and meta- 
analysis is, "What is the magnitude of the increase in IOP at specific perioperative time points in adults undergoing surgery in the prone position?"

\section{Methods}

To ensure rigorous and transparent presentation of the methods and results of this systematic review and meta-analysis, the Preferred Reporting Items for Systematic reviews and Meta-Analyses (PRISMA) guidelines (Moher, Liberati, Tetzlaff, Altman, \& PRISMA Group, 2009) have been followed.

\section{Search Strategies}

An expert health sciences reference librarian was consulted to identify the most appropriate search terms and databases for an exhaustive and varied literature search. Keywords or medical subject headings (MeSH) included intraocular pressure or ocular tension, and prone position. Search strategies included

- online searching of the PubMed, CINAHL, and Scopus databases, and the Cochrane Database of Systematic Reviews for published and unpublished literature;

- ancestry searching of reference lists from relevant reports to locate additional applicable references;

- author searching of individuals identified in the literature as experts in the field; and a - dissertation search of the ProQuest database.

The author reviewed report abstracts for eligibility and obtained full-text copies of all potentially eligible reports.

\section{Inclusion and Exclusion Criteria}

Criteria for inclusion in the meta-analysis were reports written in English; published or unpublished reports of primary studies that encompassed dissertations, 
conference abstracts, and presentations; studies that used either a one-group, pretest posttest design or a multiple-group, pretest posttest design; reports where the minimum age of the study participants was 18-years or older; studies that included a specific measured outcome of IOP using any type of tonometer; studies where the participants received any type of general or spinal anesthesia; and reports of studies that included sufficient data to calculate an effect size. When reports did not include sufficient data to calculate an effect size, the author contacted the researchers and statisticians on at least two separate occasions two to three weeks apart to obtain missing data.

Reports were excluded if the IOP was measured in adults not undergoing surgery. Reports were also excluded if data from only one time point of IOP measurement were provided. Participant groups were additionally excluded if they were receiving an intervention specifically intended to mitigate IOP; however, participant groups representing control arms receiving placebos or no interventions were included in the systematic review and meta-analysis.

\section{Risk of Bias Within Individual Studies}

Each report included in the systematic review and meta-analysis was independently appraised and critically evaluated for its level of strength and quality by the author and an experienced evidence reviewer to assess the risk of bias within individual studies. The Association of periOperative Registered Nurses (AORN) Research Evidence Appraisal Tool - Study, available on the AORN website (https://www.aorn.org/guidelines/about-aorn-guidelines/evidence-rating) was used for this purpose. When using the AORN appraisal tool, non-experimental designs (e.g., observational studies) are assigned the lowest level of strength, quasi-experimental 
designs are assigned a moderate level of strength, and strong study designs (e.g., randomized controlled trials) are assigned the highest level of strength (i.e., experimental). An assessment of measures such as sample size, generalizability, bias, reliability, and validity is conducted to determine whether study quality is high, good, or low. The author and evidence reviewer achieved 100 percent consensus on study design and quality levels for each of the included studies by discussing their independent appraisals during conference calls.

\section{Risk of Bias Across Studies}

Several strategies were used to manage risk of bias that may affect cumulative evidence across studies (Valentine, 2009). To avoid bias due to a narrow or limited search, a comprehensive and diverse literature search was conducted (White, 2009). Only research studies were included in the systematic review and meta-analysis to ensure sufficient strength and quality of the included studies. An analysis of publication bias was conducted to determine whether unpublished research was unintentionally excluded. As well, only studies with objective measurements of IOP at two or more perioperative time points were included.

\section{Coding and Data Extraction}

The author used an iterative process that included reviewing the literature and studying codebooks used by experienced meta-analysts to develop a codebook for data extraction and coding of included studies. Based on content analysis of studies specific to the effects of prone position on IOP, the codebook was revised. The codebook was pilottested by the author using five randomly selected studies to identify missed coding 
categories and verify fit between coding categories and study characteristics before it was used to code and extract data from all eligible reports (Wilson, 2009).

To address the research question and statistically analyze the effects and methodologies of each of the reports, the author coded eligible studies and extracted necessary data. Effect size data for each of the reports included in the systematic review and meta-analysis was independently coded by a trained researcher. Coding discrepancies on effect size data for each of the eligible studies were discussed by the author and independent researcher until 100 percent consensus was achieved.

Data related to study characteristics (i.e., authors, year of publication, publication status, geographic location, reported funding) and data related to study design (i.e., type of study, study quality, type of tonometer, type of head positioning device, inclusion of ophthalmologic exams by participants) were collected from each of the included studies. Data related to participant and surgery characteristics (i.e., age; gender; American Society of Anesthesiologists [ASA; 2018] physical status classification; body mass index [BMI]; type of surgery; type of anesthesia; duration of anesthesia, prone position, and surgery; estimated blood loss [EBL]) were also collected when available. The researchers extracted data necessary to calculate effect sizes for all time points recorded during the perioperative phases of the procedures.

\section{Analyses}

Meta-analyses were conducted using Comprehensive Meta-Analysis Software, Version 3 (Borenstein, Hedges, Higgins, \& Rothstein, 2018). To allow for similarity with the order of events as they traditionally occur during surgery and to achieve the greatest number of comparisons for analysis at each time point, the time points for meta-analysis 
were selected from the time points recorded by the researchers. Analyses were conducted for the following time points $(\mathrm{T})$ :

T1 After induction of anesthesia to 0 minutes to 10 minutes of prone position, and T2 0 minutes to 10 minutes of prone position to the end of prone position.

Standardized mean difference effect sizes were calculated for each participant group and each measured time point (Cohen, 1992).

Effect size values were weighted by the inverse of the variance to account for sample size and adjust for bias. Because heterogeneity was observed among study designs, sample attributes, and outcome measures, and to account for between- and within-study variation, a random effects model was selected a priori to synthesize effect sizes. Using a random effects model assumes that the true effect size varies from one study to the next (Borenstein, Hedges, Higgins, \& Rothstein, 2009a, p. 77). Effect sizes were interpreted as per Cohen (1992) with 0.2 considered a small effect size, 0.5 considered a medium effect size, and 0.8 or greater considered a large effect size. The calculated effect sizes were converted to the metric used to measure IOP (i.e., $\mathrm{mmHg}$ ) using the procedures described by Lipsey and Wilson (2001) to facilitate interpretation of effect size findings.

Publication bias. A funnel plot was constructed to assess the extent of publication bias for the meta-analysis. Notably, a funnel plot may suggest publication bias, but does not eliminate the bias (Sutton, 2009). A minimum of three studies is necessary in order to create a funnel plot (Borenstein et al., 2018). Asymmetry of the funnel plot was measured by conducting an Egger's test (Borenstein et al., 2018; Egger, Smith, Schneider, \& Minder, 1997; Sterne Egger, \& Moher, 2011). When there are less 
than 10 studies included in the meta-analysis an Egger's test is not advised because the power of the test may be too low to distinguish true asymmetry from chance (Sterne et al., 2011). For this reason, a funnel plot was constructed and an Egger's test was conducted only when the analysis included 10 or more participant groups (T1). Orwin's Fail-safe $N$ test was conducted when the Egger's test was significant, to estimate the number of missing studies required to overturn the conclusions of the meta-analysis (Orwin, 1983; Sutton, 2009). Orwin's Fail-safe $N$ assesses the impact of publication bias to determine whether the overall observed effect is robust (Orwin, 1983; Sutton, 2009).

Heterogeneity. The studies included in the meta-analysis were assessed for heterogeneity after deciding on the model and calculating effect sizes. Heterogeneity is any kind of variability among the studies included in a meta-analysis, according to the Cochrane Collaboration (Deeks, Higgins, \& Altman, 2011). Heterogeneity testing explores whether the same effect is being evaluated by all studies (i.e., the null hypothesis); Higgins, Thompson, Decks, \& Altman, 2003). Cochrane’s Q, which estimates statistical significance; Tau-squared $\left(T^{2}\right)$, which estimates the absolute value of the true variance between studies, but not the proportion of the variance; and $I$-squared $\left(I^{2}\right)$, which estimates the proportion of true variance, but not the absolute value of the variance, were all used to test homogeneity of variance among effect sizes (Borenstein, Hedges, Higgins, \& Rothstein, 2009b). Using an $I^{2}$ test for assessing the impact of heterogeneity in a meta-analysis is recommended by Higgins and Thompson (2002) as this test quantifies the influence (as opposed to the amount) of heterogeneity and expresses the percentage of variability due to heterogeneity rather than chance (p. 1553). An $I^{2}$ value of $0 \%$ indicates there is no heterogeneity, values of $25 \%$ reflect low observed 
variation, values of $50 \%$ reflect moderate levels, and values of $75 \%$, reflect high levels of observed variation (Higgins et al., 2003). To show the dispersion of true effect sizes around the mean, prediction intervals for each time point were also calculated (Borenstein, Hedges, Higgins, \& Rothstein, 2009c).

\section{Results}

The flow of study selection is depicted in Figure 4.2. In total, 135 records were identified for possible inclusion, and of these, nine studies were included in the systematic review and meta-analysis. Four studies had multiple participant groups (Czorlick et al., 2018; Hunt et al., 2004; Pinar et al., 2018; Sugata et al., 2012), resulting in a total of 14 participant groups and 229 participants for analysis. Table 4.1 contains a summary of the studies included in this review and meta-analysis.

\section{Study Characteristics}

All of the studies included in the systematic review and meta-analysis were obtained from peer-reviewed journals. The researchers of three studies (33.3\%) reported receiving some type of funding or donated supplies (Emery et al., 2015; Pinar et al., 2018; Sugata et al., 2012). Although the literature was searched without any date restriction, all of the studies included in the systematic review and meta-analysis were published between 2001 and 2018. The greatest number of studies $(s)$ were published in $2018(s=2)$ with the greatest number of participants also occurring in $2018(n=88)$. The majority $(s=7)$ were conducted in Asia $(s=4)$ or North America $(s=3)$, with the majority of participants from Asia $(n=107)$.

\section{Participant Characteristics}


Participant and surgery characteristics are shown in Table 4.2. The mean age of the participants was 53.2 years $( \pm 8.1)$ and ranged from 43.3 years to 69 years. The majority of the participants were men $(n=122 ; 55.0 \%)$. Participant race and socioeconomic status were not reported by any of the researchers. Participants ranged between having a healthy weight to being slightly overweight $\left(22.5 \mathrm{~kg} / \mathrm{m}^{2}\right.$ to $\left.27.7 \mathrm{~kg} / \mathrm{m} 2\right)$ with a mean BMI of $24.9 \mathrm{~kg} / \mathrm{m}^{2}( \pm 1.6$; Centers for Disease Control and Prevention, 2016). Czorlich et al., (2018) excluded patients with a BMI greater than $30 \mathrm{~kg} / \mathrm{m}^{2}$. The ASA (2018) physical classification status was reported cumulatively as class I (i.e., healthy), class II (i.e., with mild systemic disease), or class III (i.e., with severe systemic disease) by the researchers of four reports ( $n=130$; Agah et al., 2011; Cheng et al., 2001; Nuri Deniz et al., 2013; Pinar et al., 2018). Sugata et al., (2012) reported patient comorbidities for diabetes ( $n=5$ of $24 ; 20.8 \%$ ), and hypertension $(n=9$ of $24 ; 37.5 \%)$.

\section{Surgery Characteristics}

The majority of the participants underwent spine surgery $(n=170 ; 74.2 \%)$. Other participants underwent percutaneous nephrolithotomy $(n=43 ; 18.8 \%)$ or cranial surgery $(n=16 ; 7 \%)$. The vast majority of participants $(n=222 ; 97 \%)$ received general anesthesia by either inhalation $(n=115 ; 51.8 \%)$, intravenous propofol $(n=60 ; 27 \%)$, or unspecified methods $(n=27 ; 12.2 \%)$, or received spinal anesthesia $(n=20 ; 9 \%)$. As shown in Table 4.2, the mean duration of surgery was 156.0 minutes $( \pm 24.2)$ with a range of 120 minutes to 181 minutes. The mean EBL was 330.1 milliliters (mL; \pm 222.1 ) with a range of $120 \mathrm{~mL}$ to $615 \mathrm{~mL}$.

\section{Study Design Characteristics}


The nine reports included in this systematic review and meta-analysis comprised four experimental ( $n=97$; Carey, Shaw, Weber, \& DeVine, 2014; Emery et al., 2015; Nuri Deniz et al., 2013; Pinar et al., 2018), and five non-experimental ( $n=132$; Agah et al., 2011; Cheng et al., 2001; Czorlich et al., 2018; Hunt et al., 2004; Sugata et al., 2012). Five were high quality ( $n=146$; Carey et al., 2014; Czorlich et al., 2018; Emery et al., 2015; Pinar et al., 2018; Sugata et al., 2012) and four were good quality ( $n=83$; Agah et al., 2011; Cheng et al., 2001; Hunt et al., 2004; Nuri Deniz et al., 2013). The researchers used three different tonometers to measure IOP; however, the Tono-Pen XL was used most frequently $(s=7 ; n=166)$. The most frequently used method for positioning the patient's head was skull pins or clamps $(n=105 ; 45.9 \%)$. Other methods included a horseshoe-shaped headrest $(n=71 ; 31 \%)$, a pillow or viscoelastic gel ring-shaped headrest $(n=30 ; 13.1 \%)$, or a silicone headrest $(n=23 ; 10 \%)$. Two researchers reported having 88 participants undergo preoperative ophthalmologic examinations (Czorlich et al., 2018; Pinar et al., 2018). One researcher reported having 48 participants undergo postoperative ophthalmologic examinations (Czorlich et al., 2018).

\section{Effect Sizes}

Results of the meta-analysis for each time point are shown in Table 4.3. A graphical representation of the magnitude of changes in IOP and upper prediction intervals for $\mathrm{T} 0$ through $\mathrm{T} 2$ is shown in Figure 4.3. In total, between induction of anesthesia and the end of prone position, IOP increases significantly by $17.6 \mathrm{mmHg}$ (i.e., $7.5 \mathrm{mmHg}+10.1 \mathrm{mmHg}=17.6 \mathrm{mmHg}$ ). Based on the upper limits of the prediction intervals, in $95 \%$ of all populations, IOP could increase by as much as $57.8 \mathrm{mmHg}$ (i.e., $19.8 \mathrm{mmHg}+38.0 \mathrm{mmHg}=57.8 \mathrm{mmHg}$ ). The IOP increases significantly after the 
patient is placed into the prone position $(\mathrm{T} 1:+7.5 \mathrm{mmHg}, p<0.001)$ and continues to increase significantly while the patient is in the prone position $(\mathrm{T} 2:+10.1 \mathrm{mmHg}, p=$ 0.002). The forest plots of effect sizes for each participant group included in the metaanalysis for $\mathrm{T} 1$ and $\mathrm{T} 2$ are shown in Figure 4.4 and Figure 4.5. The funnel plot for publication bias for $\mathrm{T} 1$ is shown in Figure 4.6.

\section{Discussion}

The results of this systematic review and analysis have shown that IOP increases significantly for adult patients undergoing surgery in the prone position. As shown in Figure 4.3, if an individual had a baseline IOP of $13.3 \mathrm{mmHg}$ after induction of anesthesia (as indicated by the pooled mean calculated for T0), by the end of prone position, IOP could increase to $30.9 \mathrm{mmHg}(13.3 \mathrm{mmHg}+7.5 \mathrm{mmHg}+10.1 \mathrm{mmHg}=$ $30.9 \mathrm{mmHg}$ ). Based on the upper limits of the prediction intervals, IOP could increase to $71.1 \mathrm{mmHg}(13.3 \mathrm{mmHg}+19.8 \mathrm{mmHg}+38.0 \mathrm{mmHg}=71.1 \mathrm{mmHg})$. An IOP of 71.1 $\mathrm{mmHg}$ is more than three times the highest parameter of normal IOP (i.e., $21 \mathrm{mmHg}$ ).

The mean IOP for the general population has been reported as $15.5( \pm 2.5) \mathrm{mmHg}$ (Carey et al., 2014). An IOP of $23 \mathrm{mmHg}$ is three standard deviations above the mean (i.e., $15.5 \mathrm{mmHg}+2.5 \mathrm{mmHg}+2.5 \mathrm{mmHg}+2.5 \mathrm{mmHg}=23 \mathrm{mmHg}$ ) and has thus been considered as a marker of abnormally elevated IOP (Carey et al., 2014). Yoshimura et al., (2015) conducted a study to evaluate predictive factors associated with increased IOP during spine surgery in the prone position. The researchers found that an IOP of 23 $\mathrm{mmHg}$ or greater was predictive of an IOP of $30 \mathrm{mmHg}$ or greater. Riva, Sinclair, and Grunwald (1981) found that the highest IOP at which the retina was able to maintain a constant blood flow was $29.6( \pm 2) \mathrm{mmHg}$. Pillunat, Anderson, Knighton, Joos, and 
Feuer (1997), found that blood flow to the optic nerve remained nearly constant until IOP reached $40 \mathrm{mmHg}$. The researchers noted; however, that some individuals do not exhibit autoregulation, and even a very modest increase in IOP can lead to a decline in blood flow to the optic nerve.

\section{Implications for Practice}

Increased IOP puts the patient at risk for glaucoma, detached retina, or partial to complete vision loss (Amorim Correa \& Acioly, 2018; Kwee et al., 2015; Leibovitch et al., 2006). Intraocular pressure increases of the magnitude found in this systematic review and meta-analysis clearly demonstrate the need for implementing intraoperative interventions to mitigate the increase in IOP and reduce the potential for serious ocular complications in patients undergoing surgery in the prone position.

Positioning the patient in a 5-degree to 10-degree reverse Trendelenburg prone position may be a simple intervention to prevent some instances of postoperative vision loss. This position has been shown to decrease IOP in healthy volunteers (Ozcan et al, 2004; Walick, Kragh, Ward, \& Crawford, 2007) and in patients undergoing spine surgery (Carey et al., 2014; Emery et al., 2015; Fukui, Ahmad, McHugh, Tempelhoff, \& Cheng, 2004; Fukui, Tempelhoff, \& Cheng, 2005). Positioning surgical patients with the head above the heart helps reduce venous congestion in the eye and orbit and decrease intraocular and intraorbital pressure (Bonnaig, Dailey, \& Archdeacon, 2014; Carey et al., 2014; Grant et al., 2010; Kamel, \& Barnette, 2014; Nickels, Manlapaz, \& Farag, 2014). Reducing the length of time the patient is in the prone position may also help to mitigate the increase in IOP. The ASA Task Force on Perioperative Visual Loss, North American Neuro-Ophthalmology Society, and Society for Neuroscience in Anesthesiology and 
Critical Care (2019) suggest staging procedures when patients will be in the prone position for prolonged periods of time. Utilizing a series of shorter procedures rather than one prolonged procedure may help reduce the patient's risk for postoperative vision loss; however, the risks associated with multiple surgeries may outweigh the benefits of staged procedures (Shifa et al., 2016).

Because IOP increases during prone position, intraoperative monitoring of IOP either continuously or at established intervals or time points (e.g., after initiation of prone position, after every 60 minutes of prone position) seems prudent. Yoshimura et al., (2015) suggested that measuring IOPs after one hour of surgery in the prone position could provide an opportunity for implementing interventions to prevent additional increases in IOP. Eddama (2013) also suggested that regular measurement of IOP during prolonged surgery provided an opportunity for implementing a change in the patient's position when critical thresholds are reached.

Implementing periodic intraoperative position changes or rest periods (where the ocular level is above the heart) can help to reduce IOP. In a quasi-experimental study, Molloy and Watson (2012) implemented a five-to-seven-minute level supine intervention after 60 minutes of steep Trendelenburg position and found there was a significant decrease in IOP.

When the patient is in the prone position, there is a risk for direct compression on the eye (Bonnaig et al., 2014). Yu, Chou, Yang, and Chang (2010) found that the prone position was a precipitating factor for eye injury. Preventing direct pressure and assessing and monitoring the patient's eyes at regular intervals throughout the procedure may help to reduce the incidence of postoperative vision loss (ASA Task Force on Perioperative 
Visual Loss et al, 2019; Locastro et al., 1991; Nickels et al., 2014; Shifa et al., 2016). Avoiding specific headrests or positioning devices that may increase pressure on the eye (e.g., horseshoe-shaped, Wilson frame) or using skull pins or tongs to position the head may also help to prevent pressure on the orbits and reduce the risk for postoperative vision loss (Asok et al., 2009; Bekar et al., 1996; Grossman \& Ward, 1993; Hollenhorst et al., 1954; Hoski et al., 1993; Quraishi et al., 2012; Wolfe et al., 1992). Direct compression from a horseshoe-shaped head positioner has been reported as a cause of postoperative vision loss when the patient is in the prone position (Abraham et al., 2003; Bekar et al., 1996; Grossman \& Ward, 1993; Hollenhorst et al., 1954; Hoski et al., 1993; Locastro et al., 1991; Wolfe et al., 1992). In a case-controlled study of 80 patients with ischemic optic neuropathy compared with 315 matched control patients, the ASA Postoperative Visual Loss Study Group (2012) found that Wilson frame use was an independent risk factor for postoperative vision loss.

Administering specific medications or anesthetics may also be effective in reducing IOP or mitigating the intraoperative increase in IOP (Farag et al., 2012; Pinar et al., 2018; Sugata et al., 2012). Pinar et al., (2018) found that the increase in IOP was significantly less in patients undergoing lumbar disc surgery in the prone position under spinal anesthesia compared with patients receiving general anesthesia. Sugata et al., (2012) found that IOPs were higher in patients undergoing prone spine surgery with general anesthesia maintained with sevoflurane compared with patients receiving general anesthesia maintained with intravenous propofol. Farag et al., (2012) found that the administration of topical brimonidine $2 \%$ helped reduce intraoperative IOP. 
Another important consideration for practice is the need to evaluate whether patients undergoing surgery in the prone position should receive a preoperative ophthalmologic examination to reduce the risk for ocular injury (Akhaddar \& Boucetta, 2012; ASA Task Force on Perioperative Visual Loss et al., 2019; Singer \& Salim, 2010; Stang-Veldhouse et al., 2010; Stewart et al., 2016). Preoperative ophthalmologic examinations may be helpful in identifying patients at risk for postoperative vision loss. Increases in IOP may be more harmful in older patients, patients with risk factors for postoperative vision loss, or in patients who are predisposed to developing diabetes or glaucoma than in younger, healthier patients (Akhaddar \& Boucetta, 2012; ASA Task Force on Perioperative Visual Loss et al., 2019; Singer \& Salim, 2010; Stang-Veldhouse et al., 2010; Stewart et al., 2016). Patients at risk for acute angle-closure glaucoma associated with the prone position may benefit from preoperative laser iridotomy (Singer $\&$ Salim, 2010; Stewart et al., 2016). The ASA Task Force on Perioperative Visual Loss et al., (2019) recommend evaluating the need for preoperative ophthalmologic examination on a case-by-case basis.

The results of this systematic review and meta-analysis support the use of the Perioperative Patient Focused Model as the conceptual foundation for this perioperative research. Providing quantitative evidence about the magnitude of the intraoperative increase in IOP resulting from the prone position supports the implementation of nursing interventions that are patient-focused and will improve patient outcomes by mitigating increases in IOP and reducing the risk for permanent postoperative vision loss and other ocular complications in adult surgical patients.

\section{Implications for Future Research}


Further research relative to the magnitude of IOP increases in patients undergoing surgery in the prone position is warranted. Further research to provide validation and demonstrate reliability of the Perioperative Patient Focused Model is also warranted. To allow for consistent data collection, comparison, meta-analysis, and reporting, researchers of future studies should use standardized time points for measurement (i.e., before induction, after induction, after change to prone position and every 30 minutes to 60 minutes thereafter, after return to supine position, before arousal, and postoperatively). Further, researchers should present data in a consistent format for each time point (i.e., sample size, mean, standard deviation). To determine whether certain variables affect the strength of the relationship between prone position and IOP, researchers should study patients of all ages and ethnicities, without restriction of BMI or comorbidities.

\section{Limitations}

This systematic review and meta-analyses has several limitations. The number of included studies and participants is small $(s=9 ; N=229)$. As shown in Figure 4.2, studies were excluded for a variety of reasons; however, five studies were excluded from the analyses solely because of a lack of data necessary to calculate an effect size. The researchers were contacted a minimum of two times to obtain missing data, but none responded. One researcher excluded participants based on BMI (Czorlich et al., 2018); therefore, the mean value for this variable may not fully reflect the true characteristics of all adult surgical patients.

The meta-analysis examined only two intraoperative time points. The analysis for $\mathrm{T} 2$ reflects IOP measurements from patients in the prone position for varying lengths of time. Having data for specific time points would be preferable. This lack of data 
collection by researchers is likely due to the difficulty of measuring IOP with the patient in prone position. Because researchers measured IOP at varying intraoperative time points, all studies could not be included at all time points examined in the meta-analysis. Additionally, there were not enough studies included at each time point to allow for moderator analyses.

Heterogeneity was significant at both time points $\left(\mathrm{T} 1: I^{2}=91.5, p<0.001 ; \mathrm{T} 2: I^{2}\right.$ $=95.4, p<0.001$ ), indicating that variation across studies was substantial, potentially limiting generalizability. Notably, heterogeneity among the studies included in a metaanalysis is very common and should be anticipated, not regarded as the exception (Berlin, 1995). The significant Egger's regression intercept for the funnel plot (bias $=9.2 ; p=$ 0.00019) may also be indicative of potential publication bias in the studies included in the meta-analysis. The Egger's test has low power for meta-analyses containing small to moderate numbers of studies (Sutton, 2009). However, Orwin's Fail-safe N is 177 (SMD $=1.71$, suggesting a need for 177 additional studies with an effect size of 0 before the cumulative effect would become trivial (defined as a Cohen's $d$ of 0.1). With such high numbers of studies required to overturn the conclusions of the meta-analysis, the overall observed effect size can be considered robust (Orwin, 1983; Sutton, 2009).

\section{Conclusion}

Intraocular pressure increases significantly while the patient is in the prone position. The greatest increase in IOP occurs within 10 minutes after the patient is placed into the prone position. The IOP continues to increase significantly while the patient is in prone position, but to a lesser degree. Intraocular pressure increases of the magnitude found in this systematic review and meta-analysis clearly demonstrate the need for 
implementing interventions to mitigate the increase in IOP and reduce the risk for postoperative vision loss and other ocular complications in patients undergoing surgery in the prone position. 


\section{References}

Abraham, M., Sakhuja, N., Sinha, S., \& Rastogi, S. (2003). Unilateral visual loss after cervical spine surgery. Journal of Neurosurgical Anesthesiology, 15(4), 319-322.

Agah, M., Ghasemi, M., Roodneshin, F., Radpay, B., \& Moradian, S. (2011). Prone position in percutaneous nephrolithotomy and postoperative visual loss. Urology Journal, 8(3), 191-196.

Akhaddar, A., \& Boucetta, M. (2012). Subconjunctival hemorrhage as a complication of intraoperative positioning for lumbar spinal surgery. Spine Journal, 12(3), 274. doi: 10.1016/j.spinee.2012.02.007

American Academy of Ophthalmology. (2018). Intraocular pressure. Retrieved from https://www.aao.org/bcscsnippetdetail.aspx?id=f010bbf6-3f3e-486b-b5cd0ad86ddb9d74

American Society of Anesthesiologists. (2018). ASA Physical Status Classification System. Retrieved from https://www.asahq.org/standards-and-guidelines/asaphysical-status-classification-system

American Society of Anesthesiologists Postoperative Visual Loss Study Group. (2012). Risk factors associated with ischemic optic neuropathy after spinal fusion surgery. Anesthesiology, 116(1), 15-24. doi: 10.1097/ALN.0b013e31823d012a

American Society of Anesthesiologists Task Force on Perioperative Visual Loss, North American Neuro-Ophthalmology Society, \& Society for Neuroscience in Anesthesiology and Critical Care. (2019). Practice Advisory for Perioperative Visual Loss Associated with Spine Surgery. Anesthesiology, 130(1), 12-30. doi: 10.1097/ALN.0000000000002503 
Amorim Correa, J. L., \& Acioly, M. A. (2018). The enigma of orbital compartment syndrome after lumbar spine surgery in the prone position: Case report and literature review. World Neurosurgery, 110, 309-314. doi:

10.1016/j.wneu.2017.11.111

Asok, T., Aziz, S., Faisal, H. A., Tan, A. K., \& Mallika, P. S. (2009). Central retinal artery occlusion and opthalmoplegia following spine surgery in the prone position. Medical Journal of Malaysia, 64(4), 323-324.

Bekar, A., Türeyen, K., \& Aksoy, K. (1996). Unilateral blindness due to patient positioning during cervical syringomyelia surgery: Unilateral blindness after prone positioning. Journal of Neurosurgical Anesthesiology, 8(3), 227-229.

Berg, K. T., Harrison, A. R., \& Lee, M. S. (2010). Perioperative visual loss in ocular and nonocular surgery. Clinical Ophthalmology, 4, 531-546.

Berlin, J. A. (1995). Invited commentary: Benefits of heterogeneity in meta-analysis of data from epidemiological studies. American Journal of Epidemiology, 142(4), 465-468. doi: 10.1093/oxfordjournals.aje.a117645

Bonnaig, N., Dailey, S., \& Archdeacon, M. (2014). Proper patient positioning and complication prevention in orthopaedic surgery. Journal of Bone and Joint Surgery, American Volume, 96(13), 1135-1140. doi: 10.2106/JBJS.M.01267

Borenstein, M., Hedges, L. V., Higgins, J., \& Rothstein, H. (2009a). Fixed-effect versus random-effects models. In Introduction to meta-analysis (pp. 77-86). West Sussex, UK: John Wiley \& Sons, Ltd. 
Borenstein, M., Hedges, L. V., Higgins, J., \& Rothstein, H. (2009b). Identifying and quantifying heterogeneity. In Introduction to meta-analysis (pp. 107-125). West Sussex, UK: John Wiley \& Sons, Ltd.

Borenstein, M., Hedges, L. V., Higgins, J., \& Rothstein, H. (2009c). Prediction intervals. In Introduction to meta-analysis (pp. 127-133). West Sussex, UK: John Wiley \& Sons, Ltd.

Borenstein, M., Hedges, L. V., Higgins, J., \& Rothstein, H. (2018). Comprehensive Meta-Analysis. Retrieved from https://www.meta-analysis.com

Boyd, K. (2018). What is ischemic optic neuropathy? Retrieved from https://www.aao.org/eye-health/diseases/what-is-ischemic-optic-neuropathy

Carey, T. W., Shaw, K. A., Weber, M. L., \& DeVine, J. G. (2014) Effect of the degree of reverse Trendelenburg position on intraocular pressure during prone spine surgery: A randomized controlled trial. Spine Journal, 14(9), 2118-2126. doi: 10.1016/j.spinee. 2013

Centers for Disease Control and Prevention. (2016). Defining adult overweight and obesity. Retrieved from https://www.cdc.gov/obesity/adult/defining.html

Cheng, M. A., Todorov, A., Tempelhoff, R., McHugh, R., Chowder, C. M., \& Lauryssen, C. (2001). The effect of prone positioning on intraocular pressure in anesthetized patients. Anesthesiology, 95(6), 1351-1355.

Cohen, J. A. (1992). A power primer. Psychological Bulletin, 12(1), 155-159.

Czorlich, P., Krätzig, T., Kluge, N., Skevas, C., Knospe, V., Spitzer, M. S., . . Elcker, S. O. (2018). Intraocular pressure during neurosurgical procedures in context of head 
position and loss of cerebrospinal fluid. Journal of Neurosurgery. Advance online publication. doi: 10. 3171/2018.3.JNS173098

Deeks, J. J., Higgins, J. P. T., \& Altman, D. G. (Eds.). (2011). Chapter 9: Analyzing data and undertaking meta-analysis. In J. J. Deeks, J. P. T Higgins, \& D. G. Altman (Eds.). Cochrane handbook for systematic reviews of interventions Version 5.1.0 (Updated March 2011). Retrieved from www.handbook.cochrane.org

Dilger, J. A., Tétzlaff, J. E., Bell, G. R., Kosmorsky, G. S., Agnor, R. C., \& O’Hara, J. F. Jr. (1998). Ischaemic optic neuropathy after spinal fusion. Canadian Journal of Anaesthesia, 45(1), 63-66. doi: 10.1007/BF03011996

Eddama, M. (2013). Re: Raised intraocular pressure and perioperative visual loss in laparoscopic colorectal surgery: A catastrophe waiting to happen? A systematic review of evidence from other surgical specialties. Techniques in Coloproctology, 17(2), 247. doi: 10.1007/s10151-013-0979-x

Egger, M., Smith, G. D., Schneider, M., \& Minder, C. E. (1997). Bias in meta-analysis detected by a simple, graphical test. BMJ Clinical Research, 315(7109), 629-634. doi: $10.1136 / \mathrm{bmj} .315 .7109 .629$

Emery, S. E., Daffner, S. D., France, J. C., Ellison, M., Grose, B. W., Hobbs, G. R., \& Clovis, N. B. (2015). Effect of head position on intraocular pressure during lumbar spine fusion: A randomized, prospective study. Journal of Bone \& Joint Surgery (American), 97(22), 1817-1823. doi: 10.2106/JBJS.0.00091

Farag, E., Sessler, D. I., Kovaci, B., Wang, L., Mascha, E. J., Bell, G., . . Kurz, A. (2012). Effects of crystalloid versus colloid and the $\alpha-2$ agonist brimonidine versus placebo on intraocular pressure during prone spine surgery: A factorial 
randomized trial. Anesthesiology, 116(4), 807-815. doi:

10.1097/ALN.0b013e3182475c10

Freshcoln, M., \& Diehl, M. R. (2014). Repositioning during robotic procedures to prevent postoperative visual loss. OR Nurse, 8(4), 36-41.

Fukui, K., Ahmad, M., McHugh, T., Tempelhoff, R., \& Cheng, M. A. (2004). The effect of head elevation on intraocular pressure in anesthetized patients undergoing prone position spine surgery [Abstract]. Journal of Neurosurgical Anesthesiology, 16(4), 358. doi: 10.1097/00008506-200410000-00087

Fukui, K., Tempelhoff, R., \& Cheng, M. A. (2005). Intraocular pressure during prone position surgery: Effects of time and head elevation [Abstract]. Journal of Neurosurgical Anesthesiology, 17(4), 251. doi:

10.1097/01.ana.0000187769.61921.85

Ghomi, A. (2012). Robotics in practice: New angles on safer positioning. Contemporary $O B / G Y N, 57(10), 26-37$.

Gkegkes, I. D., Karydis, A., Tyritzis, S. I., \& Iavazzo, C. (2015). Ocular complications in robotic surgery. International Journal of Medical Robotics, 11(3), 269-274. doi: $10.1002 /$ rcs. 1632

Goni, V., Tripathy, S. K., Goyal, T., Tamuk, T., Panda, B. B., \& Shashidhar, B. K. (2012). Cortical blindness following spinal surgery: Very rare cause of perioperative vision loss. Asian Spine Journal, 6(4), 287-290. doi: 10.4184/asj.2012.6.4.287

Grant, G. P., Szirth, B. C., Bennett, H. L., Huang, S. S., Thaker, R. S., Heary, R. F., \& Turbin, R. E. (2010). Effects of prone and reverse Trendelenburg positioning on 
ocular parameters. Anesthesiology, 112(1), 57-65. doi:

10.1097/ALN.0b013e3181c294e1

Grossman, W., \& Ward, W. T. (1993). Central retinal artery occlusion after scoliosis surgery with a horseshoe headrest: Case report and literature review. Spine, 18(9), 1226-1228.

Guillaume, J. E., \& Gowreesunker, P. (2013). Horner's syndrome in the prone position: A case report. Acta Anaesthesiologica Belgica, 64(3), 119-121.

Hayreh, S. S. (2001). Blood flow in the optic nerve head and factors that may influence it. Progress in Retinal and Eye Research, 20(5), 595-624.

Higgins, J. P. T., \& Thompson, S. G. (2002). Quantifying heterogeneity in a metaanalysis. Statistics in Medicine, 21(11), 1539-1558. doi: 10.1002/sim.1186

Higgins, J. P. T., Thompson, S. G., Decks, J. J., \& Altman, D. G. (2003). Measuring inconsistency in meta-analysis. BMJ, 327(7414), 557-560. doi: 10.1136/bmj.327.7414.557

Hollenhorst, R. W., Svien, H. J., \& Benoit, C. F. (1954). Unilateral blindness occurring during anesthesia for neurosurgical operations. AMA Archives of Ophthalmology, $52(6), 819-830$.

Hoski, J. J., Eismont, F. J., \& Green, B. A. (1993). Blindness as a complication of intraoperative positioning: A case report. Journal of Bone and Joint Surgery, $75(8), 1231-1232$.

Hunt, K., Bajekal, R., Calder, I., Meacher, R., Eliahoo, J., \& Acheson, J. F. (2004). Changes in intraocular pressure in anesthetized prone patients. Journal of Neurosurgical Anesthesiology, 16(4), 287-290. 
Kamel, I., \& Barnette, R. (2014). Positioning patients for spine surgery: Avoiding uncommon position-related complications. World Journal of Orthopedics, 5(4), 425-443. doi: 10.5312/wjo.v5.i4.425

Kan, K. M., Brown, S. E., \& Gainsburg, D. M. (2015). Ocular complications in roboticassisted prostatectomy: A review of pathophysiology and prevention. Minerva Anestesiologica, 81(5), 557-566.

Katz, D. M., Trobe, J. D., Cornblath, W. T., \& Kline, L. B. (1994). Ischemic optic neuropathy after lumbar spine surgery. Archives of Ophthalmology, 112(7), 925931.

Kendrick, H. (2012). Post-operative vision loss (POVL) following surgical procedures. Journal of Anesthesia and Clinical Research, 3(1), 184. doi: 10.4172/21556148.1000184

Kwee, M. M., Ho, Y. H., \& Rozen, W. M. (2015). The prone position during surgery and its complications: A systematic review and evidence-based guidelines. International Surgery, 100(2), 292-303. doi: 10.9738/INTSURG-D-13-00256.1

Lee, L. A., \& Newman, N. (2018). Postoperative visual loss after anesthesia for nonocular surgery. UpToDate. Retrieved from https://www.uptodate.com/contents/postoperative-visual-loss-after-anesthesia-fornonocular-surgery.

Leibovitch, I., Casson, R., Laforest, C., \& Selva, D. (2006). Ischemic orbital compartment syndrome as a complication of spinal surgery in the prone position. Ophthalmology, 113(1), 105-108. doi: 10.1016/j.ophtha.2005.09.025 
Li, A., Swinney, C., Veeravagu, A., Bhatti, I., \& Ratliff, J. (2015). Postoperative visual loss following lumbar spine surgery: A review of risk factors. World Neurosurgery, 84(6), 2010-2021. doi: 10.1016/j.wneu.2015.08.030

Lipsey, M., \& Wilson, D. (2001). Interpreting and using meta-analysis results. In Practical meta-analysis: Applied social research (Vol 49, pp. 146-168). Thousand Oaks, CA: Sage.

Locastro, A., Novak, K. D., \& Biglan, A. W. (1991). Central retinal artery occlusion in a child after general anesthesia. American Journal of Ophthalmology, 112(1), 9192.

Manfredini, M., Ferrante, R., Gildone, A., \& Massari, L. (2000). Unilateral blindness as a complication of intraoperative positioning for cervical spinal surgery. Journal of Spine Disorders, 13(3), 271-272.

Moher, D., Liberati, A., Tetzlaff, J., Altman, D. G., \& PRISMA Group. (2009). Preferred reporting items for systematic reviews and meta-analyses: The PRISMA statement. PLoS Medicine, 6(7), e1000097. doi: 10.1371/journal.pmed.1000097

Molloy, B. L., \& Watson, C. (2012). A comparative assessment of intraocular pressure in prolonged steep Trendelenburg position versus level supine position intervention. Journal of Anesthesiology \& Clinical Science. doi: 10.7243/2049-9752-1-9

Newman, N. J. (2008). Perioperative visual loss after nonocular surgeries. American Journal of Ophthalmology, 145(4), 604-610. doi: 10.1016/j.ajo.2007.09.016

Nickels, T. J., Manlapaz, M. R., \& Farag, E. (2014). Perioperative visual loss after spine surgery. World Journal of Orthopaedics, 5(2), 100-106. doi:

10.5312/wjo.v5.i2.100 
Nuri Deniz, M., Erakgün, A., Sertöz, N., Yilmaz, S. G., Ateş, H., \& Erhan, E. (2013).

The effect of head rotation on intraocular pressure in prone position: A randomized trial. Brazilian Journal of Anesthesiology, 63(2), 209-212. doi: $10.1016 / \mathrm{S} 0034-7094(13) 70217-4$

Nuzzi, R., \& Tridico, R. (2016). Ocular complications in laparoscopic surgery: Review of existing literature and possible prevention and treatment. Seminars in Ophthalmology, 31(6), 584-592. doi: 10.3109/08820538.2015.1009557

Orwin, R. G. (1983). A fail-safe $N$ for effect size in meta-analysis. Journal of Educational Statistics, 8(2), 157-159. doi: 10.2307/1164923

Ozcan, M. S., Praetel, C., Bhatti, M. T., Gravenstein, N., Mahla, M. E., \& Seubert, C. N. (2004). The effect of body inclination during prone positioning on intraocular pressure in awake volunteers: A comparison of two operating tables. Anesthesia \& Analgesia, 99(4), 1152-1158. doi: 10.1213/01.ANE.0000130851.37039.50

Patil, C. G., Lad, E. M., Lad, S. P., Ho, C., \& Boakye, M. (2008). Visual loss after spine surgery: A population-based study. Spine, 33(13), 1491-1496. doi: 10.1097/BRS.0b013e318175d1bf

Pillunat, L. E., Anderson, D. R., Knighton, R. W., Joos, K. M., \& Feuer, W. J. (1997). Autoregulation of human optic nerve head circulation in response to increased intraocular pressure. Experimental Eye Research, 64(5), 727-744. doi: 10.1006/exer.1996.0263

Pinar, H. U., Kaşdoğan, Z. E. A., Başaran, B., Çöven, İ., Karaca, Ö., \& Doğan, R. (2018). The effect of spinal versus general anesthesia on intraocular pressure in lumbar 
disc surgery in the prone position: A randomized controlled trial. Journal of Clinical Anesthesia, 46, 54-58. doi: 10.1016/j.jclinane.2018.01.026

Pinkney, T. D., King, A. J., Walter, C., Wilson, T. R., Maxwell-Armstrong, C., \& Acheson, A. G. (2012). Raised intraocular pressure (IOP) and perioperative visual loss in laparoscopic colorectal surgery: A catastrophe waiting to happen? A systematic review of evidence from other surgical specialties. Techniques in Coloproctology, 16(5), 331-335. doi: 10.1007/s10151-012-0879-5

Quraishi, N. A., Wolinsky, J. P., \& Gokaslan, Z. L. (2012). Transient bilateral postoperative visual loss in spinal surgery. European Spine Journal, 21(Suppl 4), S495-S498. doi: 10.1007/s00586-011-2117-7

Reddy, A., Foroozan, R., Edmond, J. C., \& Hinckley, L. K. (2008). Dilated superior ophthalmic veins and posterior ischemic optic neuropathy after prolonged spine surgery. Journal of Neuro-Ophthalmology, 28(4), 327-328. doi:

10.1097/WNO.0b013e318175c86c

Riva, C. E, Sinclair, S. H., \& Grunwald, J. E. (1981). Autoregulation of retinal circulation in response to decrease of perfusion pressure. Investigative Ophthalmology \& Visual Science, 21(1), 34-38.

Rothrock, J. D., \& Smith, D. A. (2000). Selecting the perioperative patient focused model. AORN Journal, 71(3), 1030-1037.

Russell, D. J., \& Dutton, J. J. (2011). Bilateral spontaneous subperiosteal orbital hemorrhages following endoscopic retrograde cholangiopancreatography. Ophthalmic Plastic \& Reconstructive Surgery, 27(3), e49-e50. doi: 10.1097/IOP.0b013e3181cd5f65 
Shen, Y., Drum, M., \& Roth, S. (2009). The prevalence of perioperative visual loss in the United States: A 10-year study from 1996 to 2005 of spinal, orthopedic, cardiac, and general surgery. Anesthesia \& Analgesia, 109(5), 1534-1545. doi:

10.1213/ane.0b013e3181b0500b

Shifa, J., Abebe, W., Bekele, N., \& Habte, D. (2016). A case of bilateral visual loss after spinal cord surgery. Pan African Medical Journal, 23, 119. doi:

10.11604/pamj.2016.23.119.8443

Singer, M. S., \& Salim, S. (2010). Bilateral acute angle-closure glaucoma as a complication of facedown spine surgery. Spine Journal, 10(9), e7-e9. doi: 10.1016/j.spinee.2010.07.006

Stambough, J. L., Dolan, D., Wener, R., \& Godfrey, E. (2007). Ophthalmologic complications associated with prone positioning in spine surgery. Journal of the American Academy of Orthopaedic Surgeons, 15(3), 156-165.

Stang-Veldhouse, K. N., Yeu, E., Rothenberg, D. M., \& Mizen, T. R. (2010). Unusual presentation of perioperative ischemic optic neuropathy following major spine surgery. Journal of Clinical Anesthesia, 22(1), 52-55. doi:

10.1016/j.jclinane.2009.01.018

Sterne, J. A. C., Egger, M., \& Moher, D. (Eds.). (2011). Chapter 10: Addressing reporting biases. In J. J. Deeks, J. P. T Higgins, \& D. G. Altman (Eds.). Cochrane handbook for systematic reviews of interventions Version 5.1.0 (Update March 2011). Retrieved from www.handbook.cochrane.org 
Stewart, R. J., Landy, D. C., \& Lee, M. J. (2016). Unlateral acute angle-closure glaucoma after lumbar spine surgery: A case report and systematic review of the literature. Spine, 41(5), E297-E299. doi: 10.1097/BRS.0000000000001224

Sugata, A., Hayashi, H., Kawaguchi, M., Hasuwa, K., Nomura, Y., \& Furuya, H. (2012). Changes in intraocular pressure during prone spine surgery under propofol and sevoflurane anesthesia. Journal of Neurosurgical Anesthesia., 24(2), 152-156. doi: 10.1097/ANA.0b013e31823fe822

Sutton, A. J. (2009). Publication bias. In H. Cooper, L. V. Hedges, \& J. C. Valentine (Eds.). The handbook of research synthesis and meta-analysis (2nd ed., pp. 435452). New York, NY: Russell Sage Foundation.

Szmuk, P., Steiner, J. W., Pop, R. B., You, J., Weakley, D. R., Swift, D. M., \& Sessler, D. I. (2013). Intraocular pressure in pediatric patients during prone surgery. Anesthesia \& Analgesia, 116(6), 1309-1313. doi:

10.1213/ANE.0b013e31828d3730

Thompson, S. G. (1994). Why sources of heterogeneity in meta-analysis should be investigated. BMJ, 309(6965), 1351-1355.

Valentine, J. C. (2009). Judging the quality of primary research. In H. Cooper, L. V. Hedges, \& J. C. Valentine, (Eds.), The handbook of research synthesis and metaanalysis (2nd ed., pp. 129-146). New York, NY: Russell Sage Foundation.

Walick, K. S., Kragh, J. E., Ward, J. A., \& Crawford, J. J. (2007). Changes in intraocular pressure due to surgical positioning. Spine, 32(23), 2591-2595. doi: 10.1097/BRS.0b013e318158cc23 
Weinreb, R. N., \& Khaw, P. T. (2004). Primary open-angle glaucoma. Lancet, 363(9422), 1711-1720. doi: 10.1016/S0140-6736(04)16257-0

West, J., Askin, G., Clarke, M., \& Vernon, S. A. (1990). Loss of vision in one eye following scoliosis surgery. British Journal of Ophthalmology, 74, 243-244.

White, H. D. (2009). Scientific communication and literature retrieval. In H. Cooper, L. V. Hedges, \& J. C. Valentine (Eds.). The handbook of research synthesis and meta-analysis (2nd ed., pp. 51-71). New York, NY: Russell Sage Foundation.

Wilson, D. B. (2009). Systematic coding. In H. Cooper, L. V. Hedges, \& J. C. Valentine, (Eds.), The handbook of research synthesis and meta-analysis (2nd ed., pp. 159176). New York, NY: Russell Sage Foundation.

Wolfe, S. W., Lospinuso, M. F., \& Burke, S. W. (1992). Unilateral blindness as a complication of patient positioning for spinal surgery: A case report. Spine, 17(5), 600-605.

Yoshimura, K., Hayashi, H., Tanaka, Y., Nomura, Y., \& Kawaguchi, M. (2015). Evaluation of predictive factors associated with increased intraocular pressure during prone position spine surgery. Journal of Anesthesia, 29(2), 170-174. doi: $10.1007 / \mathrm{s} 00540-014-1921-8$

Yu, H. D., Chou, A. H., Yang, M. W., \& Chang, C. J. (2010). An analysis of perioperative eye injuries after nonocular surgery. Acta Anaesthesiologica Taiwanica, 48(3), 122-129. doi: 10.1016/S1875-4597(10)60043-4 
Table 4.1.

Summary of Studies Included in the Systematic Review and Meta-analysis $(s=9 ; N=229)$.

\begin{tabular}{|c|c|c|c|c|c|}
\hline $\begin{array}{l}\text { First Author } \\
\text { (Year) } \\
\text { Country }\end{array}$ & 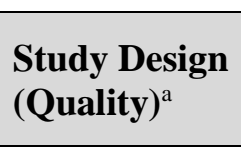 & $\begin{array}{l}\text { Participant Groups and } \\
\text { Observations/Interventions }\end{array}$ & $\begin{array}{l}\text { IOP Measures } \\
\text { (Tonometer) } \\
\text { [Head Positioning] }\end{array}$ & Outcome Measures & $\begin{array}{l}\text { Effect Sizes } \\
(\text { Cohen's } d \text { ) }\end{array}$ \\
\hline $\begin{array}{l}\text { Agah } \\
(2011) \\
\text { Iran }\end{array}$ & $\begin{array}{l}\text { Non- } \\
\text { experimental } \\
(\text { Good) }\end{array}$ & $\begin{array}{l}\text { - } 20 \text { patients undergoing } \\
\text { PCNL in prone position }\end{array}$ & $\begin{array}{l}\text { Measurement of IOP at } \\
\text { five different time } \\
\text { points } \\
\text { (Tono-Pen XL) } \\
\text { [Ring-shaped headrest] }\end{array}$ & $\begin{array}{l}\text { Differences in IOP } \\
\text { levels at each time point }\end{array}$ & $\begin{array}{l}\text { T1: } 11.34 \\
\text { T2: } 10.5\end{array}$ \\
\hline $\begin{array}{l}\text { Carey } \\
(2014) \\
\text { United States }\end{array}$ & $\begin{array}{l}\text { Experimental } \\
\text { (High) }\end{array}$ & $\begin{array}{l}7 \text { patients undergoing spine } \\
\text { surgery in neutral prone } \\
\text { position } \\
\text { - } 6 \text { patients undergoing spine } \\
\text { surgery in } 5^{\circ} \text { reverse } \\
\text { Trendelenburg position }{ }^{\mathrm{b}} \\
6 \text { patients undergoing spine } \\
\text { surgery in } 10^{\circ} \text { reverse } \\
\text { Trendelenburg position }\end{array}$ & $\begin{array}{l}\text { Measurement of IOP at } \\
\text { five different time } \\
\text { points } \\
\text { (Tono-Pen XL) } \\
\text { [Horseshoe-shaped } \\
\text { headrest] }\end{array}$ & $\begin{array}{l}\text { Differences in IOP } \\
\text { levels at each time point }\end{array}$ & \\
\hline $\begin{array}{l}\text { Cheng } \\
(2001) \\
\text { United States }\end{array}$ & $\begin{array}{l}\text { Non- } \\
\text { experimental } \\
\text { (Good) }\end{array}$ & $\begin{array}{l}\text { - } 20 \text { men undergoing spine } \\
\text { surgery in prone position }\end{array}$ & $\begin{array}{l}\text { Measurement of IOP at } \\
\text { five different time } \\
\text { points } \\
\text { (Tono-Pen XL) } \\
\text { [Skull pins] }\end{array}$ & $\begin{array}{l}\text { Differences in IOP } \\
\text { levels at each time point }\end{array}$ & \\
\hline $\begin{array}{l}\text { Czorlich } \\
(2018) \\
\text { Germany }\end{array}$ & $\begin{array}{l}\text { Non- } \\
\text { experimental } \\
\text { (High) }\end{array}$ & $\begin{array}{l}16 \text { patients undergoing } \\
\text { spine surgery and dural } \\
\text { opening in prone position } \\
\text { (A) } \\
16 \text { patients undergoing } \\
\text { cranial surgery and dural } \\
\text { opening in the prone } \\
\text { position (B) } \\
16 \text { patients undergoing } \\
\text { cranial surgery and dural } \\
\text { opening in the lateral } \\
\text { position }(\mathrm{C})^{\mathrm{b}}\end{array}$ & $\begin{array}{l}\text { Measurement of IOP at } \\
\text { seven different time } \\
\text { points } \\
\text { (Tono-Pen XL) } \\
\text { [Skull clamp] }\end{array}$ & $\begin{array}{l}\text { Differences in IOP } \\
\text { levels at each time point }\end{array}$ & $\begin{array}{l}\text { T1A: } 2.82 \\
\text { T1B: } 3.44 \\
\text { T1D: } 2.32\end{array}$ \\
\hline
\end{tabular}




\begin{tabular}{|c|c|c|c|c|c|}
\hline $\begin{array}{l}\text { First Author } \\
\text { (Year) } \\
\text { Country } \\
\end{array}$ & 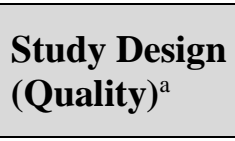 & $\begin{array}{l}\text { Participant Groups and } \\
\text { Observations/Interventions }\end{array}$ & $\begin{array}{l}\text { IOP Measures } \\
\text { (Tonometer) } \\
\text { [Head Positioning] }\end{array}$ & Outcome Measures & $\begin{array}{l}\text { Effect Sizes } \\
\text { (Cohen's } d \text { ) }\end{array}$ \\
\hline & & $\begin{array}{l}16 \text { patients undergoing } \\
\text { spine surgery in prone } \\
\text { position (D) }\end{array}$ & & & \\
\hline & & $\begin{array}{l}\text { Note. Patients with BMI > } \\
30 \mathrm{~kg} / \mathrm{m}^{2} \text { excluded. }\end{array}$ & & & \\
\hline $\begin{array}{l}\text { Emery } \\
(2015) \\
\text { United States }\end{array}$ & $\begin{array}{l}\text { Experimental } \\
\text { (High) }\end{array}$ & $\begin{array}{l}\text { - } 27 \text { patients undergoing } \\
\text { spine surgery in prone } \\
\text { position } \\
25 \text { patients undergoing } \\
\text { spine surgery in } 10^{\circ} \\
\text { reverse Trendelenburg } \\
\text { position }\end{array}$ & $\begin{array}{l}\text { Measurement of IOP at } \\
\text { six to } 19 \text { different time } \\
\text { points } \\
\text { (Tono-Pen XL) } \\
\text { [Tong traction] }\end{array}$ & $\begin{array}{l}\text { Differences in IOP } \\
\text { levels at each time point }\end{array}$ & $\mathrm{T} 1: 1.97$ \\
\hline $\begin{array}{l}\text { Hunt } \\
(2004) \\
\text { United } \\
\text { Kingdom }\end{array}$ & $\begin{array}{l}\text { Non- } \\
\text { experimental } \\
(\text { Good })\end{array}$ & $\begin{array}{l}\text { - } 10 \text { patients undergoing } \\
\text { spine surgery in prone } \\
\text { position } \\
10 \text { patients undergoing } \\
\text { spine surgery in prone } \\
\text { position }\end{array}$ & $\begin{array}{l}\text { Measurement of IOP at } \\
\text { three different time } \\
\text { points } \\
\text { (Tono-Pen XL) } \\
\text { [PL: Pillow or Ring- } \\
\text { shaped headrest } \\
\text { PN: Skull pins] }\end{array}$ & $\begin{array}{l}\text { Differences in IOP } \\
\text { levels at each time point }\end{array}$ & $\begin{array}{l}\text { T1PL: } 1.28 \\
\text { T1PN: } 1.08 \\
\text { T2PL: } 0.58 \\
\text { T2PN: } 0.5\end{array}$ \\
\hline $\begin{array}{l}\text { Nuri Deniz } \\
(2013) \\
\text { Turkey }\end{array}$ & $\begin{array}{l}\text { Experimental } \\
\text { (Good) }\end{array}$ & $\begin{array}{l}\text { - } 23 \text { patients undergoing } \\
\text { PCNL in prone position } \\
\text { - } 22 \text { patients undergoing } \\
\text { PCNL in prone position } \\
\text { with } 45^{\circ} \text { right lateral head } \\
\text { rotation }^{\mathrm{b}}\end{array}$ & $\begin{array}{l}\text { Measurement of IOP at } \\
\text { two different time } \\
\text { points } \\
\text { (Perkins MK2) } \\
\text { [Silicone headrest] }\end{array}$ & $\begin{array}{l}\text { Differences in IOP } \\
\text { levels at each time point }\end{array}$ & \\
\hline $\begin{array}{l}\text { Pinar } \\
(2018) \\
\text { Turkey }\end{array}$ & $\begin{array}{l}\text { Experimental } \\
\text { (High) }\end{array}$ & $\begin{array}{l}\text { - } 20 \text { patients undergoing } \\
\text { lumbar disc surgery in } \\
\text { prone position with general } \\
\text { anesthesia }(\mathrm{G}) \\
\text { - } 20 \text { patients undergoing } \\
\text { lumbar disc surgery in } \\
\text { prone position with spinal } \\
\text { anesthesia }(\mathrm{S})\end{array}$ & $\begin{array}{l}\text { Measurements of IOP } \\
\text { at four different time } \\
\text { points } \\
\text { (Tono-Pen AVIA) } \\
\text { [Horseshoe-shaped } \\
\text { headrest] }\end{array}$ & $\begin{array}{l}\text { Differences in IOP } \\
\text { levels at each time point }\end{array}$ & $\begin{array}{l}\text { T1G: } 0.52 \\
\text { T1S: } 0.39 \\
\text { T2G: } 3.9 \\
\text { T2S: } 2.98\end{array}$ \\
\hline
\end{tabular}




\begin{tabular}{|c|c|c|c|c|c|}
\hline $\begin{array}{l}\text { First Author } \\
\text { (Year) } \\
\text { Country } \\
\end{array}$ & 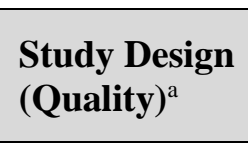 & $\begin{array}{l}\text { Participant Groups and } \\
\text { Observations/Interventions }\end{array}$ & $\begin{array}{l}\text { IOP Measures } \\
\text { (Tonometer) } \\
\text { [Head Positioning] }\end{array}$ & Outcome Measures & $\begin{array}{l}\text { Effect Sizes } \\
\text { (Cohen's } d \text { ) }\end{array}$ \\
\hline $\begin{array}{l}\text { Suguta } \\
\text { (2012) } \\
\text { Japan }\end{array}$ & $\begin{array}{l}\text { Non- } \\
\text { experimental } \\
\text { (High) }\end{array}$ & $\begin{array}{l}\text { 12 patients undergoing } \\
\text { spine surgery in prone } \\
\text { position with propofol } \\
\text { anesthesia }(\mathrm{P}) \\
12 \text { patients undergoing } \\
\text { spine surgery in prone } \\
\text { position with sevoflurane } \\
\text { anesthesia }(\mathrm{S})\end{array}$ & $\begin{array}{l}\text { Measurements of IOP } \\
\text { at five different time } \\
\text { points } \\
\text { (Tono-Pen XL) } \\
\text { [Horseshoe-shaped } \\
\text { headrest] }\end{array}$ & $\begin{array}{l}\text { Differences in IOP } \\
\text { levels at each time point }\end{array}$ & $\begin{array}{l}\text { T1P: } 3.01 \\
\text { T1S: } 3.61\end{array}$ \\
\hline
\end{tabular}

Note. $s$ = studies; IOP = intraocular pressure; $\mathrm{PCNL}=$ percutaneous nephrolithotomy; $\mathrm{BMI}=$ body mass index; $\mathrm{kg} / \mathrm{m}^{2}=\mathrm{kilograms} / \mathrm{meter}$-squared . ${ }^{a}$ Quality ratings are based on cumulative scores obtained from the Association of periOperative Registered Nurses (AORN) Research Evidence Appraisal Tool - Study.

${ }^{\mathrm{b}}$ This group was not eligible for inclusion in the meta-analysis. 
Table 4.2

Study and Participant Characteristics $(s=9 ; N=229)$

\begin{tabular}{lcc}
\hline Category & $\begin{array}{l}\text { Number of Participants } \\
\text { (Number of Studies) }\end{array}$ & $\begin{array}{l}\text { Mean } \pm \text { SD } \\
\text { (Range) or Percent }\end{array}$ \\
\hline Age (years) & $222(8)$ & $53.2 \pm 8.1$ \\
& & $(43.3-69)$ \\
Gender & $222(8)$ & 45.0 \\
Women & 100 & 55.0 \\
Men & 122 & $24.9 \pm 1.6$ \\
BMI (kg/m $\left.{ }^{2}\right)$ & $155(5)$ & $(22.5-27.7)$ \\
& & 100 \\
ASA Class I, II, or III & $130(5)$ & \\
Surgery type & $229(9)$ & 7.0 \\
Cranial & 16 & 18.8 \\
PCNL & 43 & 74.2 \\
Spine & 170 & \\
Anesthesia & $222(8)$ & 51.8 \\
General-Inhalation & 115 & 27.0 \\
General-Propofol & 60 & 12.2 \\
General-Unspecified & 27 & 9.0 \\
Spinal & 20 & \\
Duration (min) & & $247.0 \pm 9.9$ \\
Anesthesia & $24(1)$ & $(240-254)$ \\
& & $161.6 \pm 70.9$ \\
Prone position & $44(2)$ & $(80-203)$ \\
& & $156.0 \pm 24.2$ \\
Surgery & $74(4)$ & $(120-181)$ \\
& $95(3)$ & $(120-615)$ \\
Estimated blood loss (mL) & & \\
& &
\end{tabular}

Note. $s=$ studies; $S D=$ standard deviation; BMI = body mass index; $\mathrm{kg} / \mathrm{m}^{2}=$ kilograms $/ \mathrm{meter}$-squared; ASA = American Society of Anesthesiologists Physical Classification Status; PCNL = percutaneous nephrolithotomy; $\mathrm{min}=$ minutes; $\mathrm{mL}$ $=$ milliliters. 
Table 4.3

Effect Sizes and Magnitude of Change in IOP for T1 through T2 $(s=9 ; N=229)$.

\begin{tabular}{|c|c|c|c|c|c|c|c|c|c|c|c|}
\hline \multirow{2}{*}{$\begin{array}{l}\text { Time } \\
\text { Points }\end{array}$} & \multirow[b]{2}{*}{$s$} & \multirow{2}{*}{$\boldsymbol{k}$} & \multirow{2}{*}{$n$} & \multirow{2}{*}{ Model } & \multirow{2}{*}{$d$} & \multicolumn{2}{|c|}{$95 \% \mathrm{CI}$} & \multirow{2}{*}{$\mathbf{Q}$} & \multirow{2}{*}{$I^{2}$} & \multirow{2}{*}{ Mean change in IOPa } & \multirow{2}{*}{ Prediction Interval $^{b}$} \\
\hline & & & & & & $L L$ & $U L$ & & & & \\
\hline $\mathrm{T} 1$ & 6 & 11 & 179 & $\mathrm{R}$ & $2.55^{*}$ & 1.61 & 3.5 & $117.8 *$ & 91.5 & $+7.5 \mathrm{mmHg}$ & $+2.6 \mathrm{mmHg}$ to $+19.8 \mathrm{mmHg}$ \\
\hline
\end{tabular}

Note. $s=$ studies; $k=$ comparisons; $d=$ standardized mean difference; $\mathrm{CI}=$ confidence interval; $L L$ lower limit; $U L=$ upper limit; $\mathrm{Q}=\mathrm{Cochrane}$ 's $\mathrm{Q} ; I^{2}$ $=$ heterogeneity statistic $; \mathrm{IOP}=$ intraocular pressure; $\mathrm{T}=$ time point $; \mathrm{R}=$ random effects; $\mathrm{mmHg}=$ millimeters of mercury.

${ }^{a}$ Mean effect sizes were converted to the metric used to measure IOP (i.e., mmHg) following the procedures described by Lipsey and Wilson (2001). Lipsey, M. W., \& Wilson, D. B. (2001). Interpreting and using meta-analysis results. In Practical meta-analysis: Applied social research (Vol 49, pp. 146-168). Thousand Oaks, CA: Sage. $* p \leq 0.001 ; * * p=0.002$.

${ }^{\mathrm{b}}$ In $95 \%$ of all populations, the true effect size will fall within this range. 


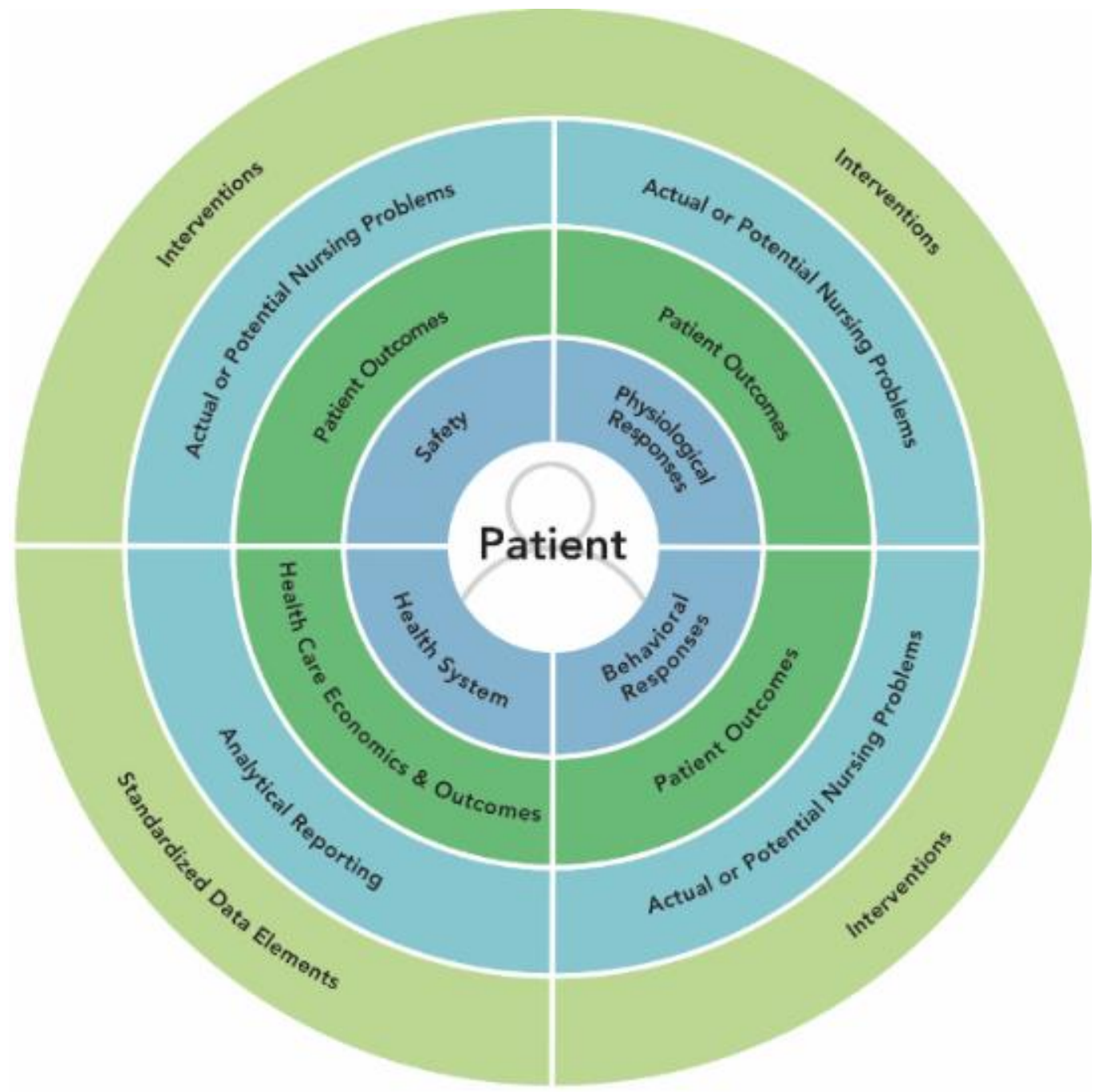

Figure 4.1. Perioperative Patient Focused Model (2017). Reprinted with permission from Guidelines for Perioperative Practice. Copyright (C) 2018, AORN, Inc, 2170 S. Parker Road, Suite 400, Denver, CO 80231. All rights reserved. 


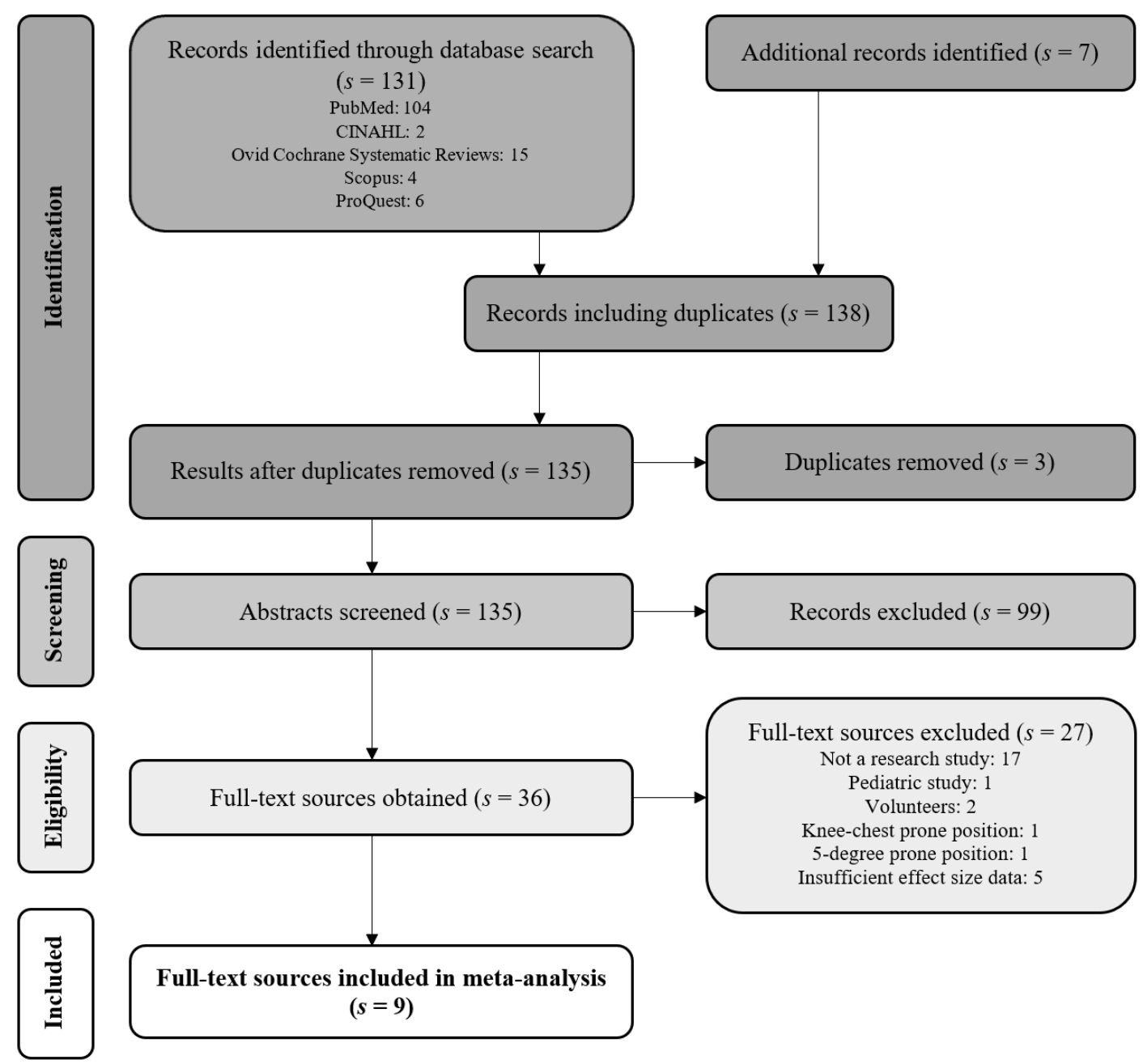

Figure 4.2. Flow diagram of meta-analysis study selection. Note. $s=$ studies. Adapted from Moher D, Liberati A, Tetzlaff J, Atman DG, PRISMA Group (2009). Preferred Reporting Items for Systematic Reviews and Meta-Analyses: The PRISMA Statement. PLoS Medicine, 6(6), e1000097. doi:10.1371/journal.pmed1000097 


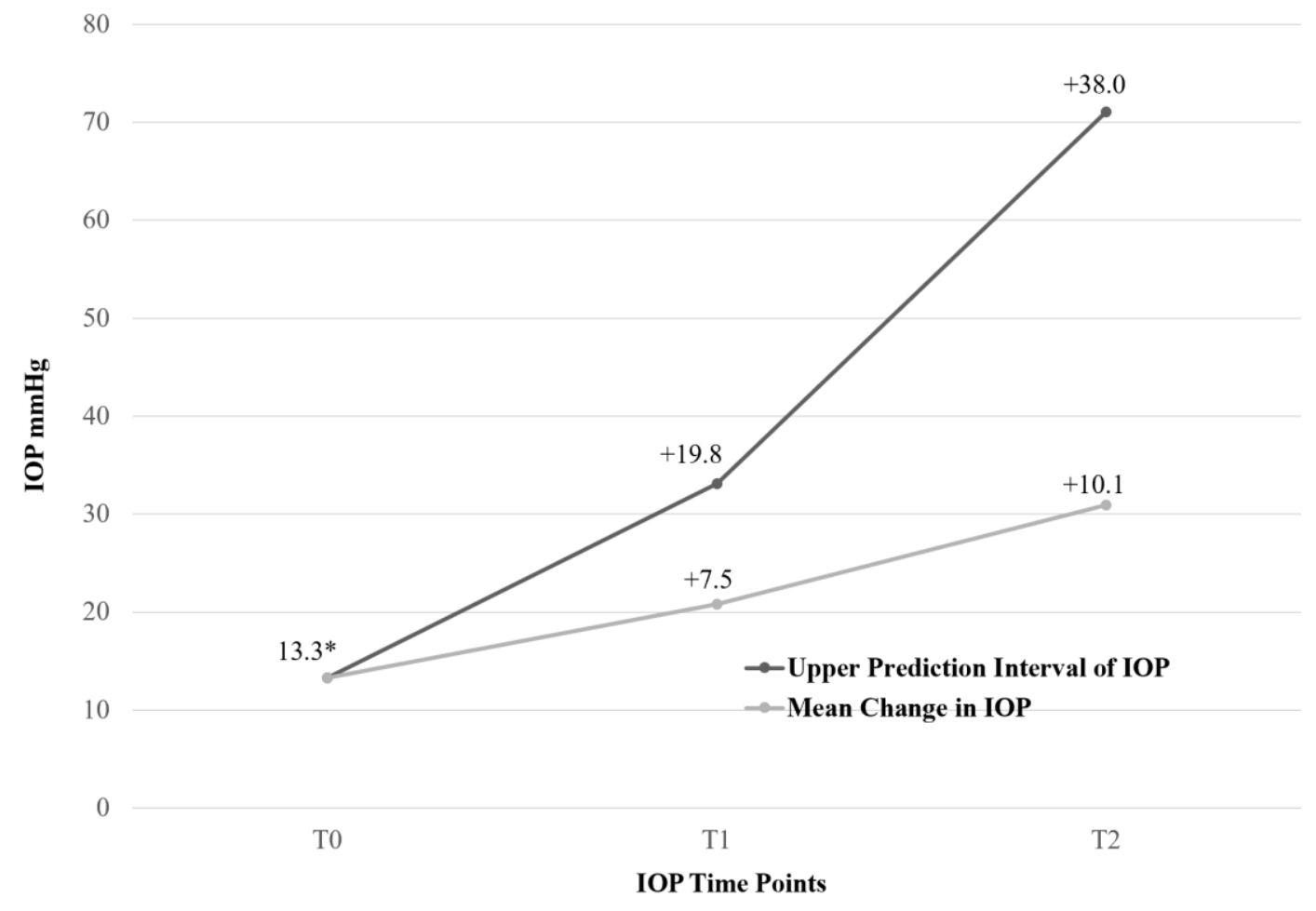

Figure 4.3. Magnitude of change in IOP and upper prediction intervals of IOP for T0 through $\mathrm{T} 2$. Note $. \mathrm{IOP}=$ intraocular pressure; $\mathrm{mmHg}=$ millimeters of mercury; $\mathrm{T}=$ time point. Intraocular pressure increases significantly when the patient is placed in prone position (T1: $+7.5 \mathrm{mmHg} ; p<0.001$ ), and continues to increase significantly until the end of prone position $(\mathrm{T} 2:+10.1 \mathrm{mmHg} ; p=0.002)$. The upper prediction interval shows that in $95 \%$ of all populations, at the end of prone position, IOP could increase to 71.1 $\mathrm{mmHg}(13.3 \mathrm{mmHg}+19.8 \mathrm{mmHg}+38.0 \mathrm{mmHg}=71.1 \mathrm{mmHg}) . *$ Pooled mean at $\mathrm{T} 0-$ After induction of anesthesia. 


\begin{tabular}{|c|c|c|c|c|c|c|c|c|c|c|}
\hline \multirow[t]{2}{*}{$\underline{\text { Study name }}$} & \multicolumn{7}{|c|}{$\underline{\text { Statistics for each study }}$} & \multicolumn{3}{|c|}{$\underline{\text { Std diff in means and } 95 \% \mathrm{CI}}$} \\
\hline & $\begin{array}{l}\text { Std diff } \\
\text { in means }\end{array}$ & $\begin{array}{l}\text { Standard } \\
\text { error }\end{array}$ & Variance & $\begin{array}{c}\text { Lower } \\
\text { limit }\end{array}$ & $\begin{array}{c}\text { Upper } \\
\text { limit }\end{array}$ & Z-Value & p-Value & & & \\
\hline Agah & 11.345 & 1.307 & 1.709 & 8.783 & 13.907 & 8.679 & 0.000 & & & \\
\hline Czorlich-A & 2.820 & 0.499 & 0.249 & 1.842 & 3.799 & 5.649 & 0.000 & & & \\
\hline Czorlich-B & 3.440 & 0.557 & 0.310 & 2.349 & 4.531 & 6.179 & 0.000 & & & \\
\hline Czorlich-D & 2.316 & 0.457 & 0.209 & 1.420 & 3.211 & 5.068 & 0.000 & & & \\
\hline Emery & 1.966 & 0.331 & 0.110 & 1.316 & 2.615 & 5.931 & 0.000 & & & \\
\hline Hunt-PL & 1.276 & 0.491 & 0.241 & 0.314 & 2.237 & 2.600 & 0.009 & & & \\
\hline Hunt-PN & 1.079 & 0.479 & 0.229 & 0.141 & 2.017 & 2.254 & 0.024 & & & \\
\hline Pinar-G & 0.517 & 0.321 & 0.103 & -0.113 & 1.147 & 1.607 & 0.108 & & & \\
\hline Pinar-S & 0.386 & 0.319 & 0.102 & -0.240 & 1.011 & 1.208 & 0.227 & & & \\
\hline Sugata-P & 3.012 & 0.596 & 0.356 & 1.843 & 4.181 & 5.051 & 0.000 & & & \\
\hline \multirow[t]{4}{*}{ Sugata-S } & 3.608 & 0.662 & 0.438 & 2.311 & 4.905 & 5.452 & 0.000 & & & \\
\hline & 2.553 & 0.483 & 0.233 & 1.607 & 3.499 & 5.291 & 0.000 & & & \\
\hline & & & & & & & & -8.00 & -4.00 & 0.00 \\
\hline & & & & & & & & \multicolumn{3}{|c|}{ After Induction } \\
\hline
\end{tabular}

Figure 4.4. Forest plot of meta-analysis of T1. Note. $\mathrm{T}=$ time point; Std $=$ Standard; $\min$ $=$ minutes. This analysis included six studies representing 11 participant groups $(n=$ 179). Effect sizes were calculated using a random effects model. The area of each square is proportional to study weight. 


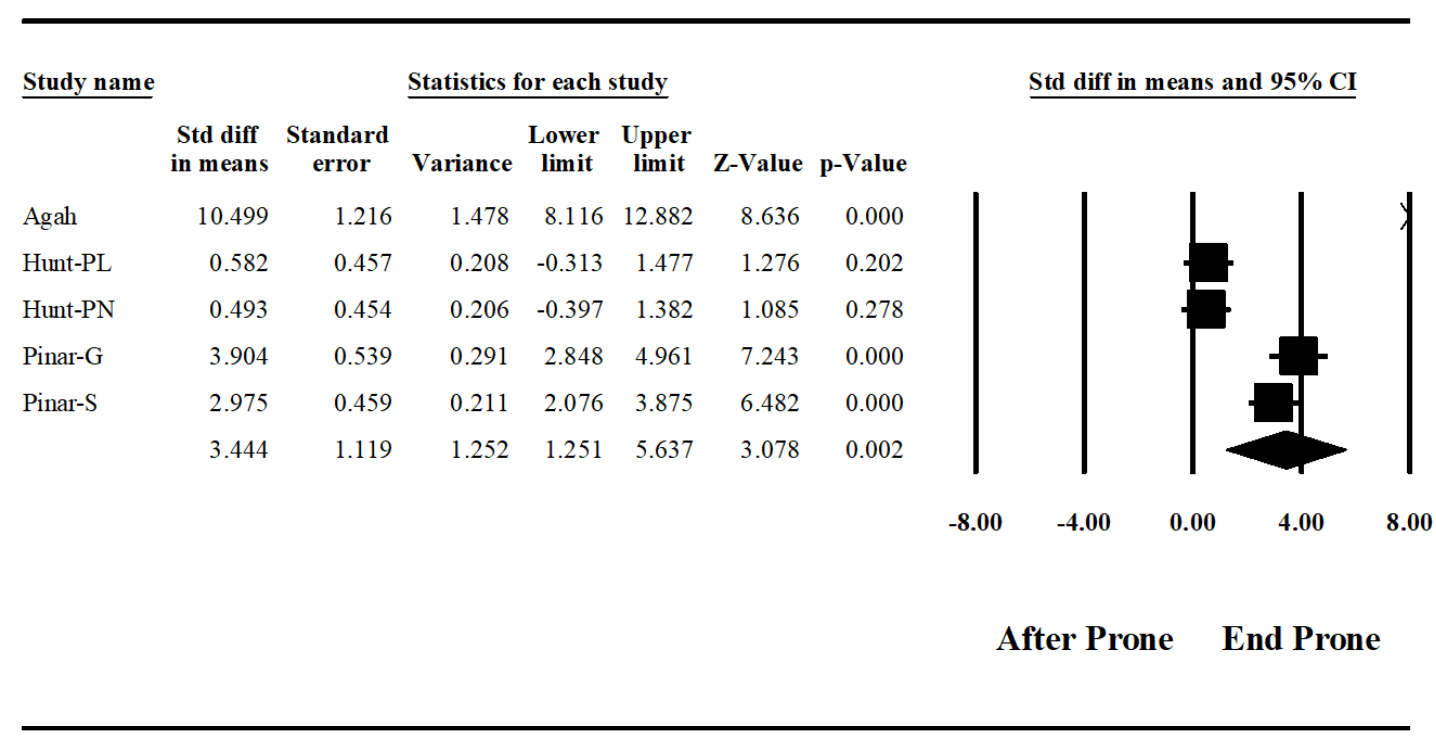

Figure 4.5. Forest plot of meta-analysis of T2. Note. $\mathrm{T}=$ time point; $\mathrm{Std}=$ Standard; $\min$ $=$ minutes. This analysis included three studies representing five participant groups $(n=$ 80). Effect sizes were calculated using a random effects model. The area of each square is proportional to study weight. 


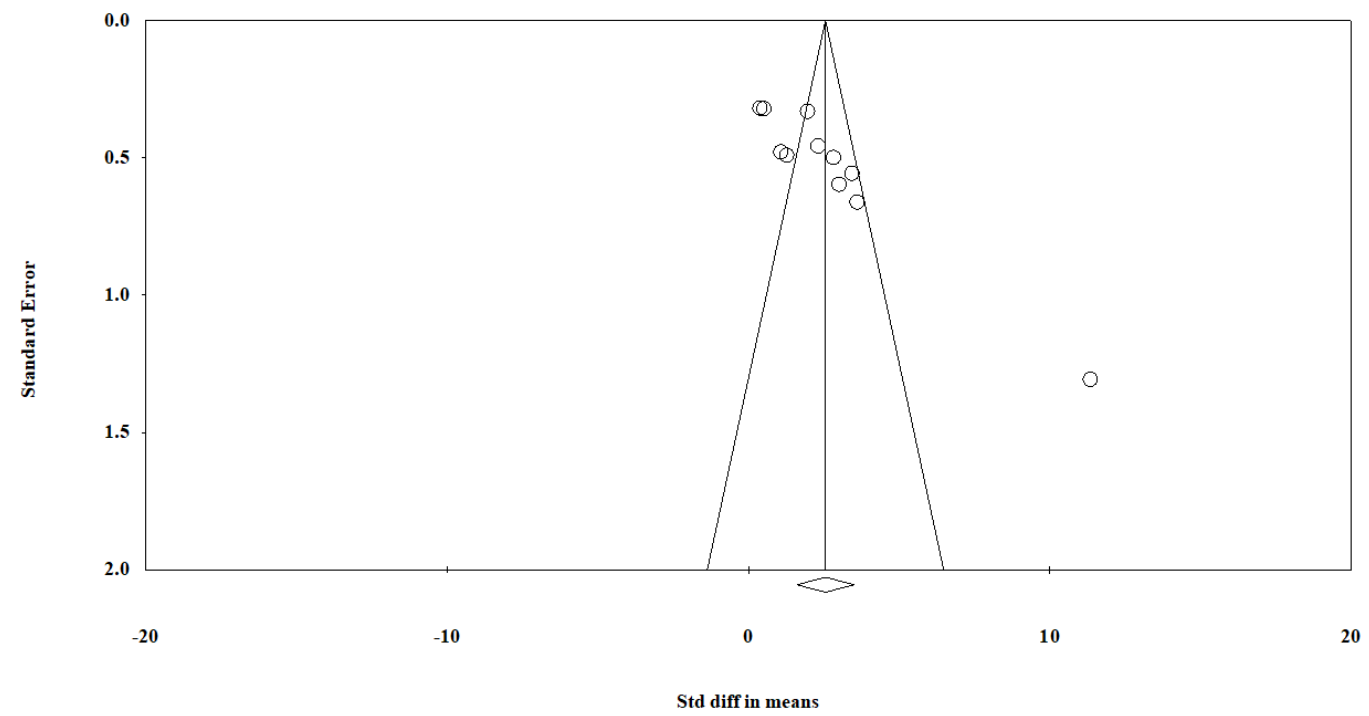

Figure 4.6. Funnel plot of publication bias for $\mathrm{T} 1$. Note $. \mathrm{T}=$ time point; $\mathrm{Std}=$ standard. Larger studies are shown at the top of the funnel. Positive smaller studies should appear at the right of the mean effect size (i.e., center line). The significant Egger's regression intercept for this funnel plot (bias $=9.2 ; p=0.00019$ ) may be indicative of potential publication bias in the studies included in the meta-analysis for this time point. However, Orwin's Fail-safe $N$ is $177(S M D=1.71)$, suggesting a need for 177 additional studies with an effect size of 0 before the cumulative effect would become trivial (defined as a Cohen's $d$ of 0.1 ). 


\section{SUMMARY}

The results of the systematic reviews and meta-analyses have shown that intraocular pressure (IOP) increases significantly for adult patients undergoing surgery in the Trendelenburg and prone positions. Increased IOP puts the patient at risk for glaucoma, detached retina, or partial to complete vision loss (Amorim Correa \& Acioly, 2018; Astuto, Minardi, Uva, \& Gullo, 2011; Borahay et al., 2013; Emery et al., 2015; Ghomi, Kramer, Askari, Chavan, \& Einarsson, 2012; Gkegkes, Karydis, Tyritzis, \& Iavazzo, 2015; Gould, Cull, Wu, \& Osmundsen, 2012; Grosso et al., 2013; Hoshikawa et al., 2014; Kwee, Ho, \& Rozen, 2015; Lee \& Newman, 2018; Leibovitch, Casson, Laforest, \& Selva, 2006; Taketani et al., 2015). Intraocular pressure increases of the magnitude found in these systematic reviews and meta-analyses demonstrate the need for implementing intraoperative interventions to mitigate the increase in IOP and reduce the potential for postoperative vision loss and other ocular complications in patients undergoing surgery in the Trendelenburg and prone position.

\section{Recommendations for Patients Undergoing Surgery in the Trendelenburg Position}

Interventions that may be helpful for mitigating or reducing IOP when the patient is undergoing surgery in the Trendelenburg position include

- monitoring IOP at established intervals or continuously (Hoshikawa et al., 2013; Lee, Dallas, Daniel, \& Cotter, 2016; Vitish-Sharma et al., 2018),

- reducing the degree of Trendelenburg position (Ghomi et al., 2012; Mathew et al., 2018; Ozcan et al., 2017; Raz et al., 2015),

- implementing a modified Trendelenburg position (Raz et al., 2015), 
- providing periodic position changes or rest periods (Blecha et al., 2017; Borahay et al., 2013; Freshcoln \& Diehl, 2014; Gkegkes et al., 2015; Gould et al., 2012; Mizrahi, Hugkulstone, Vyakarnam, \& Parker, 2011; Molloy \& Watson, 2012), and

- administering specific medications or anesthetics (Agrawal, Dureja, Verma, \& Kang, 2013; Hwang et al., 2013; Joo, Koh, Lee, \& Lee, 2016; Joo, Kim, \& Lee, 2017; Kan, Brown, \& Gainsburg, 2015; Kaur, Sharma, Kalra, Purohit, \& Chauhan, 2018; Kim et al., 2015; Mathew et al., 2018; Molloy, Cong, \& Watson, 2016; Mowafi, Al-Ghamdi, \& Rushood, 2003).

Because IOP increases during abdominal insufflation and Trendelenburg position, intraoperative monitoring of IOP either continuously or at established intervals or time points (e.g., after abdominal insufflation, after initiation of Trendelenburg position, after 60 minutes of Trendelenburg position, etc.) seems prudent. Elevated IOPs can be an indication of ocular venous congestion and decreased perfusion of the optic nerve (Yoo et al., 2014). Monitoring IOP can provide a baseline IOP and an objective measure that can help the surgical team maintain awareness of the patient's IOP, implement interventions to reduce IOP as needed, and thus reduce the potential for ocular complications and postoperative vision loss (Hoshikawa et al., 2013; Lee et al., 2016).

Steeper degrees of Trendelenburg increase the risk for postoperative complications because they place greater physiologic stress on the patient's body (Ghomi et al., 2012; Gould et al., 2012; Kadono et al., 2013). Ghomi et al., (2012) found that robotic-assisted gynecologic surgery could be performed successfully with a modest head-down tilt of 16.4 degrees. In a study to determine the head-down tilt necessary to provide surgical access and visibility, Gould et al., (2012) found the mean head-down tilt 
most often selected by the surgeons was 28.1 degrees, which was much less than the 40 degree head-down tilt the surgeons were using.

Raz et al., (2015) found that modifying the Trendelenburg position so that the patient's head and shoulders remained level significantly decreased IOP and accelerated its return to baseline levels. Implementing periodic intraoperative position changes or rest periods in supine position (or positions where the ocular level is above the heart) can help to reduce IOP. In a quasi-experimental study, Molloy and Watson (2012) implemented a five-to-seven-minute level supine intervention after 60 minutes of 32-degree to 40-degree Trendelenburg position and found there was a significant decrease in IOP after 120 minutes of Trendelenburg position. The dramatic and significant decrease in IOP that occurs before arousal from anesthesia found in this systematic review and meta-analysis (T5: -7.5 mmHg, $p<0.001$; T7: $-8.2 \mathrm{mmHg}, p<0.001$; T9: $-6.0 \mathrm{mmHg}, p<0.001$ ) also supports the implementation of periodic intraoperative position changes or rest periods as a mechanism to help reduce IOP.

Administering specific medications or anesthetics may also be effective in reducing IOP or mitigating the intraoperative increase in IOP (Agrawal et al., 2013; Hwang et al., 2013; Joo et al., 2016; Joo et al., 2017; Lee et al., 2016; Kaur et al., 2018; Kim et al., 2015; Mathew et al., 2018; Molloy et al., 2016; Mowafi et al., 2003). Agrawal et al., (2013) found that induction and maintenance of anesthesia with intravenous propofol was the most effective option for mitigating the increase in IOP in adult patients undergoing surgery in the Trendelenburg position. Likewise, Kaur et al., (2018) found that propofol-based total intravenous anesthesia was more effective than inhalational anesthesia with sevoflurane in mitigating the increase in IOP in patients undergoing 
laparoscopic surgery in the Trendelenburg position. Kitamura et al., (2018) found that continuous administration of dexmedetomidine in combination with propofol-based total intravenous anesthesia decreased IOP in patients undergoing robotic-assisted laparoscopic radical prostatectomy. Molloy and Cong (2014) found that intraoperative treatment with dorzolamide-timolol eyedrops significantly reduced elevated IOP in patients undergoing lengthy laparoscopic procedures in the Trendelenburg position, while Molloy et al., (2016) found that prophylactic therapy with dorzolamide-timolol eyedrops significantly reduced IOP in patients undergoing robotic-assisted laparoscopic prostate and gynecologic procedures.

\section{Recommendations for Patients Undergoing Surgery in the Prone Position}

Interventions that may be helpful for mitigating or reducing IOP when the patient is undergoing surgery in the prone position include

- positioning the patient in a 5-degree to 10-degree reverse Trendelenburg prone position (Carey, Shaw, Weber, \& DeVine, 2014; Emery et al., 2015; Fukui, Ahmad, McHugh, Tempelhoff, \& Cheng, 2004; Fukui, Tempelhoff, \& Cheng, 2005; Ozcan et al., 2004; Walick, Kragh, Ward, \& Crawford, 2007),

- monitoring IOP at established intervals or continuously (Eddama, 2013; Yoshimura, Hayashi, Tanake, Nomura, \& Kawaguchi, 2015),

- reducing the length of time the patient is in the prone position,

- $\quad$ staging procedures when patients will be in the prone position for prolonged periods of time (ASA Task Force on Perioperative Visual Loss, North American NeuroOphthalmology Society, \& Society for Neuroscience in Anesthesiology and Critical Care, 2019), 
- providing periodic position changes or rest periods (Molloy \& Watson, 2012),

- preventing direct pressure on the patient's eyes and assessing and monitoring the eyes at regular intervals during the procedures (ASA Task Force on Perioperative Visual Loss et al, 2019; Locastro, Novak, \& Biglan, 1991; Nickels, Manlapaz, \& Farag, 2014; Shifa, Abebe, Bekele, \& Habte, 2016),

- avoiding specific headrests or positioning devices that may increase pressure on the eye or using skull pins or tongs to position the head (Asok, Aziz, Faisal, Tan, \& Mallika, 2009; Bekar, Türeyen, \& Aksoy, 1996; Grossman \& Ward, 1993;

Hollenhorst, Svien, \& Benoit, 1954; Hoski, Eismont, \& Green, 1993; Quraishi, Wolinsky, \& Gokaslan, 2012; Wolfe, Lospinuso, \& Burke, 1992), and

- administering specific medications or anesthetics (Farag et al., 2012; Pinar et al., 2018; Sugata et al., 2012).

Positioning the patient in a 5-degree to 10-degree reverse Trendelenburg prone position may be a simple intervention to prevent some instances of postoperative vision loss. This position has been shown to decrease IOP in healthy volunteers (Ozcan et al, 2004; Walick et al., 2007) and in patients undergoing spine surgery (Carey et al., 2014; Emery et al., 2015; Fukui et al., 2004; Fukui et al., 2005). Positioning surgical patients with the head above the heart helps reduce venous congestion in the eye and orbit and decrease intraocular and intraorbital pressure (Bonnaig, Dailey, \& Archdeacon, 2014; Carey et al., 2014; Grant et al., 2010; Kamel, \& Barnette, 2014; Nickels et al., 2014).

Reducing the length of time the patient is in the prone position may also help to mitigate the increase in IOP. The ASA Task Force on Perioperative Visual Loss et al., (2019) suggests staging procedures when patients will be in the prone position for 
prolonged periods of time. Utilizing a series of shorter procedures rather than one prolonged procedure may help reduce the patient's risk for postoperative vision loss; however, the risks associated with multiple surgeries may outweigh the benefits of staged procedures (Shifa et al., 2016).

Because IOP increases during prone position, intraoperative monitoring of IOP either continuously or at established intervals or time points (e.g., after initiation of prone position, after every 60 minutes of prone position) seems prudent. Yoshimura et al., (2015) suggested that measuring IOPs after one hour of surgery in the prone position could provide an opportunity for implementing interventions to prevent additional increases in IOP. Eddama (2013) also suggested that regular measurement of IOP during prolonged surgery provided an opportunity for implementing a change in the patient's position when critical thresholds are reached. Implementing periodic intraoperative position changes or rest periods (where the ocular level is above the heart) can help to reduce IOP. In a quasi-experimental study, Molloy and Watson (2012) implemented a five-to-seven-minute level supine intervention after 60 minutes of steep Trendelenburg position and found there was a significant decrease in IOP.

When the patient is in the prone position, there is a risk for direct compression on the eye (Bonnaig et al., 2014). Yu, Chou, Yang, and Chang (2010) found that the prone position was a precipitating factor for eye injury. Preventing direct pressure and assessing and monitoring the patient's eyes at regular intervals throughout the procedure may help to reduce the incidence of postoperative vision loss (ASA Task Force on Perioperative Visual Loss et al, 2019; Locastro et al., 1991; Nickels et al., 2014; Shifa et al., 2016). Avoiding specific headrests or positioning devices that may increase pressure on the eye 
(e.g., horseshoe-shaped, Wilson frame), or using skull pins or tongs to position the head may also help to prevent pressure on the orbits and reduce the risk for postoperative vision loss and other ocular complications (Asok et al., 2009; Bekar et al., 1996; Grossman \& Ward, 1993; Hollenhorst et al., 1954; Hoski et al., 1993; Quraishi et al., 2012; Wolfe et al., 1992). Direct compression from a horseshoe-shaped head positioner has been reported as a cause of postoperative vision loss when the patient is in the prone position (Abraham, Sakhuja, Sinha, \& Rastogi, 2003; Bekar et al., 1996; Grossman \& Ward, 1993; Hollenhorst et al., 1954; Hoski et al., 1993; Locastro et al., 1991; Wolfe et al., 1992). In a case-controlled study of 80 patients with ischemic optic neuropathy compared with 315 matched control patients, the ASA Postoperative Visual Loss Study Group (2012) found that Wilson frame use was an independent risk factor for postoperative vision loss.

Administering specific medications or anesthetics may also be effective in reducing IOP or mitigating the intraoperative increase in IOP (Farag et al., 2012; Pinar et al., 2018; Sugata et al., 2012). Pinar et al., (2018) found that the increase in IOP was significantly less in patients undergoing lumbar disc surgery in the prone position under spinal anesthesia compared with patients receiving general anesthesia. Sugata et al., (2012) found that IOPs were higher in patients undergoing prone spine surgery with general anesthesia maintained with sevoflurane compared with patients receiving general anesthesia maintained with intravenous propofol. Farag et al., (2012) found that the administration of topical brimonidine $2 \%$ helped reduce intraoperative IOP.

\section{Recommendations for Preoperative Ophthalmologic Examinations}


Another important consideration is the need to determine whether patients undergoing surgery in the Trendelenburg or prone positions should receive a preoperative ophthalmologic examination to reduce the risk for ocular injury (Akhaddar \& Boucetta, 2012; ASA Task Force on Perioperative Visual Loss et al., 2019; Borahay et al., 2013; Lee et al., 2016; Singer \& Salim, 2010; Stang-Veldhouse, Yeu, Rothenberg, \& Mizen, 2010; Stewart, Landy, \& Lee, 2016). Preoperative ophthalmologic examinations may be helpful in identifying patients at risk for postoperative vision loss. Increases in IOP may be more harmful in older patients or patients who are predisposed to developing diabetes or glaucoma than in younger, healthier patients (Akhaddar \& Boucetta, 2012; ASA Task Force on Perioperative Visual Loss et al., 2019; Borahay et al., 2013; Grosso et al., 2013; Mondzelewski et al., 2015; Singer \& Salim, 2010; Stang-Veldhouse et al., 2010; Stewart et al., 2016; Taketani et al., 2015). Patients at risk for acute angle-closure glaucoma associated with the prone position may benefit from preoperative laser iridotomy (Singer \& Salim, 2010; Stewart et al., 2016). The ASA Task Force on Perioperative Visual Loss et al., (2019) recommend evaluating the need for preoperative ophthalmologic examination on a case-by-case basis.

\section{Perioperative Patient Focused Model}

The results of this systematic review and meta-analysis support the use of the Perioperative Patient Focused Model as the conceptual foundation for this perioperative research. Providing quantitative evidence about the magnitude of the intraoperative increase in IOP resulting from the Trendelenburg and prone positions supports the implementation of nursing interventions that are patient-focused and will improve patient 
outcomes by mitigating increases in IOP and reducing the risk for permanent postoperative vision loss and other ocular complications in adult surgical patients.

\section{Conclusion}

Intraocular pressure increases significantly between abdominal insufflation in supine position and 240 minutes of Trendelenburg position. The greatest increases in IOP occur after insufflation of the abdomen while the patient is in the supine position and within five minutes after the patient is placed into the Trendelenburg position. The IOP continues to increase significantly while the patient is in Trendelenburg position, but to a lesser degree. Intraocular pressure increases significantly while the patient is in the prone position. The greatest increase in IOP occurs within 10 minutes after the patient is placed into the prone position. The IOP continues to increase significantly while the patient is in prone position, but to a lesser degree. Intraocular pressure increases of the magnitude found in these systematic reviews and meta-analyses clearly demonstrate the need for implementing interventions to mitigate or lessen the increase in IOP and reduce the risk for postoperative vision loss and other ocular complications in patients undergoing surgery in the Trendelenburg and prone positions. 
Appendix A-1

\section{AOR N AORN RESEARCH EVIDENCE APPRAISAL TOOL - STUDY}

DATE REVIEWER

APPRAISAL SCORE

\begin{tabular}{|l|l|l|l|l|l|l}
\hline RW\# & CITATION \\
\hline
\end{tabular}

Does this evidence address the perioperative practice question?

$\square$ Yes $\square$ No - Do not proceed with evidence appraisal.

Does this evidence have a major flaw?

$\square$ No $\square$ Yes - Determine level of evidence and score quality as C.

Provide explanation of flaw in comments.

LEVEL OF EVIDENCE

Is this a report of a single research study?

$\square$ Yes $\square$ No (If No, go to the AORN Research Evidence Appraisal Tool - Summary)

INTERVENTION/MANIPULATION $\square$ Yes $\square$ No

The researcher performed an intervention with at least some of the participants

(ie, there was some type of treatment being tested).

CONTROL/COMPARISON GROUP $\quad \square$ Yes $\square$ No

The researcher provided standard care or a comparison intervention

that was different from the experimental intervention.

RANDOM ASSIGNMENT $\square$ Yes $\square$ No

The researcher assigned participants to a control or treatment group

on a random basis ( $\mathrm{ie}$, in a manner determined by chance).

\begin{tabular}{l|ll}
\hline YES to Intervention/Manipulation, & c LEVEL I & Randomized Controlled Trial (RCT)
\end{tabular}

Control/Comparison Group, and

Random Assignment

YES to Intervention/Manipulation or

YES to Intervention/Manipulation, and Control/Comparison Group

口 LEVEL II Quasi-Experimental (eg, controlled trial, controlled trial without randomization,

NO to Intervention/Manipulation pre-test/post-test, time series)

口 LEVEL III Non-Experimental (eg, descriptive, comparative, observational, correlational, case-control, retrospective, cross-sectional)

口 LEVEL III Qualitative (eg, interviews, surveys, focus groups)

ADDITIONAL COMMENTS: 
Appendix A-2

\begin{tabular}{|c|c|c|c|c|}
\hline QUALITY OF EVIDENCE & $\begin{array}{c}\text { A } \\
\text { HIGH }\end{array}$ & $\begin{array}{c}\text { B } \\
\text { GOOD }\end{array}$ & $\begin{array}{c}\text { C } \\
\text { Low }\end{array}$ & NA \\
\hline \multicolumn{5}{|l|}{ PURPOSE/BACKGROUND } \\
\hline - Was the purpose of the systematic review clearly defined? & & & & \\
\hline - Was the research question clear? & & & & \\
\hline $\begin{array}{l}\text { - Did the researcher(s) identify what is known and not known about the research question } \\
\text { and how the systematic review would address any gaps in knowledge? }\end{array}$ & & & & \\
\hline \multicolumn{5}{|l|}{ SEARCH } \\
\hline - Was the search strategy reproducible? & & & & \\
\hline - Were the key search terms stated? & & & & \\
\hline - Were multiple databases searched and identified? & & & & \\
\hline - Was the inclusion/exclusion criteria described? & & & & \\
\hline - Was both published and unpublished literature identified and retrieved where possible? & & & & \\
\hline - Are the types of studies to be included in the review described? & & & & \\
\hline \multicolumn{5}{|l|}{ EVIDENCE REVIEW } \\
\hline - Was there an explanation of the number of studies eliminated at each level of review? & & & & \\
\hline $\begin{array}{l}\text { - Were the details of the included studies presented (design, sample, methods, results, } \\
\text { outcomes, strengths, limitations)? }\end{array}$ & & & & \\
\hline - Were methods for appraising the strength of evidence (level and quality) rigorous? & & & & \\
\hline $\begin{array}{l}\text { - Was the evidence reviewed and appraised by at least two members of the } \\
\text { research team? }\end{array}$ & & & & \\
\hline - Were the supporting references the most current available? & & & & \\
\hline - Were the supporting references relevant to the research question? & & & & \\
\hline \multicolumn{5}{|l|}{ DATA COLLECTION } \\
\hline - Were methods of statistical analysis described? & & & & \\
\hline - Were methods of retrieving data from the individual studies described? & & & & \\
\hline - Was the data extracted by at least two members of the research team? & & & & \\
\hline \multicolumn{5}{|l|}{ RESULTS/CONCLUSIONS } \\
\hline $\begin{array}{l}\text { - Were the conclusions of the researcher(s) consistent with the results of the studies and } \\
\text { the overall strength of the evidence? }\end{array}$ & & & & \\
\hline $\begin{array}{l}\text { - Was the strength of the phenomenon being studied quantified in a summary statistic } \\
\text { (ie, effect size) that can be compared across the studies? }\end{array}$ & & & & \\
\hline \multicolumn{5}{|l|}{ LIMITATIONS/FUTURE RESEARCH } \\
\hline - Were limitations of the review discussed? & & & & \\
\hline FINAL QUALITY SCORE & & & & \\
\hline
\end{tabular}

Reprinted with permission. Copyright (C) 2015, AORN, Inc, 2170 S. Parker Road, Suite

400, Denver, CO 80231. All rights reserved. 


\section{REFERENCES}

Abraham, M., Sakhuja, N., Sinha, S., \& Rastogi, S. (2003). Unilateral visual loss after cervical spine surgery. Journal of Neurosurgical Anesthesiology, 15(4), 319-322.

Adisa, A. O., Onakpoya, O. H., Adenekan, A. T., \& Awe, O. O. (2016). Intraocular pressure changes with positioning during laparoscopy. Journal of the Society of Laparoendoscopic Surgeons, 20(4), e2016.00078. doi: 10.4293/JSLS.2016.00078

Agah, M., Ghasemi, M., Roodneshin, F., Radpay, B., \& Moradian, S. (2011). Prone position in percutaneous nephrolithotomy and postoperative visual loss. Urology Journal, 8(3), 191-196.

Agrawal, M., Dureja, V., Verma, A. P., \& Kang, L. S. (2013). A comparative study of four combinations of anesthetic drugs for assessing the intraocular pressure changes during gynaecological laparoscopic procedures. Anesthesia Essays and Researches, 7(3), 319-325. doi: 10.4103/0259-1162.123221

Akhaddar, A., \& Boucetta, M. (2012). Subconjunctival hemorrhage as a complication of intraoperative positioning for lumbar spinal surgery. Spine Journal, 12(3), 274. doi: 10.1016/j.spinee.2012.02.007

Akhavan, A., Gainsburg, D. M., \& Stock, J. A. (2010). Complications associated with patient positioning in urologic surgery. Urology, 76(6), 1309-1316. doi: 10.1016/j.urology.2010.02.060

American Academy of Ophthalmology. (2018). Intraocular pressure. Retrieved from https://www.aao.org/bcscsnippetdetail.aspx?id=f010bbf6-3f3e-486b-b5cd0ad86ddb9d74 
American Academy of Orthopaedic Surgeons. (2014). Annual incidence of common musculoskeletal procedures and treatment. Retrieved from https://www.aaos.org/research/stats/CommonProceduresTreatmentsMarch2014.pdf

American Hospital Association (2019). Hospital Utilization Rates By Type Of Hospital: 1990 To 2016 [Selected Years] ProQuest Statistical Abstract of the U.S. 2019 Online Edition. Retrieved from https://statabs.proquest.com/sa/docview.html?table-no=190\&acc-no=C70951.3\&year=2019\&z=BE4C43C6A1BEC87A17D914F8F4771ED45FDB185B American Society of Anesthesiologists. (2018). ASA Physical Status Classification System. Retrieved from https://www.asahq.org/standards-and-guidelines/asaphysical-status-classification-system

American Society of Anesthesiologists Postoperative Visual Loss Study Group. (2012). Risk factors associated with ischemic optic neuropathy after spinal fusion surgery. Anesthesiology, 116(1), 15-24. doi: 10.1097/ALN.0b013e31823d012a

American Society of Anesthesiologists Task Force on Perioperative Visual Loss, North American Neuro-Ophthalmology Society, \& Society for Neuroscience in Anesthesiology and Critical Care. (2019). Practice Advisory for Perioperative Visual Loss Associated with Spine Surgery. Anesthesiology, 130(1), 12-30. doi: 10.1097/ALN.0000000000002503

Amorim Correa, J. L., \& Acioly, M. A. (2018). The enigma of orbital compartment syndrome after lumbar spine surgery in the prone position: Case report and 
literature review. World Neurosurgery, 110, 309-314. doi:

10.1016/j.wneu.2017.11.111

Asok, T., Aziz, S., Faisal, H. A., Tan, A. K., \& Mallika, P. S. (2009). Central retinal artery occlusion and opthalmoplegia following spine surgery in the prone position. Medical Journal of Malaysia, 64(4), 323-324.

Astuto, M., Minardi, C., Uva, M. G., \& Gullo, A. (2011). Intraocular pressure during laparoscopic surgery in paediatric patients. British Journal of Ophthalmology, 95(2), 294-295. doi: 10.1136/bjo.2010.195396

Awad, H., Santilli, S., Ohr, M., Roth, A., Yan, W., Fernandez, S, . . Patel, V. (2009). The effects of steep Trendelenburg positioning on intraocular pressure during robotic radical prostatectomy. Anesthesia \& Analgesia, 109(2), 473-478. doi: 10.1213/ane.0b013e3181a9098f

Bekar, A., Türeyen, K., \& Aksoy, K. (1996). Unilateral blindness due to patient positioning during cervical syringomyelia surgery: Unilateral blindness after prone positioning. Journal of Neurosurgical Anesthesiology, 8(3), 227-229.

Berg, K. T., Harrison, A. R., \& Lee, M. S. (2010). Perioperative visual loss in ocular and nonocular surgery. Clinical Ophthalmology, 4, 531-546.

Berlin, J. A. (1995). Invited commentary: Benefits of heterogeneity in meta-analysis of data from epidemiological studies. American Journal of Epidemiology, 142(4), 465-468. doi: 10.1093/oxfordjournals.aje.a117645

Blecha, S., Harth, M., Schlachetzki, F., Zeman, F., Blecha, C., Flora, P., . . Pawlik, M. T. (2017). Changes in intraocular pressure and optic nerve sheath diameter in patients undergoing robotic-assisted laparoscopic prostatectomy in steep $45^{\circ}$ 
Trendelenburg position. BMC Anesthesiology, 17(1), 40. doi: 10.1186/s12871017-0333-3

Bonnaig, N., Dailey, S., \& Archdeacon, M. (2014). Proper patient positioning and complication prevention in orthopaedic surgery. Journal of Bone and Joint Surgery, American Volume, 96(13), 1135-1140. doi: 10.2106/JBJS.M.01267

Borahay, M. A., Patel, P. R., Walsh, T. M., Tarnal, V., Koutrouvelis, A., Vizzeri, G., .. . Kilic, G. S. (2013). Intraocular pressure and steep Trendelenburg during minimally invasive gynecologic surgery: Is there a risk? Journal of Minimally Invasive Gynecology, 20(6), 819-824. doi: 10.1016/j.mig.2013.05.005

Borenstein, M., Hedges, L. V., Higgins, J., \& Rothstein, H. (2009a). Fixed-effect versus random-effects models. In Introduction to meta-analysis (pp. 77-86). West Sussex, UK: John Wiley \& Sons, Ltd.

Borenstein, M., Hedges, L. V., Higgins, J., \& Rothstein, H. (2009b). Identifying and quantifying heterogeneity. In Introduction to meta-analysis (pp. 107-125). West Sussex, UK: John Wiley \& Sons, Ltd.

Borenstein, M., Hedges, L. V., Higgins, J., \& Rothstein, H. (2009c). Prediction intervals. In Introduction to meta-analysis (pp. 127-133). West Sussex, UK: John Wiley \& Sons, Ltd.

Borenstein, M., Hedges, L. V., Higgins, J., \& Rothstein, H. (2018). Comprehensive Meta-Analysis. Retrieved from https://www.meta-analysis.com Boyd, K. (2018). What is ischemic optic neuropathy? Retrieved from https://www.aao.org/eye-health/diseases/what-is-ischemic-optic-neuropathy 
Carey, T. W., Shaw, K. A., Weber, M. L., \& DeVine, J. G. (2014) Effect of the degree of reverse Trendelenburg position on intraocular pressure during prone spine surgery: A randomized controlled trial. Spine Journal, 14(9), 2118-2126. doi: 10.1016/j.spinee.2013

Centers for Disease Control and Prevention. (2016). Defining adult overweight and obesity. Retrieved from https://www.cdc.gov/obesity/adult/defining.html

Cheng, M. A., Todorov, A., Tempelhoff, R., McHugh, R., Chowder, C. M., \& Lauryssen, C. (2001). The effect of prone positioning on intraocular pressure in anesthetized patients. Anesthesiology, 95(6), 1351-1355.

Cohen, J. A. (1992). A power primer. Psychological Bulletin, 12(1), 155-159.

Cullen, A., \& Ferguson, A. (2012). Perioperative management of the severely obese patient: A selective pathophysiological review. Canadian Journal of Anesthesia, 59(10), 974-996.

Czorlich, P., Krätzig, T., Kluge, N., Skevas, C., Knospe, V., Spitzer, M. S., . . Elcker, S. O. (2018). Intraocular pressure during neurosurgical procedures in context of head position and loss of cerebrospinal fluid. Journal of Neurosurgery. Advance online publication. doi: 10. 3171/2018.3.JNS173098

Deeks, J. J., Higgins, J. P. T., \& Altman, D. G. (Eds.). (2011). Chapter 9: Analyzing data and undertaking meta-analysis. In J. J. Deeks, J. P. T Higgins, \& D. G. Altman (Eds.). Cochrane handbook for systematic reviews of interventions Version 5.1.0 (Updated March 2011). Retrieved from www.handbook.cochrane.org 
Demasi, C. L., Porpiglia, F., Tempia, A., \& D’Amelio, S. (2017). Ocular blood flow in steep Trendelenburg positioning during robotic-assisted radical prostatectomy. European Journal of Ophthalmology, 28(3), 333-338. doi: 10.5301/ejo.5001061

Dilger, J. A., Tétzlaff, J. E., Bell, G. R., Kosmorsky, G. S., Agnor, R. C., \& O’Hara, J. F. Jr. (1998). Ischaemic optic neuropathy after spinal fusion. Canadian Journal of Anaesthesia, 45(1), 63-66. doi: 10.1007/BF03011996

Eddama, M. (2013). Re: Raised intraocular pressure and perioperative visual loss in laparoscopic colorectal surgery: A catastrophe waiting to happen? A systematic review of evidence from other surgical specialties. Techniques in Coloproctology, 17(2), 247. doi: 10.1007/s10151-013-0979-x

Egger, M., Smith, G. D., Schneider, M., \& Minder, C. E. (1997). Bias in meta-analysis detected by a simple, graphical test. BMJ Clinical Research, 315(7109), 629-634. doi: $10.1136 / \mathrm{bmj} .315 .7109 .629$

Emery, S. E., Daffner, S. D., France, J. C., Ellison, M., Grose, B. W., Hobbs, G. R., \& Clovis, N. B. (2015). Effect of head position on intraocular pressure during lumbar spine fusion: A randomized, prospective study. Journal of Bone \& Joint Surgery (American), 97(22), 1817-1823. doi: 10.2106/JBJS.O.00091

Farag, E., Sessler, D. I., Kovaci, B., Wang, L., Mascha, E. J., Bell, G., . . Kurz, A. (2012). Effects of crystalloid versus colloid and the $\alpha-2$ agonist brimonidine versus placebo on intraocular pressure during prone spine surgery: A factorial randomized trial. Anesthesiology, 116(4), 807-815. doi:

10.1097/ALN.0b013e3182475c10 
Fingar, K. R., Stocks, C., Weiss, A. J., \& Steiner, C. A. (2014). Most frequent operating room procedures performed in U. S. hospitals, 2003-2012. (HCUP Statistical Brief \#186). Retrieved from http://www.hcupus.ahrq.gov/reports/statbriefs/sb186-Operating-Room-Procedures-United-States2012.pdf

Freshcoln, M., \& Diehl, M. R. (2014). Repositioning during robotic procedures to prevent postoperative visual loss. OR Nurse, 8(4), 36-41.

Fukui, K., Ahmad, M., McHugh, T., Tempelhoff, R., \& Cheng, M. A. (2004). The effect of head elevation on intraocular pressure in anesthetized patients undergoing prone position spine surgery [Abstract]. Journal of Neurosurgical Anesthesiology, 16(4), 358. doi: 10.1097/00008506-200410000-00087

Fukui, K., Tempelhoff, R., \& Cheng, M. A. (2005). Intraocular pressure during prone position surgery: Effects of time and head elevation [Abstract]. Journal of Neurosurgical Anesthesiology, 17(4), 251. doi:

10.1097/01.ana.0000187769.61921.85

Ghomi, A. (2012). Robotics in practice: New angles on safer positioning. Contemporary $O B / G Y N$, 57(10), 26-37.

Ghomi, A., Kramer, C., Askari, R., Chavan, N. R., \& Einarsson, J. I. (2012). Trendelenburg position in gynecologic robotic-assisted surgery. Journal of Minimally Invasive Gynecology, 19(4), 485-489. doi: 10.1016.j.jmig.2012.03.019

Gkegkes, I. D., Karydis, A., Tyritzis, S. I., \& Iavazzo, C. (2015). Ocular complications in robotic surgery. International Journal of Medical Robotics, 11(3), 269-274. doi: $10.1002 /$ rcs. 1632 
Goni, V., Tripathy, S. K., Goyal, T., Tamuk, T., Panda, B. B., \& Shashidhar, B. K. (2012). Cortical blindness following spinal surgery: Very rare cause of perioperative vision loss. Asian Spine Journal, 6(4), 287-290. doi:

10.4184/asj.2012.6.4.287

Gould, C., Cull, T., Wu, Y. X., \& Osmundsen, B. (2012). Blinded measure of Trendelenburg angle in pelvic robotic surgery. Journal of Minimally Invasive Gynecology, 19(4), 465-468. doi: 10.1016/j.jmig.2012.03.014

Grant, G. P., Szirth, B. C., Bennett, H. L., Huang, S. S., Thaker, R. S., Heary, R. F., \& Turbin, R. E. (2010). Effects of prone and reverse Trendelenburg positioning on ocular parameters. Anesthesiology, 112(1), 57-65. doi:

10.1097/ALN.0b013e3181c294e1

Grossman, W., \& Ward, W. T. (1993). Central retinal artery occlusion after scoliosis surgery with a horseshoe headrest: Case report and literature review. Spine, 18(9), 1226-1228.

Grosso, A., Ceruti, P., Morino, M., Marchini, G., Amisano, M., \& Fioretto, M. (2017). Comment on the paper by Mondzelewski and colleagues: "Intraocular pressure during robotic assisted laparoscopic procedures utilizing steep Trendelenburg positioning.” Journal of Glaucoma, 26(4), e166-e167. doi:

10.1097/IJG.0000000000000494

Grosso, A., Scozzari, G., Bert, F., Mabilia, M. A., Siliquini, R., \& Morino, M. (2013). Intraocular pressure variation during colorectal laparoscopic surgery: Standard pneumoperitoneum leads to reversible elevation in intraocular pressure. Surgical Endoscopy, 27(9), 3370-3376. doi: 10.1007/s00464-013-2919-2 
Guillaume, J. E., \& Gowreesunker, P. (2013). Horner's syndrome in the prone position: A case report. Acta Anaesthesiologica Belgica, 64(3), 119-121.

Hayreh, S. S. (2001). Blood flow in the optic nerve head and factors that may influence it. Progress in Retinal and Eye Research, 20(5), 595-624.

Hewer, C. L. (1956). The physiology and complications of the Trendelenburg position. Canadian Medical Association Journal, 74(4), 285-288.

Higgins, J. P. T., \& Thompson, S. G. (2002). Quantifying heterogeneity in a metaanalysis. Statistics in Medicine, 21(11), 1539-1558. doi: 10.1002/sim.1186

Higgins, J. P. T., Thompson, S. G., Decks, J. J., \& Altman, D. G. (2003). Measuring inconsistency in meta-analysis. BMJ, 327(7414), 557-560. doi: $10.1136 / \mathrm{bmj} .327 .7414 .557$

Hirooka, K., Ukegawa K., Nitta, E., Ueda, N., Hayashida, Y., Hirama, H., . . Kakehi, Y. (2018). The effect of steep Trendelenburg positioning on retinal structure and function during robotic-assisted laparoscopic procedures. Journal of Ophthalmology, 2018, 1027397. doi: 10.1155/2018/1027397

Hollenhorst, R. W., Svien, H. J., \& Benoit, C. F. (1954). Unilateral blindness occurring during anesthesia for neurosurgical operations. AMA Archives of Ophthalmology, $52(6), 819-830$.

Hoski, J. J., Eismont, F. J., \& Green, B. A. (1993). Blindness as a complication of intraoperative positioning: A case report. Journal of Bone and Joint Surgery, $75(8), 1231-1232$.

Hoshikawa, Y., Tsutsumi, N., Ohkoshi, K., Serizawa, S., Hamada, M., Inagaki, K., . . . Deshpande, G. A. (2014). The effect of steep Trendelenburg positioning on 
intraocular pressure and visual function during robotic-assisted radical prostatectomy. British Journal of Ophthalmology, 98(3), 305-308. doi: 10.1136/bjophthalmol-2013-303536

Huedo-Medina, T., Sánchez-Meca, J., Marín-Martínez, F., \& Botella, J. (2006). Assessing heterogeneity in meta-analysis: $Q$ statistic or $I 2$ index? Psychological Methods, 11(2), 193-206. doi: 10.1037/1082-989X.11.2.193

Hunt, K., Bajekal, R., Calder, I., Meacher, R., Eliahoo, J., \& Acheson, J. F. (2004). Changes in intraocular pressure in anesthetized prone patients. Journal of Neurosurgical Anesthesiology, 16(4), 287-290.

Hwang, J. W., Oh, A. Y., Hwang, D. W., Jeon, Y. T., Kim, Y. B., \& Park, S. H. (2013). Does intraocular pressure increase during laparoscopic surgeries? It depends on anesthetic drugs and the surgical position. Surgical Laparoscopy, Endoscopy \& Percutaneous Techniques, 23(2), 229-232. doi: 10.1097/SLE.0b013e31828a0bba

Joo, J., Koh, H., Lee, K., \& Lee, J. (2016). Effects of systemic administration of dexmedetomidine on intraocular pressure and ocular perfusion pressure during laparoscopic surgery in a steep Trendelenburg position: Prospective, randomized, double-blinded study. Journal of Korean Medical Science, 31(6), 989-996. doi: $10.3346 / \mathrm{jkms} .2016 .31 .6 .989$

Joo, J., Kim, J., \& Lee, J. (2017). Effect of continuous systemic administration of esmolol on intraocular pressure during surgery in a sustained steep Trendelenburg position. Journal of Glaucoma, 26(12), 1068-1071. doi:

10.1097.IJG.0000000000000746 
Kadono, Y., Yaegashi, H., Machioka, K., Ueno, S., Miwa, S., Maeda, Y., . . Namiki, M. (2013). Cardiovascular and respiratory effects of the degree of head-down angle during robot-assisted laparoscopic radical prostatectomy. International Journal of Medical Robotics and Computer Assisted Surgery, 9(1), 17-22. doi: $10.1002 /$ rcs. 1482

Kamel, I., \& Barnette, R. (2014). Positioning patients for spine surgery: Avoiding uncommon position-related complications. World Journal of Orthopedics, 5(4), 425-443. doi: 10.5312/wjo.v5.i4.425

Kan, K. M., Brown, S. E., \& Gainsburg, D. M. (2015). Ocular complications in roboticassisted prostatectomy: A review of pathophysiology and prevention. Minerva Anestesiologica, 81(5), 557-566.

Katz, D. M., Trobe, J. D., Cornblath, W. T., \& Kline, L. B. (1994). Ischemic optic neuropathy after lumbar spine surgery. Archives of Ophthalmology, 112(7), 925931.

Kaur, G., Sharma, M., Kalra, P., Purohit S., \& Chauhan, K. (2018). Intraocular pressure changes during laparoscopic surgery in Trendelenburg position in patients anesthetized with propofol-based total intravenous anesthesia compared to sevoflurane anesthesia: A comparative study. Anesthesia Essays and Researches, 12(1), 67-72. doi: 10.4103/aer.AER_177_17

Kendrick, H. (2012). Post-operative vision loss (POVL) following surgical procedures. Journal of Anesthesia and Clinical Research, 3(1), 184. doi: 10.4172/21556148.1000184 
Kim, N. Y., Yoo, Y. C., Park, H. J., Choi, Y. D., Kim, C. Y., \& Bai, S. J. (2015). The effect of dexmedetomidine on intraocular pressure increase in patients during robot-assisted laparoscopic radical prostatectomy in the steep Trendelenburg position. Journal of Endourology, 29(3), 310-316. doi: 10.1089/end.2014.0381

Kitamura, S., Takechi, K., Nishihara, T., Konishi, A., Takasaki, Y., \& Yorozuya, T. (2018). Effect of dexmedetomidine on intraocular pressure in patients undergoing robot-assisted laparoscopic radical prostatectomy under total intravenous anesthesia: A randomized, double blinded placebo controlled clinical trial. Journal of Clinical Anesthesia, 49, 30-35. doi: 10.1016/j.clinane.2018.06.006

Kumar, G., \& Vyakarnam, P. (2013). Postoperative vision loss after colorectal laparoscopic surgery. Surgical Laparoscopy, Endoscopy \& Percutaneous Techniques, 23(2), e87-e88. doi: 10.1097/SLE.0b013e318277d2ae

Kwee, M. M., Ho, Y. H., \& Rozen, W. M. (2015). The prone position during surgery and its complications: A systematic review and evidence-based guidelines. International Surgery, 100(2), 292-303. doi: 10.9738/INTSURG-D-13-00256.1

Lee, L. A. (2011). Visual loss, venous congestion, and robotic prostatectomies. ASA Monitor, 75(2), 26-27.

Lee, L. A., \& Newman, N. (2018). Postoperative visual loss after anesthesia for nonocular surgery. UpToDate. Retrieved from https://www.uptodate.com/contents/postoperative-visual-loss-after-anesthesia-fornonocular-surgery.

Lee, M., Dallas, R., Daniel, C., \& Cotter, F. (2016). Intraoperative management of increased intraocular pressure in a patient with glaucoma undergoing robotic 
prostatectomy in the Trendelenburg position. Anesthesia \& Analgesia Case Reports, 6(2), 19-21. doi: 10.1213/XAA.0000000000000213

Leibovitch, I., Casson, R., Laforest, C., \& Selva, D. (2006). Ischemic orbital compartment syndrome as a complication of spinal surgery in the prone position. Ophthalmology, 113(1), 105-108. doi: 10.1016/j.ophtha.2005.09.025

Lentschener, C., Benhamou, D., Niessen, F., Mercier, F. J., \& Fernandez, H. (1996). Intra-ocular pressure changes during gynaecological laparoscopy. Anaesthesia, $51,1106-1108$.

Li, A., Swinney, C., Veeravagu, A., Bhatti, I., \& Ratliff, J. (2015). Postoperative visual loss following lumbar spine surgery: A review of risk factors. World Neurosurgery, 84(6), 2010-2021. doi: 10.1016/j.wneu.2015.08.030

Lipsey, M., \& Wilson, D. (2001). Interpreting and using meta-analysis results. In Practical meta-analysis: Applied social research (Vol 49, pp. 146-168). Thousand Oaks, CA: Sage.

Locastro, A., Novak, K. D., \& Biglan, A. W. (1991). Central retinal artery occlusion in a child after general anesthesia. American Journal of Ophthalmology, 112(1), 9192.

Manfredini, M., Ferrante, R., Gildone, A., \& Massari, L. (2000). Unilateral blindness as a complication of intraoperative positioning for cervical spinal surgery. Journal of Spine Disorders, 13(3), 271-272.

MacDonald, J. J. \& Washington, S. J. (2012). Positioning the surgical patient. Anaesthesia and Intensive Care Medicine, 13(11), 528532. 
Mathew, D. J., Greene, R. A., Mahsood, Y. J., Hallaji, N., Vargas, A. M. B., Jin, Y. P., . . . Buys, Y. M. (2018). Preoperative brimonidine tartrate $0.2 \%$ does not prevent an intraocular pressure rise during prostatectomy in steep Trendelenburg position. Journal of Glaucoma. Advance online publication. doi: 10.1097/IJG.0000000000001047

Mizrahi, H., Hugkulstone, C. E., Vyakarnam, P., \& Parker, M. C. (2011). Bilateral ischaemic optic neuropathy following laparoscopic proctocolectomy: A case report. Annals of the Royal College of Surgery of England, 93(5), e53-e54. doi: $10.1308 / 147870811 X 582828$

Mizumoto, K., Gosho, M., Iwaki, M., \& Zako, M. (2017). Ocular parameters before and after steep Trendelenburg positioning for robotic-assisted laparoscopic radical prostatectomy. Clinical Ophthalmology, 11, 1643-1650. doi: 10.2147/OPTH.S139874

Moher, D., Liberati, A., Tetzlaff, J., Altman, D. G., \& PRISMA Group. (2009). Preferred reporting items for systematic reviews and meta-analyses: The PRISMA statement. PLoS Medicine, 6(7), e1000097. doi: 10.1371/journal.pmed.1000097

Molloy, B. L. (2011). Implications for postoperative visual loss: Steep Trendelenburg position and effects on intraocular pressure. AANA Journal, 79(2), 115-121.

Molloy, B. L., \& Cong, X. (2014). Perioperative dorzolamide-timolol intervention for rising intraocular pressure during steep Trendelenburg positioned surgery. AANA Journal, 82(3), 203-211. 
Molloy, B. L., Cong, X., \& Watson, C. (2016). Preventive dorzolamide-timolol for rising intraocular pressure during steep Trendelenburg position surgery. AANA Journal, 84(3), 189-196.

Molloy, B. L., \& Watson, C. (2012). A comparative assessment of intraocular pressure in prolonged steep Trendelenburg position versus level supine position intervention. Journal of Anesthesiology \& Clinical Science. doi: 10.7243/2049-9752-1-9

Mondzelewski, T. J., Schmitz, J. W., Christman, M. S., Davis, K. D., Lujan, E., L’Esperance, J. O., \& Auge, B. K. (2015). Intraocular pressure during roboticassisted laparoscopic procedures utilizing steep Trendelenburg positioning. Journal of Glaucoma, 24(6), 399-404. doi: 10.1097/IJG.0000000000000302

Mowafi, H. A., Al-Ghamdi, A., Rushood, A. (2003). Intraocular pressure changes during laparoscopy in patients anesthetized with propofol total intravenous anesthesia versus isoflurane inhaled anesthesia. Anesthesia \& Analgesia, 97(2), 471-474. doi: 10.1213/01.ANE.0000067532.56354.58

Newman, N. J. (2008). Perioperative visual loss after nonocular surgeries. American Journal of Ophthalmology, 145(4), 604-610. doi: 10.1016/j.ajo.2007.09.016

Nickels, T. J., Manlapaz, M. R., \& Farag, E. (2014). Perioperative visual loss after spine surgery. World Journal of Orthopaedics, 5(2), 100-106. doi: 10.5312/wjo.v5.i2.100

Nuri Deniz, M., Erakgün, A., Sertöz, N., Yilmaz, S. G., Ateş, H., \& Erhan, E. (2013). The effect of head rotation on intraocular pressure in prone position: A randomized trial. Brazilian Journal of Anesthesiology, 63(2), 209-212. doi: 10.1016/S0034-7094(13)70217-4 
Nishikawa, M., Watanabe, H., \& Kurahashi, T. (2017). Effects of 25- and 30-degree Trendelenburg positions on intraocular pressure changes during robot-assisted radical prostatectomy. Prostate International, 5(4), 135-138. doi: 10.1016/j.prnil.2017.03.008

Nuzzi, R., \& Tridico, R. (2016). Ocular complications in laparoscopic surgery: Review of existing literature and possible prevention and treatment. Seminars in Ophthalmology, 31(6), 584-592. doi: 10.3109/08820538.2015.1009557

Orwin, R. G. (1983). A fail-safe $N$ for effect size in meta-analysis. Journal of Educational Statistics, 8(2), 157-159. doi: 10.2307/1164923

Ozcan, M. F., Akbulut, Z., Gurdal, C., Tan, S., Yildiz, Y., Bayraktar, S., Ozcan, A. N., . . . Balbay, M. D. (2017). Does steep Trendelenburg positioning effect the ocular hemodynamics and intraocular pressure in patients undergoing robotic cystectomy and robotic prostatectomy? International Urology and Nephrology, 49(1), 55-60. doi: $10.1007 / \mathrm{s} 11255-016-1449-\mathrm{y}$

Ozcan, M. S., Praetel, C., Bhatti, M. T., Gravenstein, N., Mahla, M. E., \& Seubert, C. N. (2004). The effect of body inclination during prone positioning on intraocular pressure in awake volunteers: A comparison of two operating tables. Anesthesia \& Analgesia, 99(4), 1152-1158. doi: 10.1213/01.ANE.0000130851.37039.50

Patil, C. G., Lad, E. M., Lad, S. P., Ho, C., \& Boakye, M. (2008). Visual loss after spine surgery: A population-based study. Spine, 33(13), 1491-1496. doi:

10.1097/BRS.0b013e318175d1bf

Pillunat, L. E., Anderson, D. R., Knighton, R. W., Joos, K. M., \& Feuer, W. J. (1997). Autoregulation of human optic nerve head circulation in response to increased 
intraocular pressure. Experimental Eye Research, 64(5), 727-744. doi:

10.1006/exer.1996.0263

Pinar, H. U., Kaşdoğan, Z. E. A., Başaran, B., Çöven, İ., Karaca, Ö., \& Doğan, R. (2018). The effect of spinal versus general anesthesia on intraocular pressure in lumbar disc surgery in the prone position: A randomized controlled trial. Journal of Clinical Anesthesia, 46, 54-58. doi: 10.1016/j.jclinane.2018.01.026

Pinkney, T. D., King, A. J., Walter, C., Wilson, T. R., Maxwell-Armstrong, C., \& Acheson, A. G. (2012). Raised intraocular pressure (IOP) and perioperative visual loss in laparoscopic colorectal surgery: A catastrophe waiting to happen? A systematic review of evidence from other surgical specialties. Techniques in Coloproctology, 16(5), 331-335. doi: 10.1007/s10151-012-0879-5

Quraishi, N. A., Wolinsky, J. P., \& Gokaslan, Z. L. (2012). Transient bilateral postoperative visual loss in spinal surgery. European Spine Journal, 21(Suppl 4), S495-S498. doi: 10.1007/s00586-011-2117-7

Raz, O., Boesel, T. W., Arianayagam, M., Lau, H., Vass, J., Huynh, C. C., . . Varol, C. (2015). The effect of the modified Z Trendelenburg position on intraocular pressure during robotic assisted laparoscopic radical prostatectomy: A randomized, controlled study. Journal of Urology, 193(), 1213-1219. doi: 10.1016/j.juro.2014.10.094

Reddy, A., Foroozan, R., Edmond, J. C., \& Hinckley, L. K. (2008). Dilated superior ophthalmic veins and posterior ischemic optic neuropathy after prolonged spine surgery. Journal of Neuro-Ophthalmology, 28(4), 327-328. doi:

10.1097/WNO.0b013e318175c86c 
Riva, C. E, Sinclair, S. H., \& Grunwald, J. E. (1981). Autoregulation of retinal circulation in response to decrease of perfusion pressure. Investigative Ophthalmology \& Visual Science, 21(1), 34-38.

Rothrock, J. D., \& Smith, D. A. (2000). Selecting the perioperative patient focused model. AORN Journal, 71(3), 1030-1037.

Russell, D. J., \& Dutton, J. J. (2011). Bilateral spontaneous subperiosteal orbital hemorrhages following endoscopic retrograde cholangiopancreatography. Ophthalmic Plastic \& Reconstructive Surgery, 27(3), e49-e50. doi:

10.1097/IOP.0b013e3181cd5f65

Shen, Y., Drum, M., \& Roth, S. (2009). The prevalence of perioperative visual loss in the United States: A 10-year study from 1996 to 2005 of spinal, orthopedic, cardiac, and general surgery. Anesthesia \& Analgesia, 109(5), 1534-1545. doi:

10.1213/ane.0b013e3181b0500b

Shifa, J., Abebe, W., Bekele, N., \& Habte, D. (2016). A case of bilateral visual loss after spinal cord surgery. Pan African Medical Journal, 23, 119. doi:

10.11604/pamj.2016.23.119.8443

Singer, M. S., \& Salim, S. (2010). Bilateral acute angle-closure glaucoma as a complication of facedown spine surgery. Spine Journal, 10(9), e7-e9. doi: 10.1016/j.spinee.2010.07.006

Stambough, J. L., Dolan, D., Wener, R., \& Godfrey, E. (2007). Ophthalmologic complications associated with prone positioning in spine surgery. Journal of the American Academy of Orthopaedic Surgeons, 15(3), 156-165. 
Stang-Veldhouse, K. N., Yeu, E., Rothenberg, D. M., \& Mizen, T. R. (2010). Unusual presentation of perioperative ischemic optic neuropathy following major spine surgery. Journal of Clinical Anesthesia, 22(1), 52-55. doi:

10.1016/j.jclinane.2009.01.018

Sterne, J. A. C., Egger, M., \& Moher, D. (Eds.). (2011). Chapter 10: Addressing reporting biases. In J. J. Deeks, J. P. T Higgins, \& D. G. Altman (Eds.). Cochrane handbook for systematic reviews of interventions Version 5.1.0 (Update March 2011). Retrieved from www.handbook.cochrane.org

Stewart, R. J., Landy, D. C., \& Lee, M. J. (2016). Unlateral acute angle-closure glaucoma after lumbar spine surgery: A case report and systematic review of the literature. Spine, 41(5), E297-E299. doi: 10.1097/BRS.0000000000001224

Sugata, A., Hayashi, H., Kawaguchi, M., Hasuwa, K., Nomura, Y., \& Furuya, H. (2012). Changes in intraocular pressure during prone spine surgery under propofol and sevoflurane anesthesia. Journal of Neurosurgical Anesthesia., 24(2), 152-156. doi: 10.1097/ANA.0b013e31823fe822

Sutton, A. J. (2009). Publication bias. In H. Cooper, L. V. Hedges, \& J. C. Valentine (Eds.). The handbook of research synthesis and meta-analysis (2nd ed., pp. 435452). New York, NY: Russell Sage Foundation.

Szmuk, P., Steiner, J. W., Pop, R. B., You, J., Weakley, D. R., Swift, D. M., \& Sessler, D. I. (2013). Intraocular pressure in pediatric patients during prone surgery. Anesthesia \& Analgesia, 116(6), 1309-1313. doi: 10.1213/ANE.0b013e31828d3730 
Taketani, Y., Mayama, C., Suzuki, N., Wada, A., Oka, T., Inamochi, K., \& Nomoto, Y. (2015). Transient but significant visual field defects after robot-assisted laparoscopic radical prostatectomy in deep Trendelenburg position. PLoS ONE, 10(4), e0123361. doi: 10.1037/journal.pone.0123361

Thompson, S. G. (1994). Why sources of heterogeneity in meta-analysis should be investigated. BMJ, 309(6965), 1351-1355.

Valentine, J. C. (2009). Judging the quality of primary research. In H. Cooper, L. V. Hedges, \& J. C. Valentine, (Eds.), The handbook of research synthesis and metaanalysis (2nd ed., pp. 129-146). New York, NY: Russell Sage Foundation.

Vecchio, R., MacFayden, B. V., \& Palazzo, F. (2000). History of laparoscopic surgery. Panminerva Medica, 42(1), 87-90.

Vitish-Sharma, P., Acheson, A. G., Stead, R., Sharp, J., Abbas, A., Hovan, M., . . King, A. J. (2018). Can the SENSIMED Triggerfish ${ }^{\circledR}$ lens data be used as an accurate measure of intraocular pressure? Acta Ophthalmologica, 96(2), e242-e246. doi: 10.1111/aos. 13456

Walick, K. S., Kragh, J. E., Ward, J. A., \& Crawford, J. J. (2007). Changes in intraocular pressure due to surgical positioning. Spine, 32(23), 2591-2595. doi:

10.1097/BRS.0b013e318158cc23

Weber, E. D., Colyer, M. H., Lesser, R. L., \& Subramanian, P. S. (2007). Posterior ischemic optic neuropathy after minimally invasive prostatectomy. Journal of Neuro-Ophthalmology, 27(4), 285-287.

Weinreb, R. N., \& Khaw, P. T. (2004). Primary open-angle glaucoma. Lancet, 363(9422), 1711-1720. doi: 10.1016/S0140-6736(04)16257-0 
Weiser, T. G., Haynes, A. B., Molina, G., Lipsitz, S. R., Esquivel, M. M., Uribe-Leitz, T., Fu, R., . . Gawande, A. A. (2016). Size and distribution of the global volume of surgery in 2012. Bulletin of the World Health Organization, 94(3), 201-209. doi: 10.2471/BLT.15.159293

West, J., Askin, G., Clarke, M., \& Vernon, S. A. (1990). Loss of vision in one eye following scoliosis surgery. British Journal of Ophthalmology, 74, 243-244.

White, H. D. (2009). Scientific communication and literature retrieval. In H. Cooper, L. V. Hedges, \& J. C. Valentine (Eds.). The handbook of research synthesis and meta-analysis (2nd ed., pp. 51-71). New York, NY: Russell Sage Foundation.

Williams, G. C., Lee, A. G., Adler, H. L., Coburn, A., Rosas, A. L., Tang, R. A., \& Scardino, P. T. (1999). Bilateral anterior ischemic optic neuropathy and branch retinal artery occlusion after radical prostatectomy. Journal of Urology, 162(4), 1384-1385.

Wilson, D. B. (2009). Systematic coding. In H. Cooper, L. V. Hedges, \& J. C. Valentine, (Eds.), The handbook of research synthesis and meta-analysis (2nd ed., pp. 159176). New York, NY: Russell Sage Foundation.

Wolfe, S. W., Lospinuso, M. F., \& Burke, S. W. (1992). Unilateral blindness as a complication of patient positioning for spinal surgery: A case report. Spine, 17(5), 600-605.

Yoo, Y. C., Shin, S., Choi, E. K., Kim, C. Y., Choi, Y. D., Bai, S. J. (2014). Increase in intraocular pressure is less with propofol than with sevoflurane during laparoscopic surgery in the steep Trendelenburg position. Canadian Journal of Anesthesia, 61(4), 322-329. doi: 10.1007/s12630-014-0112-2 
Yoo, Y. C., Kim, N. Y., Shin, S., Choi, Y. E., Hong, J. H., Kim, C. Y., . . Bai, S. J. (2015). The intraocular pressure under deep versus moderate neuromuscular blockade during low-pressure robot assisted laparoscopic radical prostatectomy in a randomized trial. PLoS ONE, 10(8), e0135412. doi:

10.1371/journal.pone.0135412

Yoshimura, K., Hayashi, H., Tanaka, Y., Nomura, Y., \& Kawaguchi, M. (2015). Evaluation of predictive factors associated with increased intraocular pressure during prone position spine surgery. Journal of Anesthesia, 29(2), 170-174. doi: $10.1007 / \mathrm{s} 00540-014-1921-8$

Yu, H. D., Chou, A. H., Yang, M. W., \& Chang, C. J. (2010). An analysis of perioperative eye injuries after nonocular surgery. Acta Anaesthesiologica Taiwanica, 48(3), 122-129. doi: 10.1016/S1875-4597(10)60043-4 


\section{VITA}

Sharon Ann Van Wicklin has more than 45 years of experience as a perioperative registered nurse $(\mathrm{RN})$. She has worked in all facets of the perioperative environment from scrub person to director. Sharon received her Associate of Science in Nursing from Ventura College, Ventura, California. She received her Bachelor of Science in Nursing and Master of Science in Nursing from Middle Tennessee State University, Murfreesboro, Tennessee. Sharon is currently a Doctor of Philosophy in Nursing candidate at Missouri State University, Columbia, Missouri. She is a member of the Sigma Theta Tau Honor Society of Nursing and the Honor Society of Phi Kappa Phi. Sharon has earned certification in operating room nursing (CNOR), as an emeritus RN first assistant (CRNFA[E]), as a retired plastic and reconstructive surgical nurse (CPSN-R), and as a legal nurse consultant (PLNC).

Sharon was recognized by the Association of periOperative Registered Nurses (AORN) as a recipient of the Outstanding Achievement in the Application of Perioperative Clinical Research Award in 2005. This award recognizes a perioperative RN whose application of perioperative clinical research reflects the goal of excellence in patient care. In 2017, Sharon received the honor of being inducted as a Fellow in the American Academy of Nursing (FAAN), and in 2018, she was inducted as a Fellow in the International Society of Plastic and Aesthetic Nurses (ISPAN-F).

In a previous position as a perioperative educator, Sharon was responsible for the creation and coordination of educational projects and programs designed to improve hospital processes for orientation and ongoing educational development for more than 125 personnel in nine perioperative departments. As a Senior Perioperative Practice Specialist for AORN, Sharon provided consultative services, authored various AORN publications including the 
AORN guidelines for perioperative practice; and, represented AORN with other professional and regulatory organizations. She was also a member of the nursing faculty at Middle Tennessee State University and the University of Phoenix.

In her current position as a perioperative consultant and editor-in-chief of Plastic Surgical Nursing, Sharon serves as a clinical consultant, peer reviewer, clinical editor, author, and presenter for a variety of perioperative educational products, seminars, workshops, and publications. Her work as a legal expert witness involves reading and reviewing medical records and testifying as to the standard of perioperative nursing care. 